\title{
Combining homogeneous and heterogeneous chemistry to model inorganic compound concentrations in indoor environments: the $H^{2} I$ model (v1.0)
}

\author{
Eve-Agnès Fiorentino ${ }^{1}$, Henri Wortham ${ }^{1}$, and Karine Sartelet ${ }^{2}$ \\ ${ }^{1}$ Laboratory of Environmental Chemistry, CNRS-UMR 7376, Aix-Marseille Université, Marseille, France \\ ${ }^{2}$ CEREA, Joint Laboratory Ecole des Ponts ParisTech - EdF R\&D, Université Paris-Est, Champs-sur-Marne, France
}

Correspondence: Eve-Agnès Fiorentino (eve-agnes.fiorentino@univ-amu.fr)

Received: 7 September 2020 - Discussion started: 5 October 2020

Revised: 4 April 2021 - Accepted: 11 April 2021 - Published: 18 May 2021

\begin{abstract}
Homogeneous reactivity has been extensively studied in recent years through outdoor air-quality simulations. However, indoor atmospheres are known to be largely influenced by another type of chemistry, which is their reactivity with surfaces. Despite progress in the understanding of heterogeneous reactions, such reactions remain barely integrated into numerical models. In this paper, a room-scale, indoor air-quality (IAQ) model is developed to represent both heterogeneous and homogeneous chemistry. Thanks to the introduction of sorbed species, deposition and surface reactivity are treated as two separate processes, and desorption reactions are incorporated. The simulated concentrations of inorganic species are compared with experimental measurements acquired in a real room, thus allowing calibration of the model's undetermined parameters. For the duration of the experiments, the influence of the simulation's initial conditions is strong. The model succeeds in simulating the four inorganic species concentrations that were measured, namely $\mathrm{NO}, \mathrm{NO}_{2}, \mathrm{HONO}$ and $\mathrm{O}_{3}$. Each parameter is then varied to estimate its sensitivity and to identify the most prevailing processes. The air-mixing velocity and the building filtration factor are uncertain parameters that appear to have a strong influence on deposition and on the control of transport from outdoors, respectively. As expected, $\mathrm{NO}_{2}$ surface hydrolysis plays a key role in the production of secondary species. The secondary production of NO by the reaction of sorbed $\mathrm{HONO}$ with sorbed $\mathrm{HNO}_{3}$ stands as an essential component to integrate into IAQ models.
\end{abstract}

\section{Introduction}

At a time when sustainable development requires more effort than ever, the improvement of building isolation has become a major concern in the field of construction and renovation. Apart from being necessary for the health and comfort of the occupants, airtight conceptions are needed to curb the energy consumption of accommodations and offices and thus decrease their carbon footprint. However, as air remains more confined with a lower exchange rate with the outdoors, the pollutants generated indoors have fewer possibilities to escape, which raises health issues. It is now established that indoor atmospheres are more polluted than those outdoors, while we spend most of our time in indoor environments: up to $90 \%$ in developed countries (Carslaw, 2007). In this context, indoor air quality (IAQ) is bound to be an increasingly important issue.

Whereas numerical simulations appear to be a standard approach for the study of outdoor atmospheres, they are less common in the field of indoor environments. Indoor environments are complex, and processes relying on the surface-tovolume ratio, which are still not fully understood but often negligible outdoors, are predominantly important in indoor environments (Weschler, 2011).

Historically, early attempts to model indoor atmospheres focused on the correct assessment of primary emissions, considering each chemical component independently. The model of Nazaroff and Cass (1986) provided the first description of the indoor environment as a chemically reactive homogeneous system, taking into account the interactions of about 30 species and groups of species based on a modified ver- 
sion of the Falls and Seinfeld (1978) mechanism. They included photolytic reactions and a simple form of deposition, considering decomposition and irreversible absorption reactions. Sarwar et al. (2002) adapted the chemical mechanism SAPRC-99 in order to take into account newer advances in $\mathrm{O}_{3}$ reactions with alkene. In particular, they introduced the chemistry of 40 volatile organic compounds (VOCs) recognized as atmospheric pollutants. Deposition was modelled as in Nazaroff and Cass (1986), and no deposition was assumed for species for which no deposition velocity was available. A more detailed chemical mechanism was tested by Carslaw (2007), who adapted the Master Chemical Mechanism (MCM) to indoor environments, including about 4600 species and 15400 reactions. Deposition was modelled similarly to Nazaroff and Cass (1986), and for the first time, a heterogeneous reaction on indoor surfaces was considered by introducing a production rate accounting for HONO secondary formation. Later, Mendez et al. (2015) implemented a simplified version of the SAPRC-07 mechanism and described deposition as a two-step process by making a distinction between transport from free space to a surface and reactivity with the surface. Further details were provided by Mendez et al. (2017), who parameterized the mass transfer effect using a model of transport-limited deposition velocity.

As highlighted by Weschler (2011), surface chemistry is responsible for secondary pollutant formation that can be of greater importance for IAQ than primary emissions. Because heterogeneous reactions can be faster than their equivalent gas-phase homogeneous reaction, their importance relative to the air exchange rate and thus their influence on indoor atmospheres are large. Secondary pollutants can persist a long time after the reagent species have been reduced to negligible levels and are very difficult to anticipate due to their strong dependence on ambient conditions.

The heterogeneous hydrolysis of $\mathrm{NO}_{2}$ is one of these reactions and is recognized as the main source of HONO in indoor environments. There is evidence that certain surfaces can act as a reservoir of sorbed $\mathrm{NO}_{2}$ and that these surfaces can release $\mathrm{HONO}$ long after the decay of $\mathrm{NO}_{2}$ (Wainman et al., 2001). Presumably, this HONO surface release depends on the ambient $\mathrm{NO}_{2}$ concentration, ambient relative humidity and the surface ability to retain water.

As a rule, it is assumed that the heterogeneous hydrolysis of $\mathrm{NO}_{2}$ leads to the formation of $\mathrm{HONO}$ and $\mathrm{HNO}_{3}$ following the stoichiometry proposed by Febo and Perrino (1991):

$2 \mathrm{NO}_{2}+\mathrm{H}_{2} \mathrm{O} \rightarrow \mathrm{HONO}+\mathrm{HNO}_{3}$.

Contrary to $\mathrm{HONO}, \mathrm{HNO}_{3}$ is not observed as a gas-phase product in this process due to its strong adsorption capacity. $\mathrm{HNO}_{3}$ remains on the surface and can react with other species. Namely, Mochida and Finlayson-Pitts (2000) studied the production of $\mathrm{NO}_{2}$ by the reaction of $\mathrm{HNO}_{3}$ with gaseous NO on porous glass. They showed that the NO concentration cannot decay below a threshold value, suggesting NO regeneration pathways. Coherently, NO formation was pointed out during $\mathrm{NO}_{2}$ hydrolysis experiments, simultaneously to $\mathrm{NO}_{2}$ exposure or at longer reaction times. FinlaysonPitts et al. (2003) measured for this reaction a HONO yield that was much less than $50 \%$ of the $\mathrm{NO}_{2}$ loss and observed that the yield of NO relative to HONO increased with time. Based on their own and previously reported observations, they suggested NO could be formed by the secondary autoionization of the sorbed $\mathrm{HONO}$ as

$2 \mathrm{HONO} \rightarrow \mathrm{NO}+\mathrm{NO}_{2}+\mathrm{H}_{2} \mathrm{O}$

and also by conversion of the sorbed HONO following a mechanism that involves $\mathrm{HNO}_{3}$ and simplifies to the net reaction

$\mathrm{HONO}+\mathrm{HNO}_{3} \rightarrow 2 \mathrm{NO}+\mathrm{H}_{2} \mathrm{O}+\mathrm{O}_{2}$.

Considering longer reaction times, NO could also react with $\mathrm{HNO}_{3}$ following the reaction (Finlayson-Pitts et al., 2003)

$\mathrm{NO}+\mathrm{HNO}_{3} \rightarrow \mathrm{HONO}+\mathrm{NO}_{2}$.

Finally, the photochemical enhancement of HONO production during $\mathrm{NO}_{2}$ hydrolysis was investigated by Ramazan et al. (2004), who showed that $\mathrm{NO}_{2}$ hydrolysis was not photo-enhanced but that HONO production was fostered by another process, which was likely the photolysis of sorbed $\mathrm{HNO}_{3}$ caused by UV rays. Other heterogeneous reactions could be pointed out, especially those involving $\mathrm{O}_{3}$, which is known to have a significant adsorption capacity.

Reviewing the state of the art of surface reactions unveils a serious void in the modelling of indoor atmospheres. Current models incorporate these phenomena very incompletely due to the strong uncertainties they are subjected to. In particular, the ratio of the production of $\mathrm{NO}$ compared with $\mathrm{HONO}$ during $\mathrm{NO}_{2}$ hydrolysis derives from mechanisms that are still unclear. The detailed scheme proposed by FinlaysonPitts et al. (2003) involves reactions of several intermediate species whose reaction rates are unknown. As a test, they introduced this scheme in the kinetic programme REACT to compute the loss of $\mathrm{NO}_{2}$ and formation of $\mathrm{HONO}$ and $\mathrm{NO}$, and they adjusted the required rate constants to obtain a good match with their cell experimental data. In this model, uptake and reactions on surfaces were not explicitly treated, which caused heterogeneous reactions to be implemented as gas-phase reactions. Ramazan et al. (2004) conducted similar work, and the parameterization they proposed was later used by Courtey et al. (2009) to model confined atmospheres, i.e. without including ventilation and primary emissions.

In this work, a room-scale IAQ model is developed to incorporate the heterogeneous chemistry described above, in addition to the homogeneous chemistry already considered by box models. The concentrations simulated by this model are compared with measurements that were performed in a real office (Gandolfo, 2018; Gandolfo et al., 2021) from 27 to 31 October 2016 in Martigues (France). The aim of these 
measurements was to study the impact of photocatalytic paints characterized in laboratory experiments (Gandolfo et al., 2015, 2017) on indoor atmosphere health. Whereas laboratory tests had been conducted with paints containing up to $7 \% \mathrm{TiO}_{2}$ nanoparticles, this campaign was restricted to a non-photocatalytic paint (reference paint) and to the same paint enriched with a commercially viable amount of $3.5 \% \mathrm{TiO}_{2}$ nanoparticles. Two types of measurements were obtained using either UV-blocking or borosilicate windows. The simulations presented in this paper are compared with the data obtained with the UV-blocking window only to minimize the effect of photo-induced processes, which will be studied in a separate paper. The organic compound concentrations are fixed to their measured values to focus on the modelling of inorganic species.

The present model, called the $\mathrm{H}^{2} \mathrm{I}$ (homogeneous heterogeneous indoor) model, assumes a uniformly mixed environment, taking into account emissions, ventilation, chemistry and deposition processes. The chemical mechanism solving the gas-phase chemistry is a version of the RACM2 chemical scheme (Goliff et al., 2013) based upon the earlier Regional Atmospheric Chemistry Mechanism (RACM; Stockwell et al., 1997) implemented in the Polyphemus air-quality modelling platform (Kim et al., 2009). Deposition is modelled as in Mendez et al. (2017). As in Finlayson-Pitts et al. (2003) and Ramazan et al. (2004), the rate constants of the heterogeneous reactions are adjusted to obtain a reasonable match to the experimental data. Contrary to other box models (Nazaroff and Cass, 1986; Sarwar et al., 2002; Carslaw, 2007; Courtey et al., 2009; Mendez et al., 2015), this model does not assume that the light is homogeneous throughout the room. Here, two different parts are considered: one irradiated by direct light and another illuminated indirectly. This is one of the first models to consider the evolution of light intensity in each part through the day, as well as the volumes that they occupy, without making use of computational fluid dynamics (CFD) simulations (Won et al., 2019).

First, this paper provides a detailed description of the $\mathrm{H}^{2} \mathrm{I}$ model. The input data and the tuneable parameters of the model are then described. These parameters are calibrated by comparing the simulation results to the concentration profiles that were acquired in Martigues (France). For each experiment, the set of parameters leading to the best simulation, called the reference simulation, is provided. Each of the parameters is then varied to estimate its sensitivity, thereby identifying the most impacting processes. Finally, a surface saturation limit is implemented to test the model in high $\mathrm{NO}_{2}$ conditions.

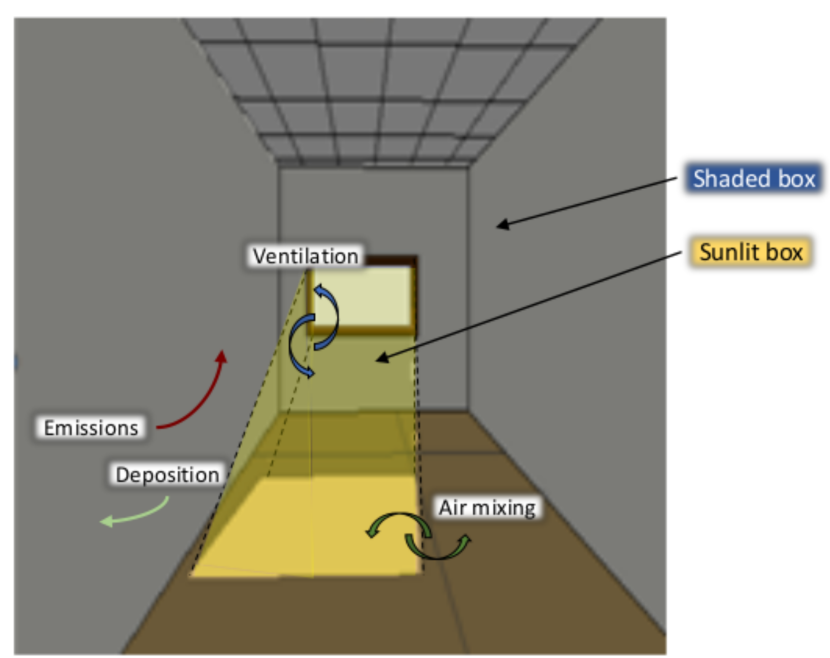

Figure 1. Schema of the sunlit and shaded boxes in the experiment room at 13:00 on 30 October.

\section{Presentation of the $\mathrm{H}^{2} \mathrm{I}$ (homogeneous heterogeneous indoor) model}

\subsection{Mass balance equation}

The room is divided into two volumes: a volume illuminated by the light of the sun and a darker volume illuminated by indirect light. As the light in these two volumes has different intensities, the magnitudes of the photolytic reactions occurring inside these volumes are different, leading to different concentrations in each volume (see Fig. 1 for a schema). $m_{i}^{j}$ $[\mu \mathrm{g}]$ is the mass of species $i$ in the box $j$, with $j=\{L, G\}, L$ denoting the sunlit box illuminated by direct light, and $G$ denoting the gloomy box illuminated indirectly by diffuse and reflected light (see Appendix A for a summary of the symbols used). The evolution of $m_{i}^{j}$ with time is given by the classical box model equation (e.g. Sarwar et al., 2002; Carslaw, 2007) complemented by a box exchange term (Furtaw et al., 1996):

$$
\begin{aligned}
\frac{\mathrm{d} m_{i}^{j}}{\mathrm{~d} t}= & k_{\mathrm{AER}} f m_{i}^{\mathrm{Out}, j}-k_{\mathrm{AER}} m_{i}^{j}-k_{\mathrm{DEP}, i}^{j} m_{i}^{j} \\
& +k_{\mathrm{BOX}}^{j} \Delta_{j} m_{i}+\sum_{p} Q_{p i}^{j}+\sum_{q} R_{i q}^{j},
\end{aligned}
$$

where $t$ is the time [s], $k_{\mathrm{AER}}$ is the air exchange rate between the room and outside the room $\left[\mathrm{s}^{-1}\right]$, including the rest of the building, $f$ is the outdoor-to-indoor filtration factor [] (i.e. the fraction of air exchange with outdoors), $m_{i}^{\text {Out }, j}$ is the outdoor mass of species $i$ introduced in box $j[\mu \mathrm{g}]$, $k_{\mathrm{DEP}, i}^{j}$ is the deposition rate of species $i\left[\mathrm{~s}^{-1}\right], k_{\mathrm{BOX}}$ is the air exchange rate between the boxes $\left[\mathrm{s}^{-1}\right], \Delta_{j} m_{i}$ is the corresponding mass transfer $[\mu \mathrm{g}], Q_{p i}$ is the emission rate of source $p\left[\mu \mathrm{g} \mathrm{s}^{-1}\right.$ ], and $R_{i q}^{j}$ is the mass reaction rate between species $i$ and species $q\left[\mu \mathrm{g} \mathrm{s}^{-1}\right.$ ]. 
By denoting $V_{\text {box }}^{j}$ as the volume of the box $j\left[\mathrm{~m}^{3}\right]$, the mass transfer from box $L$ to box $S$ is expressed as

$\Delta_{L} m_{i}=-m_{i}^{L}+\frac{V_{\mathrm{box}}^{L}}{V_{\mathrm{box}}^{G}} m_{i}^{G}$,

and the mass transfer from box $S$ to box $L$ is expressed as

$\Delta_{G} m_{i}=\frac{V_{\mathrm{box}}^{G}}{V_{\mathrm{box}}^{L}} m_{i}^{L}-m_{i}^{G}$.

The evolution of the species concentrations is obtained by dividing Eq. (1) by the box volume. This yields

$$
\begin{aligned}
\frac{\mathrm{d} C_{i}^{j}}{\mathrm{~d} t}= & k_{\mathrm{AER}} f C_{i}^{\mathrm{Out}}-k_{\mathrm{AER}} C_{i}^{j}-k_{\mathrm{DEP}, i}^{j} C_{i}^{j}+k_{\mathrm{BOX}}^{j} \Delta_{j} C_{i} \\
& +\sum_{p} \frac{Q_{p i}^{j}}{V_{\mathrm{box}}^{j}}+\sum_{q} \frac{R_{i q}^{j}}{V_{\mathrm{box}}^{j}},
\end{aligned}
$$

where $C_{i}^{j}=m_{i}^{j} / V_{\text {box }}^{j}$ is the indoor concentration of species $i$ in volume $j\left[\mu \mathrm{g} \mathrm{m}^{-3}\right.$ ], $C_{i}^{\mathrm{Out}}$ is the outdoor concentration of species $i\left[\mu \mathrm{g} \mathrm{m}^{-3}\right]$ and $\Delta_{j} C_{i}$ is the concentration variation caused by the gas transfers between boxes $\left[\mu \mathrm{g} \mathrm{m}^{-3}\right]$, given by

$$
\begin{aligned}
& \Delta_{L} C_{i}=-C_{i}^{L}+C_{i}^{G}, \\
& \Delta_{G} C_{i}=C_{i}^{L}-C_{i}^{G} .
\end{aligned}
$$

On the right-hand side of Eq. (4), the first term is the intake of species coming from outdoors. The second term is the concentration loss due to the leakages not only to the outdoors but also to the other rooms in the building. The third term is deposition. The fourth term represents the mixing between the two volumes. The fifth term represents the indoor sources that release species $i$, and the last term is the contribution of the reactions involving species $i$.

The two types of sources encountered in the experiments of this campaign are the emissions of the paint boards placed on the walls $\left(Q_{\text {paint }, i}\right)$ and the emissions from the building $\left(Q_{\text {room, } i}\right)$ released by the building materials, furniture and appliances of the neighbouring rooms. The room emissions in the box $j$ can be written as

$Q_{\text {room }, i}^{j}=Q_{\text {room }, i} \frac{V_{\text {box }}^{j}}{V_{\text {room }}}$,

where $V_{\text {room }}=32.8 \mathrm{~m}^{3}$ is the total volume of the room. The paint emissions are derived from their surface emission rates:

$Q_{\text {paint }, i}^{j}=E_{\text {paint }, i}^{j} S_{\text {paint }}^{j}$,

where $E_{\text {paint }, i}$ represents the paint surface emission rates obtained experimentally [ $\mu \mathrm{g} \mathrm{m}^{-2} \mathrm{~s}^{-1}$ ], and $S_{\text {paint }}^{j}$ is the surface of paint in the box $j\left[\mathrm{~m}^{2}\right]$. In the box illuminated by direct light, Eq. (4) thus gives

$$
\begin{aligned}
\frac{\mathrm{d} C_{i}^{L}}{\mathrm{~d} t}= & k_{\mathrm{AER}}\left(f C_{i}^{\mathrm{Out}}-C_{i}^{L}\right)-k_{\mathrm{DEP}, i}^{L} C_{i}^{L} \\
& +k_{\mathrm{BOX}}^{L}\left(-C_{i}^{L}+C_{i}^{G}\right)+\frac{Q_{\mathrm{room}, i}}{V_{\mathrm{room}}} \\
& +\frac{E_{\mathrm{pain}, i}^{L} S_{\mathrm{paint}, i}^{L}}{V_{\mathrm{box}}^{L}}+\sum_{q} \frac{R_{i q}^{L}}{V_{\mathrm{box}}^{L}},
\end{aligned}
$$

and in the shaded box, Eq. (4) gives

$$
\begin{aligned}
\frac{\mathrm{d} C_{i}^{G}}{\mathrm{~d} t}= & k_{\mathrm{AER}}\left(f C_{i}^{\mathrm{Out}}-C_{i}^{G}\right)-k_{\mathrm{DEP}, i}^{G} C_{i}^{G} \\
& +k_{\mathrm{BOX}}^{G}\left(C_{i}^{L}-C_{i}^{G}\right)+\frac{Q_{\mathrm{room}, i}}{V_{\mathrm{room}}}+\frac{E_{\mathrm{paint}, i}^{G} S_{\text {paint }, i}^{G}}{V_{\mathrm{box}}^{G}} \\
& +\sum_{q} \frac{R_{i q}^{G}}{V_{\mathrm{box}}^{G}} .
\end{aligned}
$$

\subsection{Box evolution and exchanges between the boxes}

We denote $V_{\text {box }}^{L}$ and $V_{\text {box }}^{G}$ as the volumes of the sunlit and shaded boxes, respectively. Accordingly, the total surface of the room $S_{\text {room }}=62.7 \mathrm{~m}^{2}$ is split into two parts, $S_{\text {box }}^{L}$ and $S_{\text {box }}^{G}$. Their evolution through the day is constrained by the relationships

$$
\begin{aligned}
& V_{\text {room }}=V_{\text {box }}^{L}+V_{\text {box }}^{G}, \\
& S_{\text {room }}=S_{\text {box }}^{L}+S_{\text {box }}^{G} .
\end{aligned}
$$

Hourly values of $V_{\text {box }}^{L}$ and $S_{\text {box }}^{L}$ were estimated by modelling the solar flux in the room (Tlili et al., 2021). The position of the sun and extrapolation of its beams from the windows were assessed using the Revit 2018 software; the irradiated surface and beam volume were then calculated by vertical and horizontal projections of the indoor solar flux using Autocad 2016 (see http://www.autodesk.fr, last access: 12 May 2021, for both software). The evolution of $V_{\text {box }}^{L}$ and $S_{\text {box }}^{L}$ as a function of time $t_{\mathrm{h}}[\mathrm{h}]$ is inferred from these values by fitting a Gaussian law (Fig. 2):

$V_{\text {box }}^{L}\left(t_{\mathrm{h}}\right)=\frac{A_{\mathrm{v}}}{\sigma_{\mathrm{v}} \sqrt{2 \pi}} \mathrm{e}^{-\frac{\left(t_{\mathrm{h}}-\mu_{\mathrm{v}}\right)^{2}}{2 \sigma_{\mathrm{v}}^{2}}}$,

with $A_{\mathrm{v}}=36.505 \mathrm{~m}^{3} \mathrm{~h}, \sigma_{\mathrm{v}}=2.154 \mathrm{~h}$ and $\mu_{\mathrm{v}}=11.199 \mathrm{~h}$,

$S_{\text {box }}^{L}\left(t_{\mathrm{h}}\right)=\frac{A_{\mathrm{b}}}{\sigma_{\mathrm{b}} \sqrt{2 \pi}} \mathrm{e}^{-\frac{\left(t_{\mathrm{h}}-\mu_{\mathrm{b}}\right)^{2}}{2 \sigma_{\mathrm{b}}^{2}}}$

with $A_{\mathrm{b}}=36.958 \mathrm{~m}^{2} \mathrm{~h}, \sigma_{\mathrm{b}}=2.1950 \mathrm{~h}$ and $\mu_{\mathrm{b}}=11.555 \mathrm{~h}$. $V_{\text {box }}^{G}$ and $S_{\text {box }}^{G}$ are deduced from $V_{\text {box }}^{L}$ and $S_{\text {box }}^{L}$ using Eq. (10). 

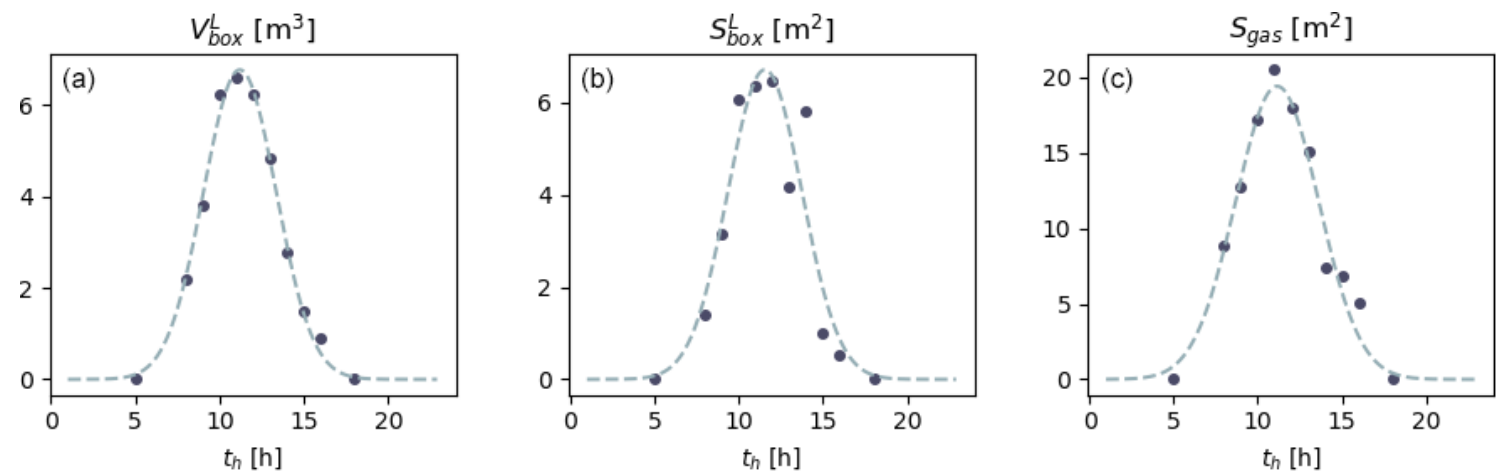

Figure 2. From the left to the right: evolution of (a) $V_{\text {box }}^{L}$, (b) $S_{\text {box }}^{L}$ and (c) $S_{\text {gas }}$ with GMT hour. The solid circles denote the values estimated numerically, and the dashed lines are the Gaussian laws they allow for the inference of. These parameterizations are representative of the time period (27 to 31 October) and location (Martigues, France) of the experiments.

We stress that Eqs. (11) and (12) are valid only for the geometry of the room where the measurements were acquired (building orientation and window position) and for the period during which the campaign was performed (end of October). $S_{\text {box }}^{L}$ and $S_{\text {box }}^{G}$ divide the total solid surface of the experimental room, including the walls, window, floor and ceiling. The complement of $S_{\text {box }}^{L}$ to obtain the total surface of the sunlit box is the same as the complement of $S_{\mathrm{box}}^{G}$, which is necessary to obtain the total surface of the shaded box. This complement is the surface allowing gas transfer between the boxes and is denoted as $S_{\text {gas }}$. This latter complement was estimated with the same method as the one used for $V_{\text {box }}^{L}$ and $S_{\text {box }}^{L}$ (Tlili et al., 2021), giving (Fig. 2)

$S_{\text {gas }}\left(t_{\mathrm{h}}\right)=\frac{A_{\mathrm{g}}}{\sigma_{\mathrm{g}} \sqrt{2 \pi}} \mathrm{e}^{-\frac{\left(t_{\mathrm{h}}-\mu_{\mathrm{g}}\right)^{2}}{2 \sigma_{\mathrm{g}}^{2}}}$,

where $A_{\mathrm{g}}=120.04 \mathrm{~m}^{2} \mathrm{~h}, \sigma_{\mathrm{g}}=2.4683 \mathrm{~h}$ and $\mu_{\mathrm{g}}=11.154 \mathrm{~h}$.

The variation of mass within the boxes due to the air mixing is proportional to the surface $S_{\text {gas }}$. This proportionality is expressed by the air exchange constant $k_{\mathrm{BOX}}$, defined as (Furtaw et al., 1996)

$k_{\mathrm{BOX}}^{j}=u_{\mathrm{inf}} \frac{S_{\mathrm{gas}}}{V_{\mathrm{box}}^{j}}$,

where $u_{\text {inf }}$ is the average velocity of air in the room $\left[\mathrm{m} \mathrm{s}^{-1}\right]$. This velocity was estimated based on a tracer injection experiment and numerical tests (see Sects. 3.2 and 5.1.1).

\subsection{Chemical mechanism}

Numerical simulations cannot afford the computation of the millions of reactions occurring in real atmospheres. Approximations are required to reduce this complexity and to alleviate computational efforts. Modellers can opt for different types of kinetic chemical mechanisms, depending on the targeted accuracy. In particular, the lumped-species approach allows the use of a reduced number of compounds, with each compound representing several species having similar properties (Gery et al., 1989; Stockwell et al., 1990; Yarwood et al., 2005; Carter, 2010; Goliff et al., 2013), such as reactivity with $\mathrm{OH}$ or carbon bounds. A given species can be represented by a single model compound or by the combination of several model compounds. Mendez et al. (2015) compared the concentrations they obtained with this kind of lumpedspecies model, SAPRC-07 (Carter, 2010), to the concentrations Carslaw (2007) simulated with the detailed chemistry model MCM and concluded that their overall behaviours were consistent with respect to the $\mathrm{O}_{3}, \mathrm{NO}_{x}\left(\mathrm{NO}+\mathrm{NO}_{2}\right)$ and $\mathrm{HO}_{x}\left(\mathrm{HO}+\mathrm{HO}_{2}\right)$ variations. Considering that the general dynamics of homogeneous indoor chemistry can be reproduced by semi-explicit models initially developed for outdoor atmospheres, RACM2, which is also a lumped-speciesbased model, is used in this paper to solve the chemical reactivity.

To introduce the surface chemistry highlighted by laboratory studies but hardly present in current indoor models, the RACM2 scheme is modified to take into account the heterogeneous reactions listed in Table 1. The resulting modified version of the RACM2 scheme comprises 117 species and 389 reactions, among which 34 are photolytic and 38 heterogeneous. To further investigate the reactions highlighted in the Introduction, some surface species are introduced, namely $\mathrm{NO}_{(\mathrm{ad})}, \mathrm{NO}_{2(\mathrm{ad})}, \mathrm{HONO}_{(\mathrm{ad})}$ and $\mathrm{HNO}_{3(\mathrm{ad})}$. These species can either sorb, desorb or react together. $\mathrm{HNO}_{3(\mathrm{ad})}$ is not allowed to desorb based on the experimental observation that $\mathrm{NO}_{2}$ hydrolysis never yields gaseous $\mathrm{HNO}_{3}$ (FinlaysonPitts et al., 2003). The kinetic constants of desorption and surface reactions are uncertain and are thus considered tuneable parameters. Adsorption and decomposition reactions are modelled by combining transport to the boundary layer and surface adhesion (Mendez et al., 2015; Morrison et al., 2019), as detailed below. 
Table 1. Heterogeneous reactions added to the RACM2 model. The symbol $\chi$ designates the species that undergo unimolecular decomposition. These species are $\mathrm{O}_{3}, \mathrm{NO}_{3}, \mathrm{HNO}_{4}$ and $\mathrm{H}_{2} \mathrm{O}_{2}$. Reactions $\left(\mathrm{S}_{1}\right),\left(\mathrm{S}_{2}\right),\left(\mathrm{S}_{3}\right)$ and $\left(\mathrm{S}_{4}\right)$ (surface reactions) are the model equivalent of Reactions (R1), (R3), (R2) and (R4), respectively.

\begin{tabular}{|c|c|}
\hline Reactions & $\begin{array}{l}\text { Kinetic } \\
\text { constants }\end{array}$ \\
\hline \multicolumn{2}{|l|}{ Unimolecular decomposition } \\
\hline$\chi \rightarrow$ & $k_{\chi}$ \\
\hline \multicolumn{2}{|l|}{ Adsorption reactions } \\
\hline $\begin{array}{l}\mathrm{NO} \rightarrow \mathrm{NO}_{(\mathrm{ad})} \\
\mathrm{NO}_{2} \rightarrow \mathrm{NO}_{2}(\mathrm{ad}) \\
\mathrm{HONO} \rightarrow \mathrm{HONO}_{(\mathrm{ad})} \\
\mathrm{HNO}_{3} \rightarrow \mathrm{HNO}_{3(\mathrm{ad})}\end{array}$ & $\begin{array}{l}k_{\mathrm{NO}} \\
k_{\mathrm{NO}_{2}} \\
k_{\mathrm{HONO}} \\
k_{\mathrm{HNO}_{3}}\end{array}$ \\
\hline \multicolumn{2}{|l|}{ Desorption reactions } \\
\hline $\begin{array}{l}\mathrm{NO}_{(\mathrm{ad})} \rightarrow \mathrm{NO} \\
\mathrm{NO}_{2(\mathrm{ad})} \rightarrow \mathrm{NO}_{2} \\
\mathrm{HONO}_{(\mathrm{ad})} \rightarrow \mathrm{HONO}\end{array}$ & $\begin{array}{l}k_{\mathrm{NO}(\mathrm{ad})} \\
k_{\mathrm{NO}_{2}(\mathrm{ad})} \\
k_{\mathrm{HONO}(\mathrm{ad})}\end{array}$ \\
\hline \multicolumn{2}{|l|}{ Surface reactions } \\
\hline $\begin{array}{l}\mathrm{NO}_{2(\mathrm{ad})} \rightarrow 0.5 \mathrm{HNO}_{3(\mathrm{ad})}+0.5 \mathrm{HONO}_{(\mathrm{ad})} \\
\mathrm{HONO}_{(\mathrm{ad})}+\mathrm{HNO}_{3(\mathrm{ad})} \rightarrow 2 \mathrm{NO}_{(\mathrm{ad})} \\
\mathrm{HONO}_{(\mathrm{ad})} \rightarrow 0.5 \mathrm{NO}_{(\mathrm{ad})}+0.5 \mathrm{NO}_{2(\mathrm{ad})} \\
\mathrm{NO}_{(\mathrm{ad})}+\mathrm{HNO}_{3(\mathrm{ad})} \rightarrow \mathrm{NO}_{2(\mathrm{ad})}+\mathrm{HONO}_{(\mathrm{ad})}\end{array}$ & $\begin{array}{l}k_{\mathrm{S} 1} \\
k_{\mathrm{S} 2} \\
k_{\mathrm{S} 3} \\
k_{\mathrm{S} 4}\end{array}$ \\
\hline
\end{tabular}

\subsection{Deposition and surface reactivity}

This section presents the computation of the kinetic constants of the adsorption and decomposition reactions. The local deposition rate $k_{\mathrm{DEP}, i}^{j}$ is modelled as the equivalent of two resistances in parallel, one corresponding to the transport-limited deposition rate $k_{\text {tran }, i}^{j}$ and the other corresponding to the surface adhesion rate $k_{\text {react }, i}^{j}$ :

$\frac{1}{k_{\mathrm{DEP}, i}^{j}}=\frac{1}{k_{\mathrm{tran}, i}^{j}}+\frac{1}{k_{\text {react }, i}^{j}}$.

When $k_{\text {react, } i}^{j}$ is larger than $k_{\text {tran }, i}^{j}$ the species loss is limited by the transport to the surface boundary layer. In contrast, when $k_{\operatorname{tran}, i}^{j}$ is larger than $k_{\text {react, }, i}^{j}$, species removal is limited by surface reactivity (Grøntoft and Raychaudhuri, 2004).

\subsubsection{Transport-limited deposition rate}

The rate constant $k_{\operatorname{tran}, i}^{j}$ can be expressed as

$k_{\mathrm{tran}, i}^{j}=v_{\mathrm{trd}, i} \frac{S_{\mathrm{box}}^{j}}{V_{\mathrm{box}}^{j}}$,

where $v_{\operatorname{trd}, i}$ is the deposition velocity limited by transport. It is computed using the method of Lai and Nazaroff (2000), following the same approach as Mendez et al. (2017) to model the heterogeneous production of HONO:

$v_{\mathrm{trd}, i}=v_{\mathrm{trd}, i}^{\mathrm{ad}} u^{*}$

where $v_{\operatorname{trd}, i}^{\mathrm{ad}}$ is a dimensionless deposition velocity whose computation is detailed below, and $u^{*}$ is the friction velocity defined by

$u^{*}=\left(\left.v \frac{\mathrm{d} U}{\mathrm{~d} y}\right|_{y=0}\right)^{1 / 2}$,

with $U$ the mean air velocity parallel to the surface $\left[\mathrm{m} \mathrm{s}^{-1}\right]$, $y$ the distance from the surface $[\mathrm{m}]$ and $v$ the air kinematic viscosity $\left[\mathrm{m}^{2} \mathrm{~s}^{-1}\right]$, defined by $\nu=\eta / \rho$ with $\eta$ the air dynamic viscosity $\left[\mathrm{kg} \mathrm{m}^{-1} \mathrm{~s}^{-1}\right]$ and $\rho$ the air volumetric mass $\left[\mathrm{kg} \mathrm{m}^{-3}\right]$. Considering the narrow temperature range encountered in these experiments, $\rho$ is approximated with the ideal gas law. The viscosity $\eta$ is expressed as a function of temperature $T[\mathrm{~K}]$ using the semi-empirical Sutherland relationship:

$\eta(T)=\eta_{0}\left(\frac{T}{T_{0}}\right)^{3 / 2} \frac{T_{0}+S_{\eta}}{T+S_{\eta}}$,

where the Sutherland's constant for air is $S_{\eta}=113 \mathrm{~K}$ (Kaper and Ferziger, 1972), and $\eta_{0}=1.783 \times 10^{-5} \mathrm{~kg} \mathrm{~m}^{-1} \mathrm{~s}^{-1}$ at $T_{0}=288.15 \mathrm{~K}$.

The derivative of $U$ is given by

$$
\left.\frac{\mathrm{d} U}{\mathrm{~d} y}\right|_{y=0}=\left(\frac{0.074}{\rho \nu}\right)\left(\frac{\rho u_{\mathrm{inf}}^{2}}{2}\right)\left(\frac{u_{\mathrm{inf}} l}{v}\right)^{-1 / 5},
$$

where $l$ is a characteristic length of the room surface, typically $l=\left(V_{\text {room }}\right)^{1 / 3}$.

As in Mendez et al. (2017), gravity is assumed to be negligible for gases; i.e. the dimensionless deposition velocity $v_{\mathrm{trd}, i}^{\mathrm{ad}}$ is the same for horizontal and vertical surfaces. Assuming that the molecule eddy diffusivity equals the fluid turbulent viscosity $v_{\mathrm{t}}$ in indoor environments, Lai and Nazaroff (2000) showed that

$\frac{1}{v_{\mathrm{trd}, i}^{\mathrm{ad}}}=\int_{r_{0}}^{30}\left(\frac{1}{\frac{v_{t}}{v}+\frac{D_{i}}{v}}\right) \mathrm{d} y^{\mathrm{ad}}$,

where $D_{i}$ is the diffusion coefficient of species $i\left[\mathrm{~m}^{2} \mathrm{~s}^{-1}\right]$, $y^{\mathrm{ad}}$ is the nondimensional distance from the surface and $r_{0}$ is the radius of the particle, taken here as zero. The ratio $v_{t} / v$ is given by Lai and Nazaroff (2000) for several intervals of $y^{\text {ad }}$. The diffusion coefficient can be estimated based on the species critical temperature $T_{\mathrm{c}}[\mathrm{K}]$ and critical volume $V_{\mathrm{c}}\left[\mathrm{cm}^{3} \mathrm{~mol}^{-1}\right]$ following various models. Among all models tested in the comparative study of Ravindran et al. (1979), the model of Chen and Othmer (1962) is the one that showed 
the best agreement with their experimental data. Considering a species $i$ diffusing in air, this model gives

$$
D_{i}=\frac{4.3 \times 10^{-5}\left(\frac{T}{100}\right)^{1.81}\left[\left(M_{\mathrm{air}}+M_{i}\right) /\left(M_{\mathrm{air}} M_{i}\right)\right]^{1 / 2}}{P\left(\frac{T_{\mathrm{c}, \mathrm{air}} T_{\mathrm{c}, i}}{10^{4}}\right)^{0.1406}\left[\left(\frac{V_{\mathrm{c}, \mathrm{air}}}{100}\right)^{0.4}+\left(\frac{V_{\mathrm{c}, i}}{100}\right)^{0.4}\right]^{2}},
$$

where $P$ is the ambient pressure [atm], $M_{i}$ is the species molar mass and $M_{\text {air }}=28.97 \mathrm{~g} \mathrm{~mol}^{-1}$.

Table 2 presents the diffusion coefficients computed with this method for a list of RACM2 compounds, with the parameters used for this calculation. In this table, $T_{\mathrm{c}}$ and $V_{\mathrm{c}}$ are the critical temperatures and volumes of representative species. The references from which the $T_{\mathrm{c}}$ values are taken are specified. When there is no reference, $T_{\mathrm{c}}$ is computed with the method of Joback and Reid (1987). As experimental values of $V_{\mathrm{c}}$ are difficult to find for a variety of species, all are computed with the method of Joback and Reid (1987).

\subsubsection{Surface reaction rate}

Surface adhesion is modelled with the rate constants $k_{\text {react }, i}^{j}$, which are defined as

$k_{\text {react }, i}^{j}=\frac{\gamma_{i} \omega_{i}}{4} \frac{S_{\text {box }}^{j}}{V_{\text {box }}^{j}}$,

where $\gamma_{i}$ is the uptake coefficient [-] and $\omega_{i}$ the thermal velocity $\left[\mathrm{m} \mathrm{s}^{-1}\right]$ of species $i . \gamma_{i}$ is the ratio of collisions of species $i$ with the surface that yield a reaction or simple deposition to the total number of collisions. $\omega_{i}$ depends on the temperature and can be expressed as

$\omega_{i}=\sqrt{2.1171 \times 10^{4} \frac{T}{M_{i}}}$.

The uptake coefficient is characteristic of the relationship between the species and the surface. It has been determined experimentally with the paints used in this study for two species, $\mathrm{NO}_{2}$ and xylene, indicating that uptake coefficients of other species are unknown. The deposition of organic species is beyond the scope of this paper, as organic concentrations are set to the measured values here. The uptake coefficients of $\mathrm{NO}, \mathrm{HONO}$ and $\mathrm{O}_{3}$ are uncertain and thus considered tuneable parameters. Since the simulated concentrations of $\mathrm{NO}_{3}, \mathrm{HNO}_{3}, \mathrm{HNO}_{4}$ and $\mathrm{H}_{2} \mathrm{O}_{2}$ are low, they are given an infinite uptake for simplicity so that their deposition is only controlled by transport $\left(k_{\mathrm{DEP}, i}^{j}=k_{\mathrm{tran}, i}^{j}\right)$. By default, the same procedure is applied to the $\mathrm{HO}_{2}$ radical, noting that when its deposition is neglected, the resulting difference in the average $\mathrm{NO}_{x}$ concentration is of the order of $0.1 \mu \mathrm{g} \mathrm{m}{ }^{-3}$. Likewise, the deposition of the $\mathrm{OH}$ radical is considered negligible compared with its consumption by homogeneous reactivity (Sarwar et al., 2002). There is evidence that lowvolatility species sorbed on surfaces can be subject to $\mathrm{OH}$ oxidation (Alwarda et al., 2018), but chemical variations of surface films caused by indoor oxidants are beyond the scope of this work.

\subsubsection{Parameterization of $\gamma_{\mathrm{NO}_{2}}$}

The uptake coefficient $\gamma \mathrm{NO}_{2}$ was measured in various laboratory conditions by Gandolfo et al. $(2015,2017)$. This section explains how parameterizations are inferred from these measurements and how they are used to calculate $\gamma \mathrm{NO}_{2}$ as a function of ambient conditions.

The measurements made as a function of the relative humidity, denoted as $H$, are normalized by the measurement made at $H_{\text {ref }}=40 \%$. This gives the following using a polynomial fitting:

$\gamma_{\mathrm{NO}_{2}}^{\mathrm{norm}, H}(H)=\sum_{k=0}^{2} a_{k} H^{k}$,

where $a_{0}=0.706, a_{1}=1.50 \times 10^{-2}$ and $a_{2}=-2.31 \times 10^{-4}$.

Considering that $\gamma \mathrm{NO}_{2}$ varies with the $\mathrm{NO}_{2}$ concentration in the room, measurements were made as a function of the $\mathrm{NO}_{2}$ concentration in parts per billion (ppb), denoted as $N$. By normalizing these measurements by the measurement made at $N_{\text {ref }}=40 \mathrm{ppb}$, an exponential fitting gives

$\gamma_{\mathrm{NO}_{2}}^{\text {norm, } N}(N)=118.06 \exp ^{\frac{-(N+64.52)}{20.41}}+0.61$.

Measurements were also made as a function of the light intensity irradiating the surface, denoted as $I$. The light intensity produced by the reactor covered a spectrum ranging from 340 to $400 \mathrm{~nm}$. Because the paint photocatalytic effect reaches saturation above a certain light threshold, a function type that does not increase too much at high intensity is chosen to express $\gamma_{\mathrm{NO}_{2}}^{\text {norm, } I}$. Using the measurements normalized by the measurement made at $I_{\text {ref }}=8.5 \mathrm{~W} \mathrm{~cm}^{-2}$, a logarithmic fitting gives

$\gamma_{\mathrm{NO}_{2}}^{\text {norm }, I}(I)=\ln (I+19.63)-2.74$.

Contrary to the other measurements, the measurements made as a function of temperature were performed at $I=$ $20 \mathrm{~W} \mathrm{~m}^{-2}$. By dividing the measurements as a function of $I$ by the measurement made at $I=20 \mathrm{~W} \mathrm{~m}^{-2}$, a relationship similar to Eq. (27) is obtained and denoted as $\gamma_{\mathrm{NO}_{2}}^{\text {norm } I_{2}}$. By multiplying the measurements as a function of temperature by $\gamma_{\mathrm{NO}_{2}}^{\text {norm } I_{2}}\left(I_{\text {ref }}\right)$, these measurements are brought to the same conditions of irradiance as the other measurements. They are then divided by the measurement made at $T_{\text {ref }}=$ 296 K. Finally, a polynomial fitting gives

$\gamma_{\mathrm{NO}_{2}}^{\text {norm, } T}(T)=b_{1} T_{\mathrm{s}}(T)+b_{0}$,

where $b_{0}=-17.62$ and $b_{1}=6.25 \times 10^{-2} \mathrm{~K}^{-1}$ for the paint containing $3.5 \% \mathrm{TiO}_{2}$. The values $b_{0}=1$ and $b_{1}=0$ are preferred for the reference paint, considering that the observed 
Table 2. Diffusion coefficients $D\left[\mathrm{~m}^{2} \mathrm{~s}^{-1}\right]$ and parameters used for their calculation following the procedure described in Sect. 2.4.1: RACM2 molar mass $M\left[\mathrm{~g} \mathrm{~mol}^{-1}\right]$, critical temperature $T_{\mathrm{c}}[\mathrm{K}]$ and critical molar volume $V_{\mathrm{c}}\left[\mathrm{cm}^{3} \mathrm{~mol}^{-1}\right]$ of representative species.

\begin{tabular}{lllrrlr}
\hline Compounds & $M$ & Representative species & $T_{\mathrm{c}}$ & $V_{\mathrm{c}}$ & Reference & $D\left(10^{-5}\right)$ \\
\hline $\mathrm{O}_{3}$ & 48 & $\mathrm{O}_{3}$ & 261.10 & 89 & Jenkins and Birdsall (1952) & 1.64 \\
$\mathrm{NO}$ & 30 & $\mathrm{NO}$ & 180.00 & 58 & Lide (2005) & 2.25 \\
$\mathrm{NO}_{2}$ & 46 & $\mathrm{NO}_{2}$ & 561.53 & 110 & - & 1.36 \\
$\mathrm{HONO}$ & 47 & $\mathrm{NO}_{2}$ & 561.53 & 110 & - & 1.36 \\
$\mathrm{NO}_{3}$ & 62 & $\mathrm{NO}_{3}$ & 534.15 & 140 & - & 1.18 \\
$\mathrm{HNO}_{3}$ & 63 & $\mathrm{HNO}_{3}$ & 648.46 & 140 & - & 1.14 \\
$\mathrm{HNO}_{4}$ & 79 & $\mathrm{HNO}_{4}$ & 669.82 & 155 & - & 1.05 \\
$\mathrm{HO}$ & 17 & $\mathrm{H}_{2} \mathrm{O}$ & 647.10 & 56 & Sato et al. (1991) & 2.24 \\
$\mathrm{HO}_{2}$ & 33 & $\mathrm{H}_{2} \mathrm{O}_{2}$ & 728.00 & 70 & Nikitin et al. (1995) & 1.69 \\
$\mathrm{H}_{2} \mathrm{O}_{2}$ & 34 & $\mathrm{H}_{2} \mathrm{O}_{2}$ & 728.00 & 70 & Nikitin et al. (1995) & 1.68 \\
\hline
\end{tabular}

decreasing trend falls within the measurement's uncertainty. $T_{\mathrm{s}}$ is the temperature of the surface of paint $[\mathrm{K}]$. In a real room, $T_{S}$ depends on a variety of factors, including location, season, orientation, ambient temperature and surface coating (Shen et al., 2011). For the simulations, $T_{\mathrm{S}}$ is set such that $T_{\mathrm{S}}=T$ in the shaded box and $T_{\mathrm{S}}=1.2 \times(T-273.15)+$ 273.15 in the sunlit box.

The $\gamma \mathrm{NO}_{2}$ at a given set of parameters $H, N$ and $T$ is calculated from the reference uptake coefficient $\gamma_{\mathrm{NO}_{2}}^{\text {ref }}$ measured at $T_{\text {ref }}=296 \mathrm{~K}, H_{\text {ref }}=40 \%, I_{\text {ref }}=8.5 \mathrm{~W} \mathrm{~m}^{-2}$ and $N_{\text {ref }}=$ $40 \mathrm{ppb}$, according to

$$
\begin{aligned}
\gamma_{\mathrm{NO}_{2}}(H, N, T) & =\gamma_{\mathrm{NO}_{2}}^{\text {ref }} \gamma_{\mathrm{NO}_{2}}^{\text {norm }, N}(N) \gamma_{\mathrm{NO}_{2}}^{\text {norm }, H}(H) \\
& \cdot \gamma_{\mathrm{NO}_{2}}^{\text {norm, } T}(T)
\end{aligned}
$$

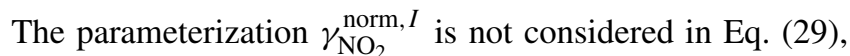
given that it was established based on measurements with a light spectrum ranging from 340 to $400 \mathrm{~nm}$ and that the measurements presented in this paper were obtained with a light spectrum starting from $395 \mathrm{~nm}$.

The dependence of $\gamma_{\mathrm{NO}_{2}}^{\text {ref }}$ with the percentage of $\mathrm{TiO}_{2}$ nanoparticles contained by the paint and the parameterizations of $\gamma_{\mathrm{NO}_{2}}^{\text {norm }}$ are presented in Fig. 3. $\gamma_{\mathrm{NO}_{2}}^{\text {ref increases with }}$ the percent of $\mathrm{TiO}_{2}$, but the values at $0 \%$ and $3.5 \%$ are very close. In the simulations, $\gamma_{\mathrm{NO}_{2}}^{\mathrm{ref}}=5 \times 10^{-6}$ is used for both paints and for the surface that is not covered by paint (floor, ceiling, rest of the walls).

\subsection{Desorption rates}

According to Ramazan et al. (2004), water competes with $\mathrm{HONO}_{(\mathrm{ad})}$ for surface sites and displaces $\mathrm{HONO}_{(\mathrm{ad})}$ towards a gas phase as the surface water vapour increases. The higher the water vapour is, the more $\mathrm{HONO}_{(\mathrm{ad})}$ desorbs. On the other hand, the lower the water vapour is, the more $\mathrm{HONO}_{(\mathrm{ad})}$ is available to react with other sorbed species such as NO. In this study, it is assumed that the same holds for the other adsorbed compounds. As no information on the surface water concentration is available, the desorption reactions are parameterized as a function of the room humidity. The desorption kinetic constants are defined as

$k_{i,(\mathrm{ad})}=\alpha_{i} k_{\mathrm{H}, i} n_{\mathrm{H}_{2} \mathrm{O}}$,

where $n_{\mathrm{H}_{2} \mathrm{O}}$ is the number of water molecules in the room computed from the water mass fraction (absolute humidity), $k_{\mathrm{H}, i}$ is the Henry's law constant of compound $i$ [bar mol kg-1] and $\alpha_{i}$ is a tuneable variable [kg bar ${ }^{-1}$ mol $^{-1} \mathrm{~s}^{-1}$ molec. ${ }^{-1}$ ]. The value of $k_{\mathrm{H}, i}$ characterizes the compound affinity for water. The temperature range of these experiments (see Table 3 ) is considered sufficiently narrow to neglect the dependence of $k_{\mathrm{H}, i}$ on temperature. At $T=298.15 \mathrm{~K}, k_{\mathrm{H}, \mathrm{NO}}=0.0019 \mathrm{bar}$ mol kg${ }^{-1}, k_{\mathrm{H}, \mathrm{NO}_{2}}=$ 0.012 bar mol kg-1 and $k_{\mathrm{H}, \mathrm{HONO}}=49$ bar mol kg${ }^{-1}$ (Linstrom and Mallard). For simplicity, in the rest of this paper, we will use $k_{i,(\mathrm{ad})}^{\prime}=\alpha_{i} k_{\mathrm{H}, i}$.

\subsection{Photolysis}

In all indoor models presented in the Introduction, light was assumed to have two origins: sunlight and artificial light. Using the indoor light intensity recommended for reading purposes, Sarwar et al. (2002) assumed that each light source accounted for $50 \%$ of the total light and accordingly combined spectral power distributions obtained from the literature to obtain the total spectral distribution. Nazaroff and Cass (1986), Mendez et al. (2015), and Carslaw (2007) computed their own outdoor photon fluxes and applied attenuation factors to account for window filtration. Carslaw (2007) and Mendez et al. (2015) used the same indoor light fluxes as Nazaroff and Cass (1986) and started with the same attenuation factors before varying them.

Whereas light intensity can be considered homogeneous in direct light whatever the distance from the window (Kowal et al., 2017), it decreases rapidly moving away from the direct sunlight (Gandolfo et al., 2016). The distribution of light intensity in the shaded volume is strongly locationspecific and thus hard to predict. However, light intensity in the shaded volume is much lower than the intensity of di- 

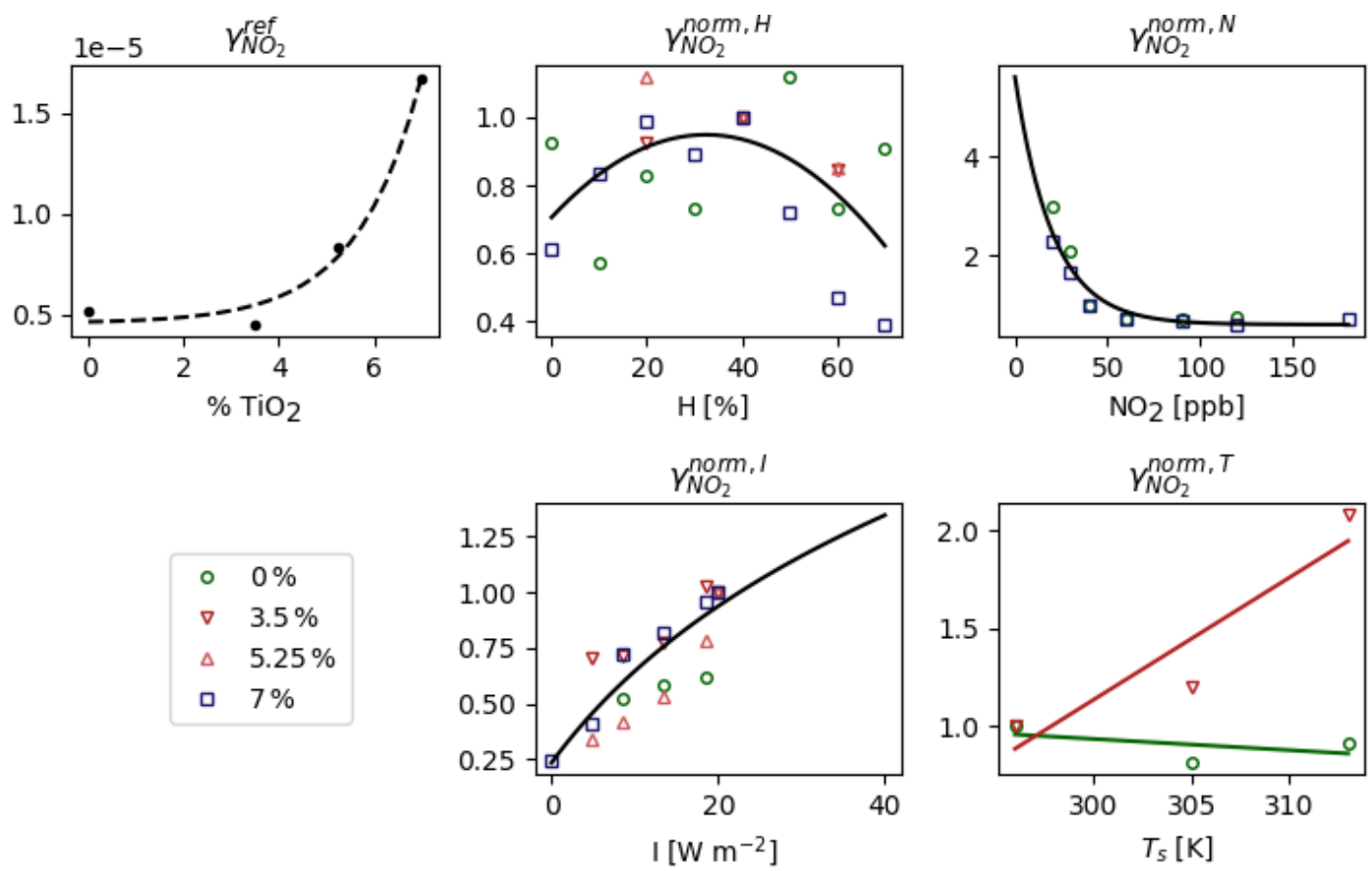

Figure 3. Evolution of $\gamma_{\mathrm{NO}_{2}}$. The dots denote measurements, and the open symbols denote normalized measurements (see text for details). The solid lines denote the parameterization as a function of $H, N, I$ and $T_{\mathrm{S}}$ (Eqs. 25-28).

rect light; therefore, the impact of the photolytic reactions occurring in the shaded volume is minor compared with that occurring in the sunlit volume. As an approximation, the photolytic constants in the shaded box are computed using a unique actinic flux that was measured close to the area illuminated by the sunlight. This model does not represent the light decrease when moving away from the window because only two boxes are considered: shaded and sunlit.

Let $\zeta$ be the indoor actinic flux [photons $\mathrm{cm}^{-2} \mathrm{~s}^{-1} \mathrm{~nm}^{-1}$ ] measured at $t=t_{\text {ref. }}$. Let $\lambda_{\min }$ and $\lambda_{\max }$ be the minimum and maximum wavelengths of the light spectrum [nm]. The photolytic constants associated with this actinic flux are given by (Nazaroff and Cass, 1986)

$J_{i}^{\mathrm{ref}}=\int_{\lambda_{\min }}^{\lambda_{\max }} \zeta(\lambda) \kappa_{i}(\lambda) \phi_{i}(\lambda) \mathrm{d} \lambda$,

where $J_{i}^{\text {ref }}$ is the photolytic constant of species $i$ [photons $\mathrm{cm}^{-2} \mathrm{~s}^{-1}$ ] at $t=t_{\mathrm{ref}}, \kappa_{i}$ the species cross section [-] and $\phi_{i}$ the species quantum yield [-]. The actinic flux used to calculate $J_{i}^{\text {ref }}$ in the indirect light was measured at $t_{\text {ref }}=11: 00$ (GMT) on 27 October (Experiment 1), and the one used to calculate $J_{i}^{\text {ref }}$ in the direct light was measured at $t_{\text {ref }}=11: 00$ (GMT) on 29 October (Experiment 3). The light spectrum starts at $\lambda_{\min }=390 \mathrm{~nm}$ in the direct light and $\lambda_{\min }=394 \mathrm{~nm}$ in the indirect light. Both spectra end at $660 \mathrm{~nm}$.

To account for the evolution of the photolytic constants with the time of day, a parameterization is inferred from the
$\mathrm{HONO}, \mathrm{NO}_{2}, \mathrm{HCHO}, \mathrm{H}_{2} \mathrm{O}_{2}$ and $\mathrm{NO}_{3}$ photolytic rates measured by a spectroradiometer in direct light on 30 October with windows that did not cut UV rays (Fig. 4):

$J_{i}(\theta)=A_{i} \exp ^{\frac{-(\theta-C)}{B}}$,

where $\theta$ is the zenith angle and $J_{i}$ is the photolytic constant of species $i$ as a function of $\theta$. The evolution of $\theta$ with the hour of the day is presented in Fig. 5. The curves fitting the $J_{i}$ rates measured in the morning and those fitting the ones measured in the afternoon are superimposed in Fig. 4, indicating no hysteresis. For each compound, the values of $B$ and $C$ are very close, with an average of $B=10.7$ and $C=50$. For a given compound, the prefactor $A$ is given by

$A_{i}=J_{i}^{\mathrm{ref}} \exp ^{\frac{\theta_{\mathrm{ref}}-C}{B}}$,

where $\theta_{\text {ref }}$ is the zenith angle corresponding to $t_{\text {ref }}$. This yields

$J_{i}(\theta)=J_{i}^{\mathrm{ref}} \exp ^{\frac{-\left(\theta-\theta_{\mathrm{ref}}\right)}{B}}$.

Equation (34) is plotted in Fig. 4 using the $J_{i}^{\text {ref }}$ calculated with the $\phi$ and $\kappa$ values available for the RACM2 chemical mechanism (Kim et al., 2009) in the Polyphemus air-quality modelling platform. We observe reasonable agreement between the measured and calculated photolytic rates.

\subsection{Numerical resolution}

The simulations start and end at the times fixed by the user (see Sect. 3.1). The time step $\Delta t$ of the main loop of time 

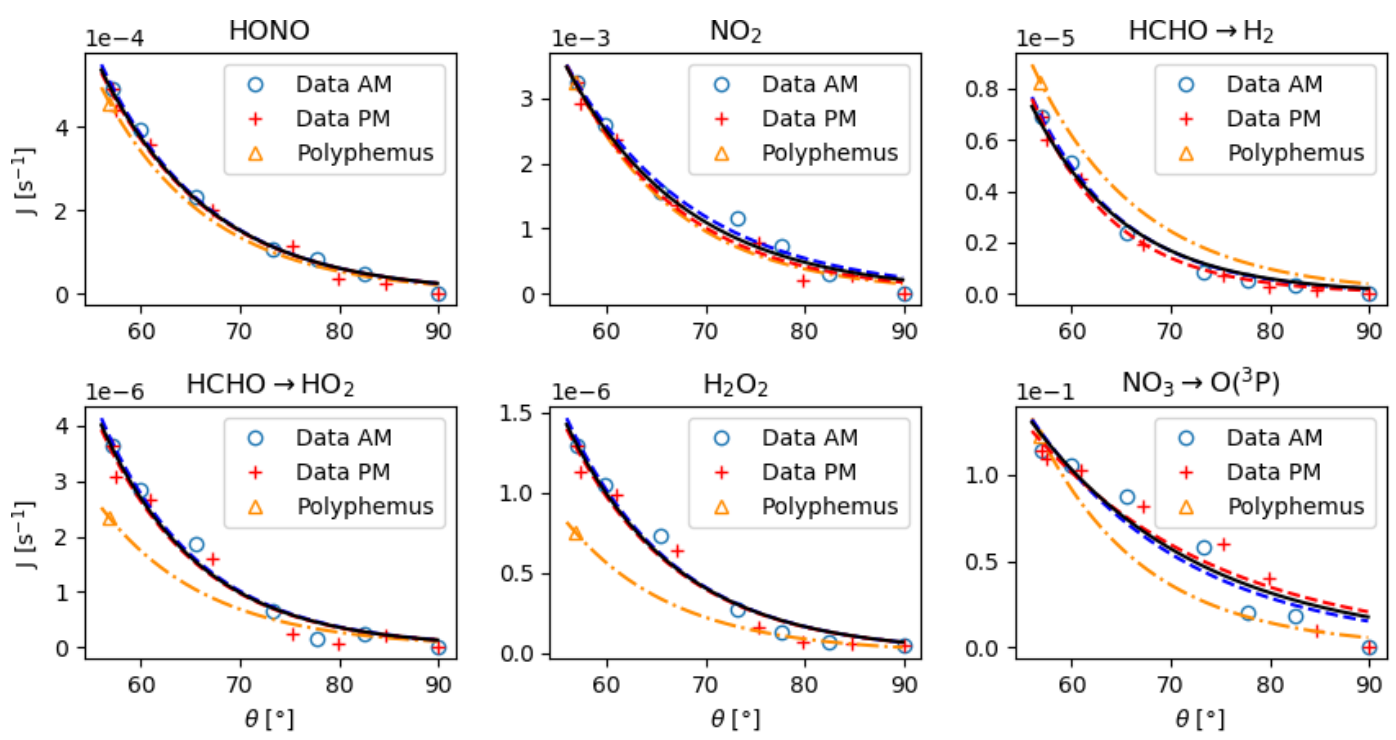

Figure 4. Photolysis rates as a function of zenith angle. The symbols $\bigcirc$ and + denote the experimental rates acquired on 30 October in the morning and in the afternoon. The blue and red dashed lines are their parameterization using Eq. (32). The black solid line is the curve obtained by fitting the data from both the morning and those from the afternoon. The $\triangle$ symbols are the photolysis rates calculated with Eq. (31) with the cross sections and quantum yields taken from Polyphemus. The yellow dash-dotted line is the deriving evolution of $J$ with $\theta$ according to Eq. (34).

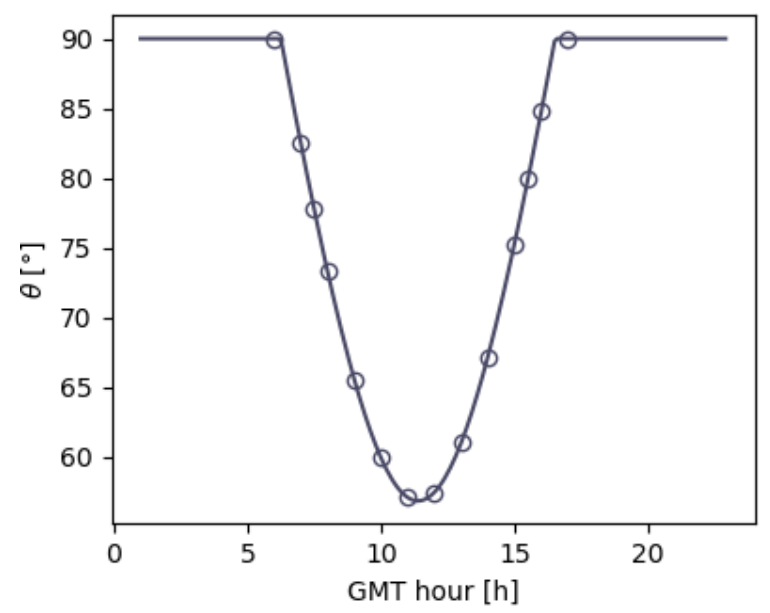

Figure 5. Zenith angle $\theta$ as a function of the hour of the day on 27 October at latitude $43.41^{\circ}$ and longitude $5.06^{\circ}$ (Martigues area). The $\bigcirc$ symbols denote the hours of the $J_{i}$ measurements by the spectroradiometer.

in the programme is set to $100 \mathrm{~s}$. It corresponds to an inputoutput time step: at the beginning of each iteration of the main loop, input data such as temperature, humidity and outdoor concentrations are read from a file, and at the end of each iteration, the concentrations are written to a file. Variables characterizing the environment and the source and sink terms are also initialized and updated in the main loop, namely box volumes and surfaces (Eqs. 10-12), box air ex- change (Eq. 14), ventilation, supply from outdoors, and emissions.

The resolution of Eq. (4) is performed using operator splitting: the evolution of the concentrations due to emissions, air exchanges between boxes, and between the room and the outside is first solved using the explicit trapezoidal rule (ETR), which is an explicit second-order solver corresponding to a two-stage Runge-Kutta method (Ascher and Petzold, 1998). The time step is adapted as described in Sartelet et al. (2006): each main time step $\Delta t$ of $100 \mathrm{~s}$ is decomposed in sub-time steps $\delta t_{k}$ determined by the ETR method, such as $\Delta t=\sum_{k} \delta t_{k}$. After each sub-time step $\delta t_{k}$, the third and last terms of the right-hand side of Eq. (4) are solved together. The evolution of the concentrations due to homogeneous and heterogeneous reactions and deposition is computed using the Rosenbrock 2 (ROS2) algorithm (Rosenbrock, 1963; Sandu et al., 1997), with time steps automatically adapted between $\delta t_{k}$ and $\delta t_{k+1}$ by the ROS2 algorithm.

In this paper, the VOC concentrations are assigned to their experimental values at each iteration of the main loop. By imposing the VOC concentrations at each main iteration, no drift is observed between experimental and calculated values, indicating that the characteristic time of their evolution caused by chemical reactivity, sources and sinks is lower than the model time step $\Delta t$. Note that this is not the case with more reactive species, such as $\mathrm{NO}$ and $\mathrm{NO}_{2}$, which may evolve significantly between two iterations. 


\section{Input data and parameters for model evaluation}

\subsection{Measurements used as input and model-measurement comparisons}

Three experiments were conducted with anti-UV windows in an office room in a new building situated in the suburban area of Martigues (France) less than 6 months after its construction. The first one was conducted without any paint board ("naked" walls), the second one with walls covered by the reference paint and the third one with walls covered by the $3.5 \% \mathrm{TiO}_{2}$ paint. The complete description of these experiments is provided by Gandolfo et al. (2021) (see also Gandolfo, 2018). This section provides a brief introduction of the data used in this paper.

The room was ventilated before each experiment. The start time of the simulation is chosen to match the beginning of the VOC concentration increase caused by the closing of the windows. When the windows were closed, the air exchange rate $k_{\mathrm{AER}}$ was determined by continued analysis of an inert gaseous tracer $\left(\mathrm{CO}_{2}\right)$ injected into the room at the beginning of the experiment. For a given day, the measured $k_{\mathrm{AER}}$ values were almost constant, which allows running the simulations with a daily average value for each experiment. Indoor temperature and humidity were measured every $10 \mathrm{~s}$. They are involved in the computation of air viscosity, friction velocity, species diffusivities, thermal and deposition velocities, and uptake values. The durations of the experiments, average ventilation rates, minimum and maximum temperatures and humidities, and average total VOC concentrations recorded are summarized in Table 3.

Outdoor concentrations, used as model input, are estimated by linear interpolation of outdoor measurements. VOCs were measured with a PTR-ToF-MS (proton transfer reaction time-of-flight mass spectrometer) equipped with a motorized valve rotating alternatively for $5 \mathrm{~min}$ outdoors and $10 \mathrm{~min}$ indoors, providing an outdoor VOC measurement every $15 \mathrm{~min}$. The $\mathrm{O}_{3}$ outdoor concentrations were measured at a rate of one measurement per minute. The $\mathrm{NO}$ and $\mathrm{NO}_{2}$ outdoor concentrations were recorded on a quarter-hourly basis by the regional air-quality network AtmoSud at a station located approximately $1.5 \mathrm{~km}$ away and for which the $\mathrm{NO}_{x}$ concentrations are expected to be representative of the concentrations close to the building. Outdoor $\mathrm{HONO}, \mathrm{OH}$ and $\mathrm{HO}_{2}$ were not measured. They are thus fixed at a constant and realistic value of $20 \mathrm{ppt}$ for HONO, $10^{6}$ molecules per cubic centimetre (molec. $\mathrm{cm}^{-3}$ ) for $\mathrm{OH}$ and $10^{8}$ molec. $\mathrm{cm}^{-3}$ for $\mathrm{HO}_{2}$ (Holland et al., 2003).

Due to the PTR-ToF-MS valve rotations, an indoor VOC measurement every 15 min was performed with a shift of 5 and $10 \mathrm{~min}$ with the previous and subsequent outdoor VOC measurement, respectively. Indoor $\mathrm{NO}_{x}$ was measured by chemiluminescence, HONO using a LOPAP (long-path absorption photometer) and $\mathrm{O}_{3}$ by spectrophotometry. All instruments were placed in a separate room. The presence of instruments in the experiment room would have increased the surface available for heterogeneous reactivity in a hardly quantifiable way, thus introducing uncertainty. $\mathrm{O}_{3}$ was captured at the centre of the room at a rate of one measurement per minute. $\mathrm{NO}_{x}$ was measured every second and $\mathrm{HONO}$ every $15 \mathrm{~s}$. The modelled $\mathrm{O}_{3}, \mathrm{HONO}$ and $\mathrm{NO}_{x}$ are compared with these experimental records. The sources of these species are infiltration from the outdoors and chemical reactivity; therefore, no emission rate is considered for them.

\subsection{Model parameters}

The inorganic species measurements are considered a benchmark to estimate the model's undetermined parameters. These parameters are the building filtration factor $f$, the kinetic constants of the surface and desorption reactions (see Table 1), the uptake coefficients of $\mathrm{O}_{3}, \mathrm{NO}$ and $\mathrm{HONO}$, the initial concentrations of the surface species $\mathrm{NO}_{(\mathrm{ad})}, \mathrm{NO}_{2(\mathrm{ad})}$, $\mathrm{HONO}_{(\mathrm{ad})}$ and $\mathrm{HNO}_{3(\mathrm{ad})}$, and, to a lesser extent, the velocity of air in the room $u_{\text {inf }}$.

The velocity of air in the room is assessed by measuring the homogenization time of a tracer gas injection. A styrene injection indicated that this velocity could range between 0.05 and $0.4 \mathrm{~m} \mathrm{~s}^{-1}$. Furtaw et al. (1996) and references therein have suggested the same admissible bounds for this parameter, with a value of $0.15 \mathrm{~m} \mathrm{~s}^{-1}$ identified as a reference for comfortable indoor conditions (McQuiston et al., 2004). In the experiments listed in Table 3, two fans were placed on both sides of the room, providing active air mixing and thus a $u_{\text {inf }}$ value likely exceeding $0.15 \mathrm{~m} \mathrm{~s}^{-1}$.

The building filtration factor controls the fluxes of outdoor pollutants that enter the room through the cracks and gaps of the building's structure. Its value derives from the routes available for transport and from the pollutant's reactivity with the materials of the building's enclosure assembly, which can scavenge components that are infiltrating (Zhao et al., 2019). Its value is component-specific and ranges from 0 (no intrusion) to 1 . In the absence of measurements, it is omitted or taken as unity in most models (Sarwar et al., 2002; Carslaw, 2007; Mendez et al., 2015). For the present study, no filtration factor measurement was made. The filtration factor is thus considered to be completely undetermined. For convenience, the same value is used for all compounds.

Among the surface species introduced in this model, $\mathrm{NO}_{2}$ is the only one whose uptake value was determined experimentally; the other ones are adjusted by the user. The value of $\gamma_{\mathrm{NO}}$ is expected to be low given that all models consider a zero deposition velocity for NO, following Nazaroff and Cass (1986). The uptake coefficients provided for NO, $\mathrm{HONO}$ and $\mathrm{O}_{3}$ are supposed to be the uptake values at $T_{\text {ref }}=$ $296 \mathrm{~K}, H_{\text {ref }}=40 \%$ and $I_{\text {ref }}=8.5 \mathrm{~W} \mathrm{~m}^{-2}$ at a concentration of $40 \mathrm{ppb}$. Their variations are parameterized with the same relationships as the ones obtained for $\mathrm{NO}_{2}$ (see Sect. 2.4.3).

Another element that can be considered uncertain is the stoichiometry of the $\mathrm{NO}_{2}$ hydrolysis reaction. Generally, it is 
Table 3. Parameters of the experiments: total duration, $k_{\mathrm{AER}}$, minimum and maximum temperature and humidity, type of paint, average total VOC concentration.

\begin{tabular}{llrrrrrrrr}
\hline Experiments & Day & $\begin{array}{r}\text { Duration } \\
{[\mathrm{h}]}\end{array}$ & $\begin{array}{r}k_{\mathrm{AER}} \\
{\left[\mathrm{h}^{-1}\right]}\end{array}$ & $\begin{array}{r}T_{\min } \\
{\left[{ }^{\circ} \mathrm{C}\right]}\end{array}$ & $\begin{array}{r}T_{\max } \\
{\left[{ }^{\circ} \mathrm{C}\right]}\end{array}$ & $\begin{array}{r}H_{\min } \\
{[\%]}\end{array}$ & $\begin{array}{r}H_{\max } \\
{[\%]}\end{array}$ & Type of paint & $\begin{array}{r}\text { VOC } \\
{[\mathrm{ppbC}]}\end{array}$ \\
\hline Experiment 1 & 27 October & 8.7 & 0.25 & 22.7 & 26.7 & 42 & 44 & No paint board & 770 \\
Experiment 2 & 28 October & 6.2 & 0.29 & 24.3 & 27.8 & 39 & 45 & $0 \% \mathrm{TiO}_{2}$ & 1063 \\
Experiment 3 & 29 October & 7.9 & 0.19 & 21.4 & 27.1 & 44 & 49 & $3.5 \% \mathrm{TiO}_{2}$ & 2911 \\
\hline
\end{tabular}

assumed that $\mathrm{HONO}_{(\mathrm{ad})}$ and $\mathrm{HNO}_{3(\mathrm{ad})}$ are formed with equal yields (Febo and Perrino, 1991). Finlayson-Pitts et al. (2003) measured the yields of gas-phase $\mathrm{HONO}, \mathrm{NO}$ and $\mathrm{N}_{2} \mathrm{O}$, expressed relative to the measured losses of $\mathrm{NO}_{2}$ in the course of $\mathrm{NO}_{2}$ heterogeneous hydrolysis experiments in laboratory systems. The measured yield of HONO was less than $50 \%$ of the $\mathrm{NO}_{2}$ loss, but the $\mathrm{NO}$ yield was attributed to secondary reaction of the $\mathrm{HONO}$ formed by $\mathrm{NO}_{2}$ on surfaces. The sum of the yields of gas-phase HONO and secondary reaction products such as NO was close to $50 \%$, but not exactly $50 \%$. Furthermore, there is, to the authors' knowledge, no available measurement of the $\mathrm{HNO}_{3}$ yield, since no $\mathrm{HNO}_{3}$ production is observed in the gas phase in the course of this type of experiment. By using $\mathrm{NO}_{2}(\mathrm{ad}) \rightarrow \beta_{\mathrm{HNO}_{3}} \mathrm{HNO}_{3(\mathrm{ad})}+\beta_{\mathrm{HONO}}$ $\mathrm{HONO}_{(\mathrm{ad})}$, small variations of $\beta_{\mathrm{HNO}_{3}}$ and $\beta_{\mathrm{HONO}}$ are considered, with the constraint that $\beta_{\mathrm{HNO}_{3}}+\beta_{\mathrm{HONO}}=1$, to ensure nitrogen conservation.

\subsection{Initial conditions}

According to Nazaroff and Cass (1986), simulations can be sensitive to changes in initial conditions over a characteristic time period that can be considered proportional to the inverse of the air exchange rate. When the simulated period extends over several days (Sarwar et al., 2002; Carslaw, 2007; Courtey et al., 2009), the influence of initial conditions can be neglected. In the present study, the air renewal time $\left(k_{\mathrm{AER}}^{-1}\right)$, i.e. the minimum time needed to break free from the initial conditions, represents about half of the simulated periods, which thus requires careful setting of the initial concentrations. The RACM2 organic and inorganic compound concentrations are initialized using the concentrations measured at the start time of the experiments, which are shown in Table 4. However, this is not sufficient to initiate the radical's chemistry, which is influenced by a variety of species, including VOCs that were not measured because they were unidentifiable or under the detection limit of the PTR-ToFMS. Without proper initialization, the chemistry of radicals is absent from the start of the experiment, which damages the inorganic chemistry and thus the comparison between the model and experiments.

To assess the initial concentrations of the species that were not detected, a simulation is run while forcing the organic and inorganic compounds to follow their measured values for a duration $d_{\text {init }}$. Then, a new simulation is launched by assigning the concentrations obtained at the end of $d_{\text {init }}$ to the compounds that were not measured; the other ones are again initiated using the concentrations measured at the start time of the experiments, which are shown in Table 4. With these new initial conditions, the simulated concentrations of radicals are higher than in the initial simulation, as shown by the variations in the $\mathrm{NO}_{x}$ profiles (see Figs. B1-B3 in the Appendix), which are strongly influenced by the concentrations of radical species. This procedure is repeated iteratively. The correspondence between these simulation runs and the $\mathrm{NO}_{x}$ concentrations is assessed by computing the mean normalized gross error (MNGE) over the first $5000 \mathrm{~s}$ of the simulation run. The time $d_{\text {init }}$ is not the same for all experiments but is fixed for a given experiment. This time is chosen depending on the rate of convergence of the simulation runs, which increases with increasing $k_{\mathrm{AER}}$ and decreases with increasing VOC concentration (see Table 3). This duration amounts to $2300 \mathrm{~s}$ for Experiment 1, $1900 \mathrm{~s}$ for Experiment 2 and $4200 \mathrm{~s}$ for Experiment 3. Proper initial concentrations are considered to be achieved when the MNGE with respect to NO and $\mathrm{NO}_{2}$ stabilizes or reaches a minimum.

In Fig. 6, the simulations performed by initializing only the compounds that were quantified experimentally are labelled as "without radical initialization". The simulations performed by initializing all species, following the procedure explained above, are labelled as "full initialization". The full initialization completely modifies the $\mathrm{NO}$ and $\mathrm{HONO}$ profiles, as well as the first part of the $\mathrm{NO}_{2}$ profile.

It is clear that all compounds do not contribute equally to the radical chemistry. Namely, the initialization of compound PPN (peroxyl propionyl nitrate) bridges about half of the gap between the simulations without radical initialization and the simulations with full initialization. Among the 68 RACM2 compounds that were not detected during the experiments but for which the model predicts a non-zero concentration, only six need to be initialized to attain proper radical chemistry. These are PAN (peroxyacetyl nitrate and higher saturated PANs), MGLY (methylglyoxal and other alpha-carbonyl aldehydes), DCB1, DCB2 and DCB3 (unsaturated dicarbonyls), and PPN. The initialization of these compounds in addition to the species measured experimentally provides the same effect on the inorganic compounds as the full initialization. 
Table 4. List of the RACM 2 compounds initialized. The table shows the definition, carbon valence and concentrations at the start of the experiments; concentrations are in micrograms per cubic metre $\left(\mu \mathrm{g} \mathrm{m}^{-3}\right)$. Compounds marked with a symbol $(*)$ were not measured experimentally, but were estimated based on simulations to assess their importance regarding initial conditions (see Sect. 3.1).

\begin{tabular}{|c|c|c|c|c|c|}
\hline Species & Definition & Carbon no. & Exp 1 & $\operatorname{Exp} 2$ & Exp 3 \\
\hline \multicolumn{6}{|c|}{ Organic compounds } \\
\hline ACD & Acetaldehyde & 2 & 15.78 & 30.16 & 39.95 \\
\hline АCT & Acetone & 3 & 11.77 & 18.80 & 18.30 \\
\hline ALD & C3 and higher aldehydes & 3 & 22.18 & 63.31 & 107.0 \\
\hline BALD & Benzaldehyde and other aromatic aldehydes & 7 & 0.559 & 2.437 & 5.879 \\
\hline BEN & Benzene & 6 & 1.220 & 2.127 & 2.203 \\
\hline $\mathrm{CO}$ & Carbon monoxide $(*)$ & 1 & 0.535 & 0.517 & 3.581 \\
\hline CSL & Cresol and other hydroxy substituted aromatics & 7 & 0.010 & 0.129 & 0.239 \\
\hline DCB1 & Unsaturated dicarbonyls $(*)$ & 4.5 & 0.238 & 0.336 & 0.888 \\
\hline DCB2 & Unsaturated dicarbonyls $(*)$ & 7 & 0.375 & 0.530 & 1.403 \\
\hline DCB3 & Unsaturated dicarbonyls $(*)$ & 4 & 0.452 & 0.643 & 1.849 \\
\hline $\mathrm{HCHO}$ & Formaldehyde & 1 & 34.88 & 42.88 & 51.58 \\
\hline ISO & Isoprene & 5 & 0.314 & 0.747 & 1.160 \\
\hline KET & Ketones & 5 & 3.002 & 8.503 & 11.50 \\
\hline LIM & $d$-limonene and other cyclic diene-terpenes & 10 & 6.151 & 8.799 & 8.273 \\
\hline MACR & Methacrolein & 4 & 3.289 & 4.803 & 5.093 \\
\hline MGLY & Methylglyoxal and other alpha-carbonyl aldehydes $(*)$ & 3 & 0.355 & 0.415 & 1.640 \\
\hline $\mathrm{MOH}$ & Methanol & 1 & 15.29 & 25.90 & 38.72 \\
\hline OLI & Internal alkenes & 5 & 2.910 & 7.802 & 15.55 \\
\hline OLT & Terminal alkenes & 3.8 & 20.20 & 35.33 & 62.52 \\
\hline ORA1 & Formic acid & 1 & 30.52 & 33.10 & 30.74 \\
\hline ORA2 & Acetic acid and higher acids & 2 & 74.17 & 123.1 & 168.1 \\
\hline PAN & Peroxyacetyl nitrate and higher saturated PANs $(*)$ & 2 & 0.360 & 0.107 & 1.511 \\
\hline PHEN & Phenol & 6 & 0.554 & 0.567 & 0.585 \\
\hline PPN & Peroxypropionyl nitrate $(*)$ & 3 & 0.483 & 0.195 & 3.978 \\
\hline $\mathrm{ROH}$ & $\mathrm{C} 3$ and higher alcohols & 3 & 10.32 & 43.99 & 105.0 \\
\hline UALD & Unsaturated aldehydes & 5 & 0.687 & 1.385 & 1.968 \\
\hline TOL & Toluene and less reactive arc & 7.1 & 3.580 & 4.702 & 4.684 \\
\hline XYL & Xylene and less reactive aromatics & 8.9 & 31.37 & 62.72 & 38.48 \\
\hline \multicolumn{6}{|c|}{ Inorganic compounds } \\
\hline HONO & Nitrous acid & & 2.706 & 4.560 & 2.384 \\
\hline NO & Nitric oxide & & 1.344 & 5.352 & 3.226 \\
\hline $\mathrm{NO}_{2}$ & Nitrogen dioxide & & 12.02 & 5.087 & 9.184 \\
\hline $\mathrm{O}_{3}$ & Ozone & & 2.767 & 0.000 & 0.992 \\
\hline
\end{tabular}

It can be inferred from this section that a careful assessment of the initial concentrations, including for compounds that were not experimentally detected, is mandatory for this type of study.

\section{Reference simulations}

The parameters presented in Sect. 3.2 are calibrated to reach the best correspondence between experimental data and simulations as possible. The filtration factor $f$ varies between experiments depending on wind conditions. The air-mixing velocity and the stoichiometry of the $\mathrm{NO}_{2}$ heterogeneous hydrolysis do not vary between experiments. However, the values of the surface kinetic reaction rates, desorption rates and uptake coefficients may vary between experiments because of differences in wall covering. Therefore, the parameters are first adjusted for each experiment independently. This set of optimized parameters is denoted as Set 1 . To determine parameter values usable in a wide range of conditions, the parameters are then varied to use the same values of surface kinetic reaction rates $k_{\mathrm{S}}$ for all experiments, but letting the desorption rates $k_{i, \text { (ad) }}^{\prime}$ vary with experiment. This leads to the set of parameters denoted as Set 2. Finally, the set of parameters denoted as Set 3 corresponds to parameters adjusted to use the same values for all experiments. Note that in the first experiment, the desorption constant $k_{\mathrm{NO}(\mathrm{ad})}^{\prime}$ still requires a lower value than the common one. In the rest of this paper, "reference simulations" will denote the simulations obtained 

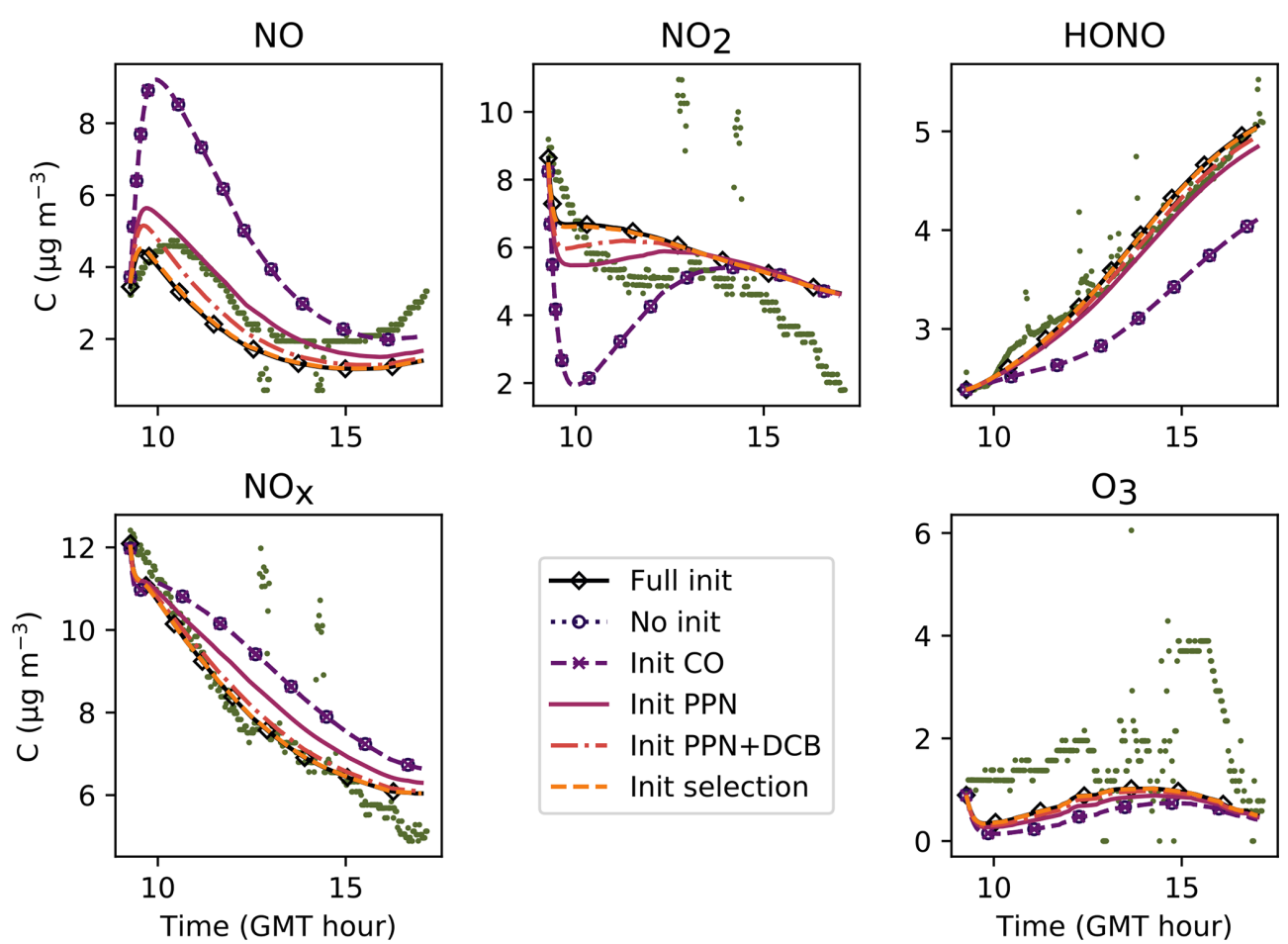

Figure 6. Inorganic concentration profiles for different initial conditions. The dots denote the experimental measurements (Experiment 3 ). "No init" means that all the compounds which were not detected during the campaign are a given a zero concentration at the start of the simulation. "Full init" means that all the compounds are initialized, even those which were not experimentally detected (see text for details). "Init CO" is like "No init" but with CO initialized. "Init PPN" is like "No init" but with PPN initialized ."Init PPN+DCB" is like "No init" but with PPN, DCB1, DCB2 and DCB3 initialized. "Init selection" is like "No init" but with PPN, DCB1, DCB2, DCB3, MGLY and PAN initialized. The curves corresponding to "Full init" and "Init selection" are close to being superimposed.

with the Set 3 parameter values, while "optimized simulations" will denote the simulations obtained with the Set 1 parameter values. All parameter values are listed in Table 5.

Figures 7, 8 and 9 present the three sets of simulations for the three experiments. In these graphs, the solid lines denote the concentrations simulated in the sunlit box and the dashed lines the concentrations in the shaded box. These two curves are identical. The $\mathrm{NO}, \mathrm{NO}_{2}$ and $\mathrm{NO}_{x}$ outlying dots observed at 10:20 and 12:10 for Experiment 1, as well as 12:45 and 14:20 for Experiment 3, are sporadic outdoor measurements and are thus not simulated by the model. During Experiment 1 , an artificial $\mathrm{NO}_{2}$ injection of about $56 \mathrm{ppb}$ (including a few parts per billion of NO) was performed at 13:30. The simulated NO and HONO outbreaks generated by this $\mathrm{NO}_{2}$ injection exceed the concentrations measured experimentally; they arise from surface chemistry and cannot be cancelled out by changing the parameters without damaging the simulated profiles before the injection.

The similarity between simulations and experiments is quantified by computing, for the four modelled inorganic compounds, the relative error between the average measured and simulated concentrations, the root mean square error (RMSE), the mean normalized gross error (MNGE), and the mean normalized bias error (MNBE), as presented in Table 6 .
For the first experiment, these indicators are computed over the period preceding the $\mathrm{NO}_{2}$ injection only.

The $\mathrm{NO}_{x}$ concentration is modelled very well in Experiments 2 and 3, with an MNGE of 4\%-6\%. For $\mathrm{NO}_{2}$, the MNGE is about $22 \%$ in Experiment 2, while it reaches about $28 \%$ in Experiment 3. Regarding NO, the MNGE is about $17 \%$ in Experiment 2 and $35 \%$ in Experiment 3. In Experiment 1 , the $\mathrm{NO}_{x}$ concentrations are systematically underestimated, with an MNBE of $-62 \%$ in the first part of the simulation. In the second part, the $\mathrm{NO}_{2}$ decay following the $\mathrm{NO}_{2}$ injection is replicated very well using the optimized parameters. For all experiments and all sets of parameters, $\mathrm{O}_{3}$ is underestimated with a relative error ranging between $50 \%$ and $60 \%$. HONO exhibits excellent statistics for Set 1 and Set 2, with an MNGE from $1 \%$ to $9 \%$ in the three experiments. However, using the common parameters (Set 3), HONO is underestimated in Experiment 2 ( $-8 \%$ MNBE) and strongly overestimated in Experiments 1 and 3 (94\% and $78 \%$ MNBE, respectively).

By comparing the simulations by sets of parameters, we can observe that for Experiments 2 and 3, the Set 1 and Set 2 parameters lead to very similar concentrations, whereas the use of common values for desorption constants (Set 3) increases the error in HONO. The Set 1 results represent the 

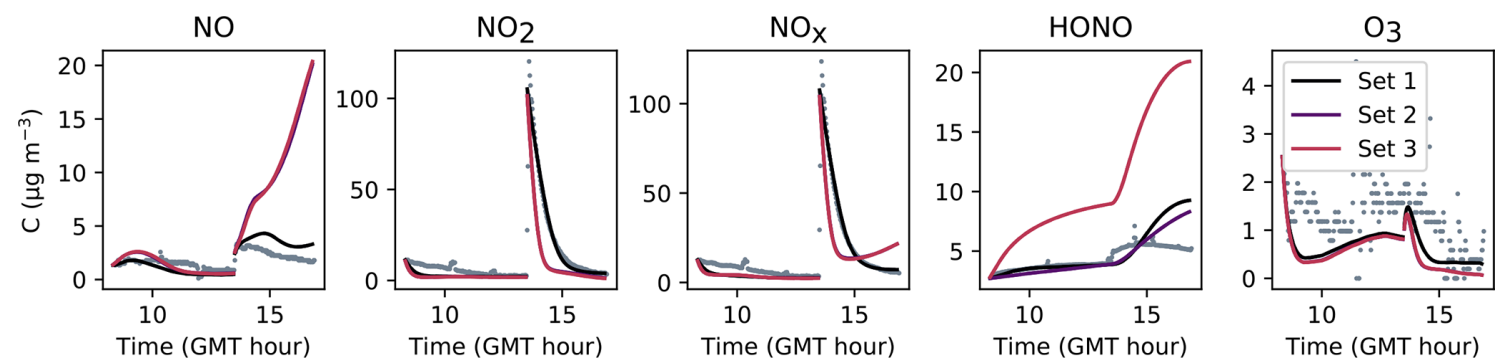

Figure 7. Simulation of Experiment 1 for the three sets of parameters. The dots denote the experimental records. The concentrations simulated in the sunlit box (solid lines) and the concentrations simulated in the shaded box (dashed lines) are superimposed.
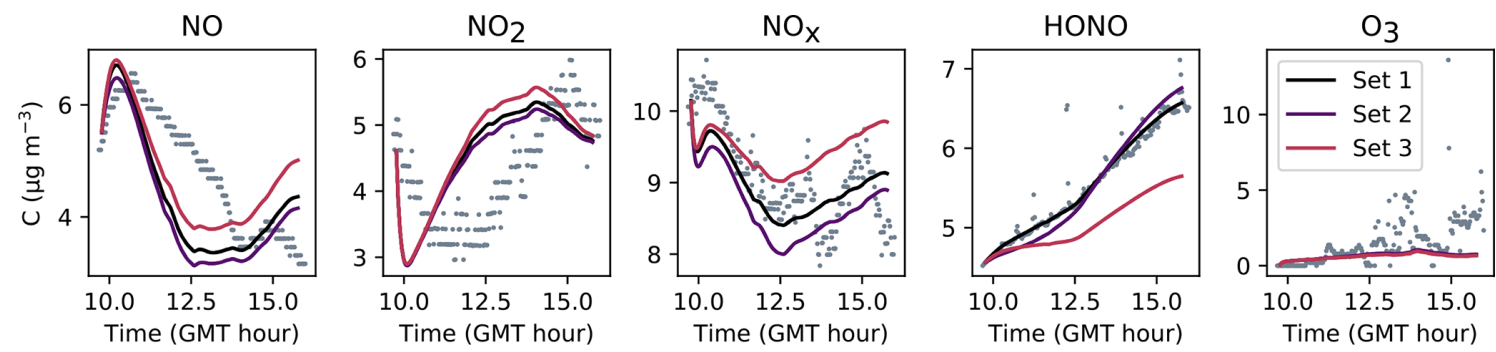

Figure 8. Simulation of Experiment 2 for the three sets of parameters. The dots denote the experimental records. The concentrations simulated in the sunlit box (solid lines) and the concentrations simulated in the shaded box (dashed lines) are superimposed.
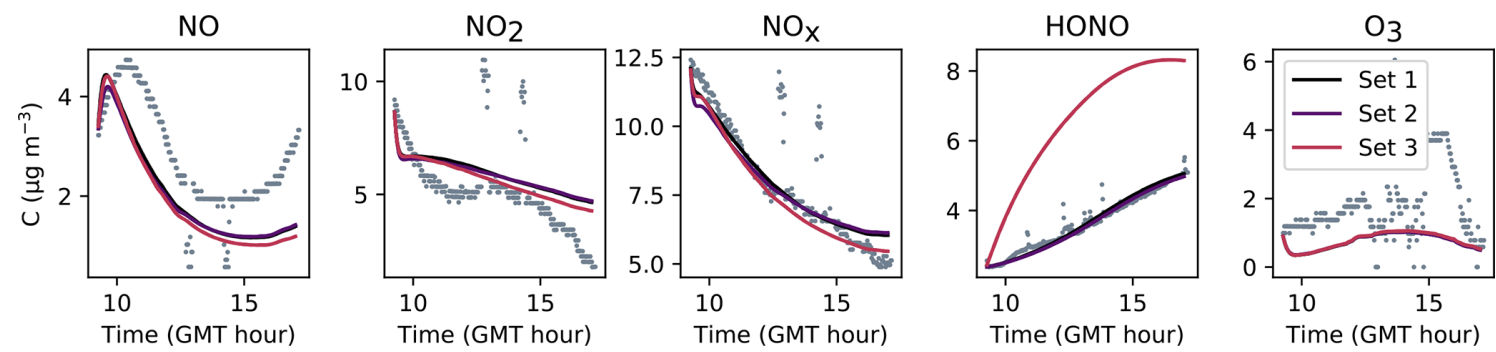

Figure 9. Simulation of Experiment 3 for the three sets of parameters. The dots denote the experimental records. The concentrations simulated in the sunlit box (solid lines) and the concentrations simulated in the shaded box (dashed lines) are superimposed.

best correspondence that can be achieved. In these experiments, the discrepancy between the model and measurements observed using common parameters (Set 3) can be cancelled out by varying the NO and HONO desorption constants (Set 2). In the first experiment, the $\mathrm{NO}_{x}$ curves are identical for Set 2 and Set 3. They differ from the Set 1 curves because, in that case, the parameters were optimized to replicate the $\mathrm{NO}_{2}$ decay and to mitigate the $\mathrm{NO}$ release following the injection.

It can be concluded from this section that by combining homogeneous and heterogeneous reactivity, the $\mathrm{H}^{2}$ I model is able to replicate the inorganic chemistry. The model parameters that could not be determined experimentally were treated as tuneable parameters. The model yields satisfying results using the same parameter values for all experiments (Set 3), apart from the NO profile in Experiment 1, for which a lower $k_{\mathrm{NO}(\mathrm{ad})}^{\prime}$ is needed. The model results can be improved to the best achievable results (Set 1 ) by merely varying the NO and HONO desorption rates (Set 2).

\section{Sensitivity study}

The purpose of this section is to investigate the relative influence of the model parameters. This section focuses on how inorganic chemistry is influenced by surface reactions. As Experiment 1 is a particular case $\left(\mathrm{NO}_{2}\right.$ injection), only Experiments 2 and 3 are considered for these tests. When a parameter is varied, the simulated results are presented for one experiment only, as the conclusions are identical for both experiments. Each tuneable parameter is investigated independently. The parameters that are not varied are given the same values as the optimized parameters (Set 1) listed in Table 5.

The initial concentrations of the gas-phase species are determined using the procedure described in Sect. 3.3 and are 
Table 5. Parameter values for each type of simulation and each experiment. The parameters are as follows: filtration factor [-], velocity of air $\left[\mathrm{m} \mathrm{s}^{-1}\right], \mathrm{NO}_{2}$ hydrolysis stoichiometric coefficients [-], uptake coefficients $\gamma_{i}[-]$, surface reactions kinetic rates $k_{\mathrm{S}}$ [s ${ }^{-1}$ ], desorption reactions kinetic rates $k_{i,(\mathrm{ad})}^{\prime}\left[\mathrm{s}^{-1}\right.$ molec. $\left.^{-1}\right]$. Set 1 refers to the simulations with optimized parameters, Set 2 refers to the simulations with common $k_{\mathrm{S}}$ constants, and Set 3 refers to the simulations with common parameter values. The factor $f$ is allowed to vary between experiments; for the rest of the parameters, all of the values that differ from the Set 3 solution are denoted in bold.

\begin{tabular}{|c|c|c|c|c|c|c|c|c|c|}
\hline \multirow{2}{*}{$\begin{array}{l}\text { Set of parameters } \\
\text { Experiment }\end{array}$} & \multicolumn{3}{|c|}{ Set 1} & \multicolumn{3}{|c|}{ Set 2} & \multicolumn{3}{|c|}{ Set 3} \\
\hline & Exp 1 & Exp 2 & Exp 3 & Exp 1 & $\operatorname{Exp} 2$ & Exp3 & Exp 1 & $\operatorname{Exp} 2$ & Exp 3 \\
\hline$f$ & 0.25 & 0.33 & 0.30 & 0.25 & 0.33 & 0.30 & 0.25 & 0.33 & 0.30 \\
\hline$u_{\text {inf }}$ & 0.24 & 0.24 & 0.24 & 0.24 & 0.24 & 0.24 & 0.24 & 0.24 & 0.24 \\
\hline$\beta_{\mathrm{HNO}_{3}}$ & 0.47 & 0.47 & 0.47 & 0.47 & 0.47 & 0.47 & 0.47 & 0.47 & 0.47 \\
\hline$\beta_{\mathrm{HONO}}$ & 0.53 & 0.53 & 0.53 & 0.53 & 0.53 & 0.53 & 0.53 & 0.53 & 0.53 \\
\hline$\gamma_{\mathrm{NO}}$ & $8 \times 10^{-9}$ & $8 \times 10^{-9}$ & $8 \times 10^{-9}$ & $8 \times 10^{-9}$ & $8 \times 10^{-9}$ & $8 \times 10^{-9}$ & $8 \times 10^{-9}$ & $8 \times 10^{-9}$ & $8 \times 10^{-9}$ \\
\hline$\gamma \mathrm{NO}_{2}$ & $1.5 \times 10^{-6}$ & $5 \times 10^{-6}$ & $5 \times 10^{-6}$ & $5 \times 10^{-6}$ & $5 \times 10^{-6}$ & $5 \times 10^{-6}$ & $5 \times 10^{-6}$ & $5 \times 10^{-6}$ & $5 \times 10^{-6}$ \\
\hline$\gamma_{\mathrm{HONO}}$ & $7 \times 10^{-7}$ & $2 \times 10^{-8}$ & $2 \times 10^{-8}$ & $2 \times 10^{-8}$ & $2 \times 10^{-8}$ & $2 \times 10^{-8}$ & $2 \times 10^{-8}$ & $2 \times 10^{-8}$ & $2 \times 10^{-8}$ \\
\hline$\gamma_{\mathrm{O}_{3}}$ & $1 \times 10^{-6}$ & $1 \times 10^{-6}$ & $1 \times 10^{-6}$ & $1 \times 10^{-6}$ & $1 \times 10^{-6}$ & $1 \times 10^{-6}$ & $1 \times 10^{-6}$ & $1 \times 10^{-6}$ & $1 \times 10^{-6}$ \\
\hline$k_{\mathrm{S} 1}$ & $5 \times 10^{-4}$ & $3 \times 10^{-3}$ & $3 \times 10^{-3}$ & $3 \times 10^{-3}$ & $3 \times 10^{-3}$ & $3 \times 10^{-3}$ & $3 \times 10^{-3}$ & $3 \times 10^{-3}$ & $3 \times 10^{-3}$ \\
\hline$k_{\mathrm{S} 2}$ & $1 \times 10^{-14}$ & $4 \times 10^{-14}$ & $4 \times 10^{-13}$ & $1 \times 10^{-13}$ & $1 \times 10^{-13}$ & $1 \times 10^{-13}$ & $1 \times 10^{-13}$ & $1 \times 10^{-13}$ & $1 \times 10^{-13}$ \\
\hline$k_{\mathrm{S} 3}$ & $5 \times 10^{-5}$ & $1 \times 10^{-5}$ & $1 \times 10^{-5}$ & $1 \times 10^{-5}$ & $1 \times 10^{-5}$ & $1 \times 10^{-5}$ & $1 \times 10^{-5}$ & $1 \times 10^{-5}$ & $1 \times 10^{-5}$ \\
\hline$k_{\mathrm{S} 4}$ & $2 \times 10^{-15}$ & $2 \times 10^{-15}$ & $2 \times 10^{-15}$ & $2 \times 10^{-15}$ & $2 \times 10^{-15}$ & $2 \times 10^{-15}$ & $2 \times 10^{-15}$ & $2 \times 10^{-15}$ & $2 \times 10^{-15}$ \\
\hline$k_{\mathrm{NO}(\mathrm{ad})}^{\prime}$ & $7 \times 10^{-23}$ & $6 \times 10^{-21}$ & $3 \times 10^{-20}$ & $2 \times 10^{-22}$ & $3 \times 10^{-21}$ & $8 \times 10^{-21}$ & $2 \times 10^{-22}$ & $8 \times 10^{-21}$ & $8 \times 10^{-21}$ \\
\hline$k_{\mathrm{NO}_{2}(\mathrm{ad})}^{\prime}$ & $1 \times 10^{-23}$ & $1 \times 10^{-22}$ & $1 \times 10^{-22}$ & $1 \times 10^{-22}$ & $1 \times 10^{-22}$ & $1 \times 10^{-22}$ & $1 \times 10^{-22}$ & $1 \times 10^{-22}$ & $1 \times 10^{-22}$ \\
\hline$k_{\mathrm{HONO}(\mathrm{ad})}^{\prime}$ & $2.5 \times 10^{-22}$ & $4.5 \times 10^{-22}$ & $1.5 \times 10^{-22}$ & $1 \times 10^{-22}$ & $7 \times 10^{-22}$ & $1.2 \times 10^{-22}$ & $5 \times 10^{-22}$ & $5 \times 10^{-22}$ & $5 \times 10^{-22}$ \\
\hline
\end{tabular}

summarized in Table 4. The sorbed species $\mathrm{NO}_{(\mathrm{ad})}, \mathrm{NO}_{2(\mathrm{ad})}$, $\mathrm{HONO}_{(\mathrm{ad})}$ and $\mathrm{HNO}_{3(\mathrm{ad})}$ do not undergo the same processes as the gas-phase species. Their evolution is driven by chemical reactivity only. Since box exchange is disabled for these species, these species' profiles in the shaded and sunlit volumes are distinct, as shown by the figures presented in this section. At the start of the simulations, the concentrations of these species rapidly converge to the values determined by surface chemistry. The sorbed species initial concentrations are thus easy to set after running a couple of simulations. For a given experiment, the initial concentrations remain unchanged whatever the parameter investigated.

\subsection{Filtration factor and velocity of air}

Indoor chemistry is influenced by the filtration factor and the velocity of air, which are parameters characteristic of the environment. The filtration factor controls the input flux of outdoor pollutants, while the velocity of air governs deposition. This section assesses to what extent these parameters affect the overall inorganic concentrations.

\subsubsection{Velocity of air}

The gas-phase and adsorbed inorganic compounds simulated with a velocity of air $u_{\text {inf }}$ ranging from 0.06 to $0.30 \mathrm{~m} \mathrm{~s}^{-1}$ are presented in Fig. 10. This range of variations corresponds to the range of expected values described in Sect. 3.2. The modelled $\mathrm{NO}_{2}$ and $\mathrm{O}_{3}$ concentrations decrease with increasing $u_{\text {inf }}$, while the modelled NO and HONO concentrations increase with increasing $u_{\text {inf }}$. These opposite behaviours de- rive from the type of source and processes contributing the most to these species concentrations. It can be easily inferred from Eqs. (16-20) that the larger $u_{\text {inf }}$ is, the larger the deposition on surfaces. When $u_{\text {inf }}$ is increased, the $\mathrm{O}_{3}$ surface removal increases. As the main source of $\mathrm{O}_{3}$ is transport from outdoors (Weschler and Shields, 1996), this loss of $\mathrm{O}_{3}$ is not counterbalanced by another source, which results in a decrease in $\mathrm{O}_{3}$ with increasing $u_{\text {inf }}$. In contrast, HONO is mainly produced by heterogeneous processes that are predominant indoors. The increase in $u_{\text {inf }}$ enhances $\mathrm{NO}_{2}$ deposition and thus $\mathrm{HONO}$ production by $\mathrm{NO}_{2}$ hydrolysis on surfaces. Indoor $\mathrm{NO}_{x}$ concentrations are influenced by both outdoor concentrations and surface chemistry (Weschler et al., 1994). In these experiments, variations with $u_{\text {inf }}$ indicate that the main $\mathrm{NO}_{2}$ source is outdoor infiltration, whereas $\mathrm{NO}$ is mainly produced by heterogeneous processes. The value retained for $u_{\text {inf is }} 0.24 \mathrm{~m} \mathrm{~s}^{-1}$, considering it is large enough to achieve effective deposition and to stimulate secondary chemistry while fulfilling the criteria presented in Sect. 3.2. As this value is the result of controlled air mixing by fans, it is kept unchanged from one experiment to the other.

\subsubsection{Filtration factor}

Contrary to $u_{\text {inf }}$, increasing $f$ leads to an increase not only in $\mathrm{NO}_{2}$ and $\mathrm{O}_{3}$ but also in $\mathrm{NO}$ and HONO (see Fig. 11). It must be stressed that increasing $f$ increases the intake of outdoor pollutants such as $\mathrm{O}_{3}, \mathrm{NO}$ and $\mathrm{NO}_{2}$, but not the losses caused by ventilation. These derive from the air exchange rate, which remains unchanged. In turn, the increased $\mathrm{NO}_{2}$ concentration fosters the secondary production of $\mathrm{HONO}$ 


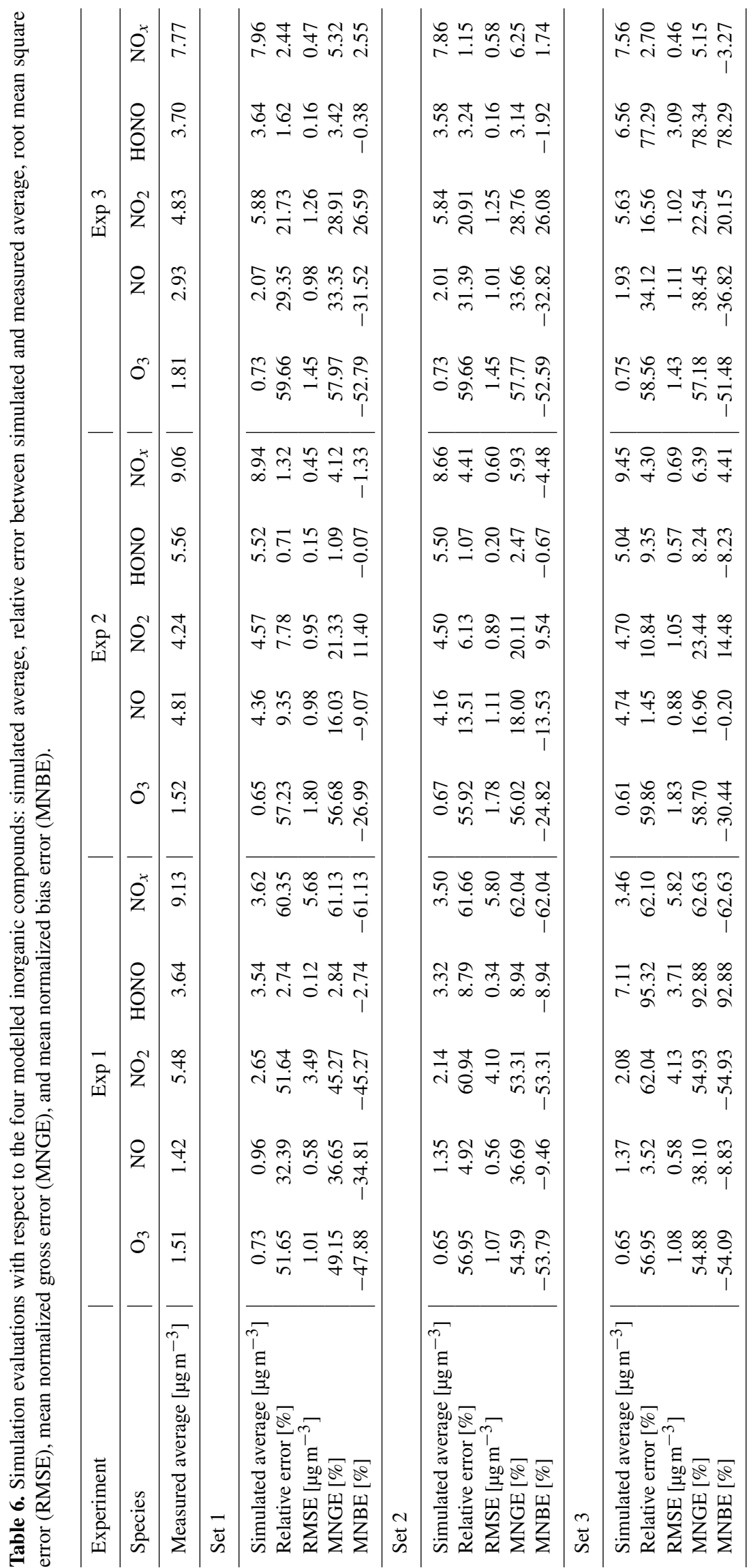



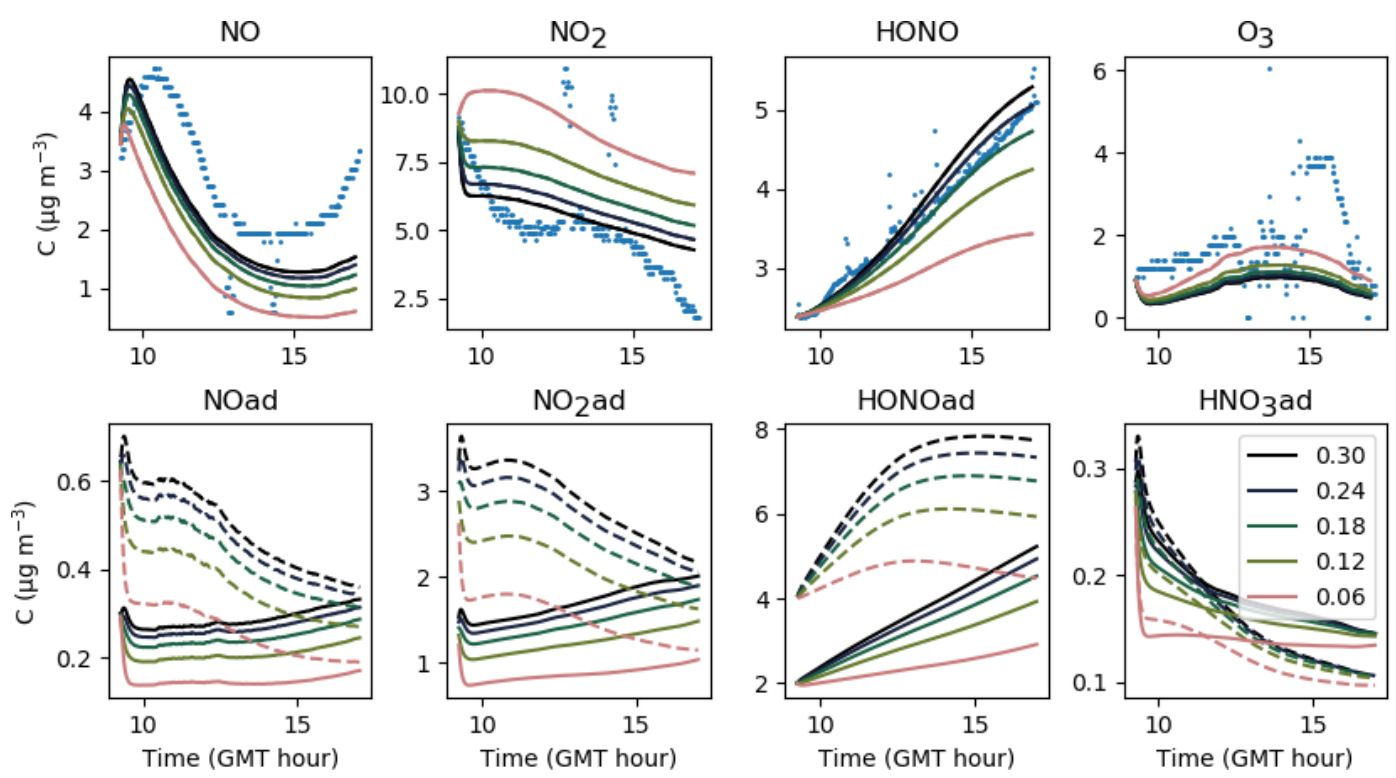

Figure 10. Gas-phase and adsorbed inorganic compounds simulated with different $u_{\text {inf }}$. The blue dots denote the experimental measurements (Experiment 3). The solid lines represent the concentrations in the sunlit box and the dashed lines the concentrations in the shaded box.
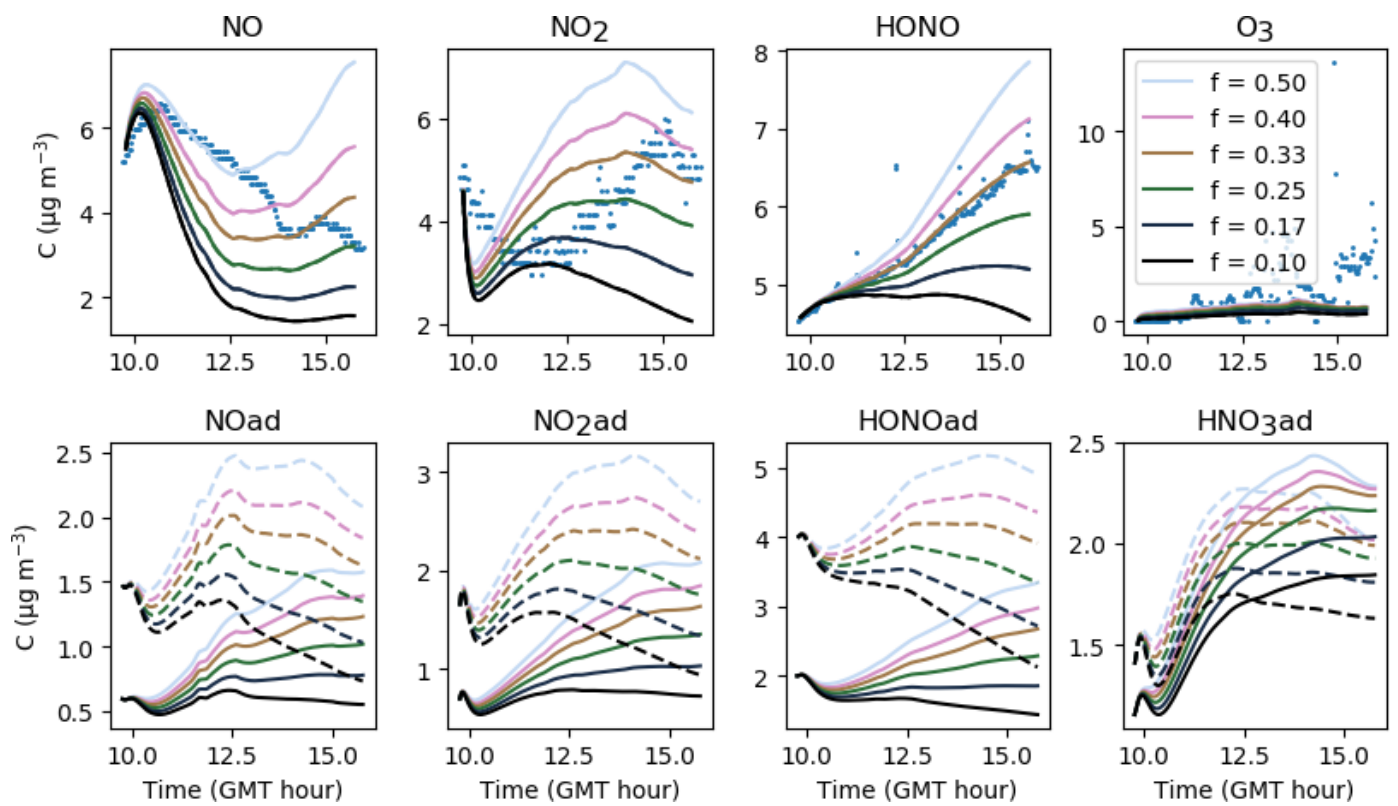

Figure 11. Gas-phase and adsorbed inorganic compounds simulated with different $f$. The blue dots denote the experimental measurements (Experiment 2). The solid lines represent the concentrations in the sunlit box and the dashed lines the concentrations in the shaded box.

and NO. For these experiments, an average value of 0.30 appears appropriate to match the overall amount of $\mathrm{NO}_{x}$ and by extension the amount of HONO. As mentioned in Sect. 4, differences between experiments can be caused by variations in outdoor wind conditions.

\section{$5.2 \mathrm{NO}_{2}$ heterogeneous hydrolysis: $\mathrm{NO}_{2}(\mathrm{ad}) \rightarrow 0.5$ $\mathrm{HNO}_{3(\mathrm{ad})}+0.5 \mathrm{HONO}_{(\mathrm{ad})}$}

The influence of $\mathrm{NO}_{2}$ heterogeneous hydrolysis is now investigated by varying its stoichiometry and kinetic rate. 


\subsubsection{Stoichiometry}

As introduced in Sect. 3.2, the stoichiometry of the $\mathrm{NO}_{2}$ hydrolysis reaction can be considered somewhat uncertain. Figure 12 presents the evolution of the inorganic concentrations with different yields $\beta_{\mathrm{HNO}_{3}}$ and $\beta_{\mathrm{HONO}}$. Because $\mathrm{HONO}$ concentrations are underestimated when $\beta_{\mathrm{HNO}_{3}}=\beta_{\mathrm{HONO}}=$ 0.5 , the ratio $\beta_{\mathrm{HNO}_{3}} / \beta_{\mathrm{HONO}}$ is kept $<1$ so that $\mathrm{HONO}_{(\mathrm{ad})}$ is always produced more than $\mathrm{HNO}_{3(\mathrm{ad})}$. When $\beta_{\mathrm{HNO}_{3}} / \beta_{\mathrm{HONO}}$ tends to 1 , the production of $\mathrm{HONO}_{(\mathrm{ad})}$ and $\mathrm{HNO}_{3(\mathrm{ad})}$ by $\mathrm{NO}_{2}$ hydrolysis becomes balanced, which favours NO production by Reaction $\left(\mathrm{S}_{2}\right)$. NO can be converted into $\mathrm{NO}_{2}$ by reacting with $\mathrm{HO}_{2}$, which increases the $\mathrm{NO}_{2}$ concentration. As less $\mathrm{HONO}_{(\mathrm{ad})}$ is available for desorption, less gas-phase HONO is released. Conversely, when the ratio $\beta_{\mathrm{HNO}_{3}} / \beta_{\mathrm{HONO}}$ is decreased, the enhanced $\mathrm{HONO}_{(\mathrm{ad})}$ production fosters $\mathrm{HONO}$ desorption, leading to higher HONO and lower $\mathrm{NO}_{x}$ gas-phase concentrations. It is noteworthy that very small variations in $\beta_{\mathrm{HNO}_{3}} / \beta_{\mathrm{HONO}}$ generate significant variations in $\mathrm{NO}_{x}$ and particularly HONO. Note that $\mathrm{O}_{3}$ is mainly controlled by transport from outdoors and is thus not affected by these parameters. The values $\beta_{\mathrm{HNO}_{3}}=0.47$ and $\beta_{\mathrm{HONO}}=0.53$ are matched to a consistent HONO production without differing too much from the classical stoichiometry assumed for this reaction. They are kept unchanged from one experiment to the other.

\subsubsection{Surface $\mathrm{NO}_{2}$ conversion}

$\mathrm{NO}_{2}$ is adsorbed on surfaces at a rate that is determined by the transport velocity towards surfaces and by the $\mathrm{NO}_{2}$ uptake of surfaces. Once $\mathrm{NO}_{2}$ is adsorbed, it is converted in the presence of water to form $\mathrm{HONO}$ and $\mathrm{HNO}_{3}$ at a kinetic rate $k_{\mathrm{S} 1}$ that is highly uncertain. The larger $k_{\mathrm{S} 1}$ is, the more rapid the conversion and the larger the HONO production. The same holds for NO that is produced by the secondary reaction of $\mathrm{HONO}_{(\mathrm{ad})}$ with $\mathrm{HNO}_{3(\mathrm{ad})}$. In turn, the $\mathrm{NO}$ increase enhances $\mathrm{NO}_{2}$ by homogeneous reactivity, thus providing new $\mathrm{NO}_{2}$ available for adsorption. However, Fig. 13 shows that HONO concentrations do not vary much when $k_{\mathrm{S} 1}$ is increased above a threshold value of $0.003 \mathrm{~s}^{-1}$. As $k_{\mathrm{S} 1}$ is increased above this value, the $\mathrm{NO}_{2 \text { (ad) }}$ concentration tends to zero. When $k_{\mathrm{S} 1}$ is decreased, the $\mathrm{NO}_{2(\mathrm{ad})}$ hydrolysis is slowed down, which decreases the $\mathrm{HONO}_{(\mathrm{ad})}$ reservoir and thus curbs $\mathrm{NO}_{y}\left(\mathrm{NO}_{x}+\mathrm{HONO}\right)$ heterogeneous production. The sensitivity of this parameter is large. The threshold value $k_{\mathrm{S} 1}=0.003 \mathrm{~s}^{-1}$ is retained, as it maximizes the $\mathrm{NO}_{2(\mathrm{ad})}$ conversion.

\subsection{NO secondary formation}

According to Sect. 5.1.1, NO is mainly produced by secondary chemistry in these experiments. In this section, the importance of two reactions forming $\mathrm{NO}_{(\mathrm{ad})}$ is studied.

\subsection{1 $\mathrm{HONO}_{(\mathrm{ad})}+\mathrm{HNO}_{3(\mathrm{ad})} \rightarrow 2 \mathrm{NO}_{(\mathrm{ad})}$}

First, $\mathrm{NO}_{(\mathrm{ad})}$ can be produced by the reaction of $\mathrm{HONO}_{(\mathrm{ad})}$ with $\mathrm{HNO}_{3(\mathrm{ad})}$ at a kinetic rate $k_{\mathrm{S} 2}$. Figure 14 shows that increasing $k_{\mathrm{S} 2}$ enhances the formation of $\mathrm{NO}_{(\mathrm{ad})}$ and thus its release to the gas phase. As less $\mathrm{HONO}_{(\mathrm{ad})}$ is available, the gas-phase HONO concentration is lowered. In contrast, if $k_{\mathrm{S} 2}$ is lowered, the reaction of $\mathrm{HONO}_{(\mathrm{ad})}$ with $\mathrm{HNO}_{3(\mathrm{ad})}$ becomes slower than the desorption of $\mathrm{HONO}_{(\mathrm{ad})}$, and most $\mathrm{HONO}_{(\mathrm{ad})}$ is released in the gas phase. In turn, the $\mathrm{NO}_{(\mathrm{ad})}$ production becomes too low to maintain an $\mathrm{NO}$ release allowing it to reach the measured concentrations. These results indicate that there is competition between the desorption of $\mathrm{HONO}_{(\mathrm{ad})}$ and the reaction of $\mathrm{HONO}_{(\mathrm{ad})}$ with $\mathrm{HNO}_{3(\mathrm{ad})}$ to consume $\mathrm{HONO}_{(\mathrm{ad})}$. When calibrating $k_{\mathrm{S} 2}$ and $k_{\mathrm{HONO}(\mathrm{ad})}^{\prime}$, a balance between these two reactions must be found to obtain consistent concentration profiles for both HONO and NO. Similarly to $k_{\mathrm{S} 1}$, the parameter $k_{\mathrm{S} 2}$ seems to be a very sensitive one, as it significantly affects $\mathrm{NO}, \mathrm{HONO}$ and also $\mathrm{NO}_{2}$ through NO. The value $k_{\mathrm{S} 2}=10^{-13} \mathrm{~s}^{-1}$ retained for the reference simulations is a compromise between the optimized values calibrated for each experiment.

\subsection{2 $\mathrm{HONO}_{(\mathrm{ad})} \rightarrow 0.5 \mathrm{NO}_{(\mathrm{ad})}+0.5 \mathrm{NO}_{2(\mathrm{ad})}$}

Another $\mathrm{NO}_{(\mathrm{ad})}$ formation pathway is the auto-ionization of $\mathrm{HONO}_{(\mathrm{ad})}$. The larger the kinetic constant $k_{\mathrm{S} 3}$ of this reaction is, the larger the $\mathrm{HONO}_{(\mathrm{ad})}$ conversion into $\mathrm{NO}_{(\mathrm{ad})}$ and $\mathrm{NO}_{2(\mathrm{ad})}$ and the lower the $\mathrm{HONO}_{(\mathrm{ad})}$ reservoir available for desorption. However, contrary to Reaction $\left(\mathrm{S}_{2}\right)$, the auto-ionization of $\mathrm{HONO}_{(\mathrm{ad})}$ does not compete with the desorption of $\mathrm{HONO}_{(\mathrm{ad})}$. It can be observed in Fig. 15 that when $k_{\mathrm{S} 3}<10^{-5}$, the effect of this reaction vanishes, indicating that the HONO concentrations are only determined by $k_{\mathrm{S} 2}$ and $k_{\mathrm{HONO}(\mathrm{ad})}^{\prime}$ : as discussed in the previous subsection, decreasing $k_{\mathrm{S} 2}$ with $k_{\mathrm{S} 3}=10^{-5}$ enhances the release of $\mathrm{HONO}$ and cuts off the production of $\mathrm{NO}_{(\mathrm{ad})}$, showing that Reaction $\left(\mathrm{S}_{2}\right)$ and desorption weigh in on the depletion of $\mathrm{HONO}_{(\mathrm{ad})}$ at an equal level. If $k_{\mathrm{S} 3}$ is raised above that value, the gas-phase $\mathrm{NO}_{x}$ concentrations increase, but it becomes more difficult to lift HONO up to the concentrations measured experimentally, indicating that $k_{\mathrm{S} 3}$ should not be increased too much when calibrating the model kinetic constants. Reaction $\left(\mathrm{S}_{3}\right)$ should be kept slow compared with the desorption of $\mathrm{HONO}_{(\mathrm{ad})}$, which is achieved using $k_{\mathrm{S} 3}=10^{-5} \mathrm{~s}^{-1}$ in this work.

\section{$5.4 \mathrm{NO}_{2}$ regeneration: $\mathrm{NO}_{(\mathrm{ad})}+\mathrm{HNO}_{3(\mathrm{ad})} \rightarrow$ $\mathrm{NO}_{2}(\mathrm{ad})+\mathrm{HONO}_{(\mathrm{ad})}$}

As discussed in the Introduction, $\mathrm{NO}_{2(\mathrm{ad})}$ and $\mathrm{HONO}_{(\mathrm{ad})}$ can be regenerated through the reaction of $\mathrm{NO}_{(\mathrm{ad})}$ with $\mathrm{HNO}_{3(\mathrm{ad})}$. Figure 16 shows that the larger the kinetic constant $k_{\mathrm{S} 4}$ of this reaction is, the lower the $\mathrm{NO}$ and $\mathrm{NO}_{2}$ concentrations, but the larger the HONO concentration. Increasing $k_{\mathrm{S} 4}$ promotes 

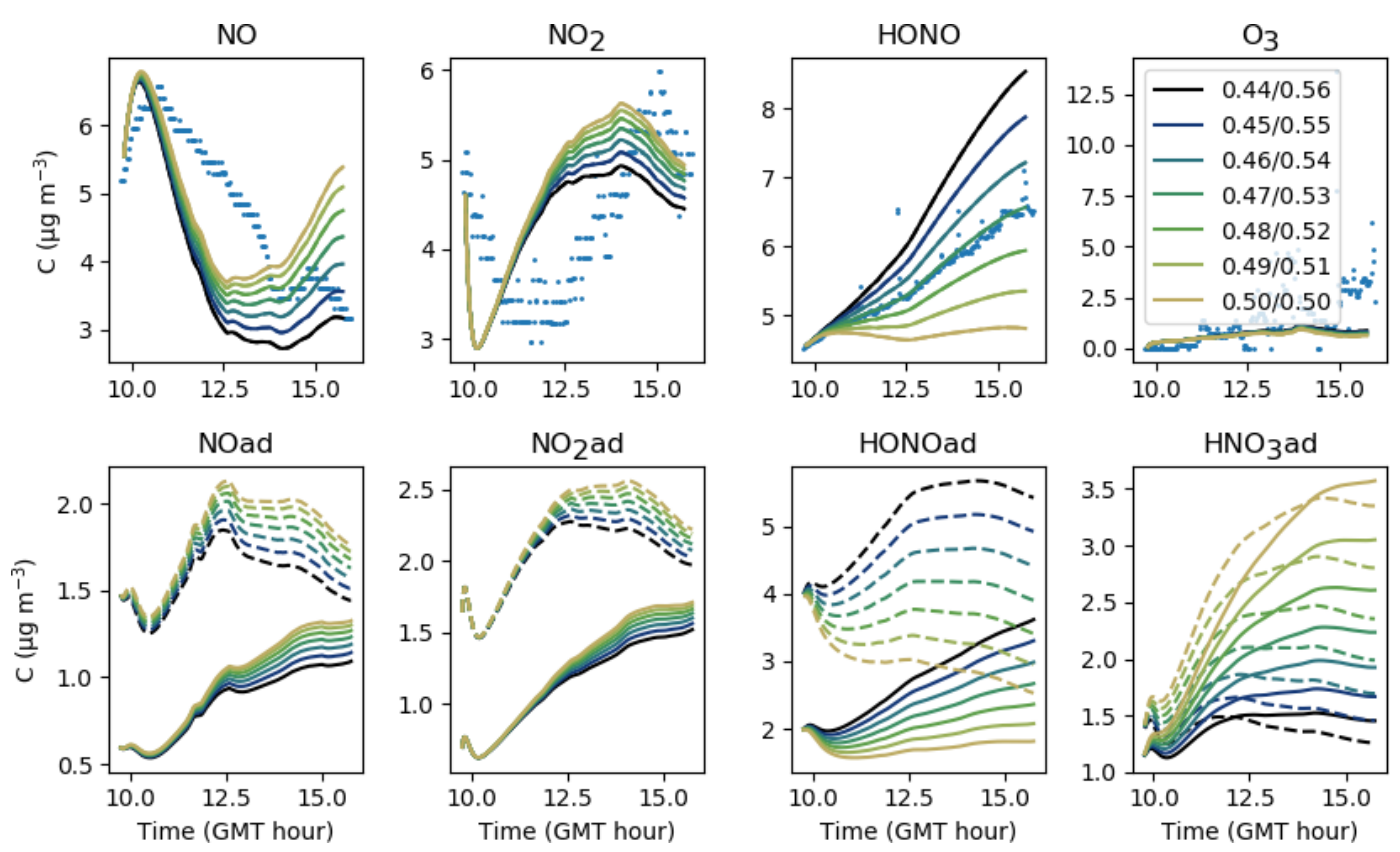

Figure 12. Gas-phase and adsorbed inorganic compounds simulated for different $\beta_{\mathrm{HNO}_{3}} / \beta_{\mathrm{HONO}}$, with $\beta_{\mathrm{HNO}} / \beta_{\mathrm{HONO}}<1$. The blue dots denote the experimental measurements (Experiment 2). The solid lines represent the concentrations in the sunlit box and the dashed lines the concentrations in the shaded box.
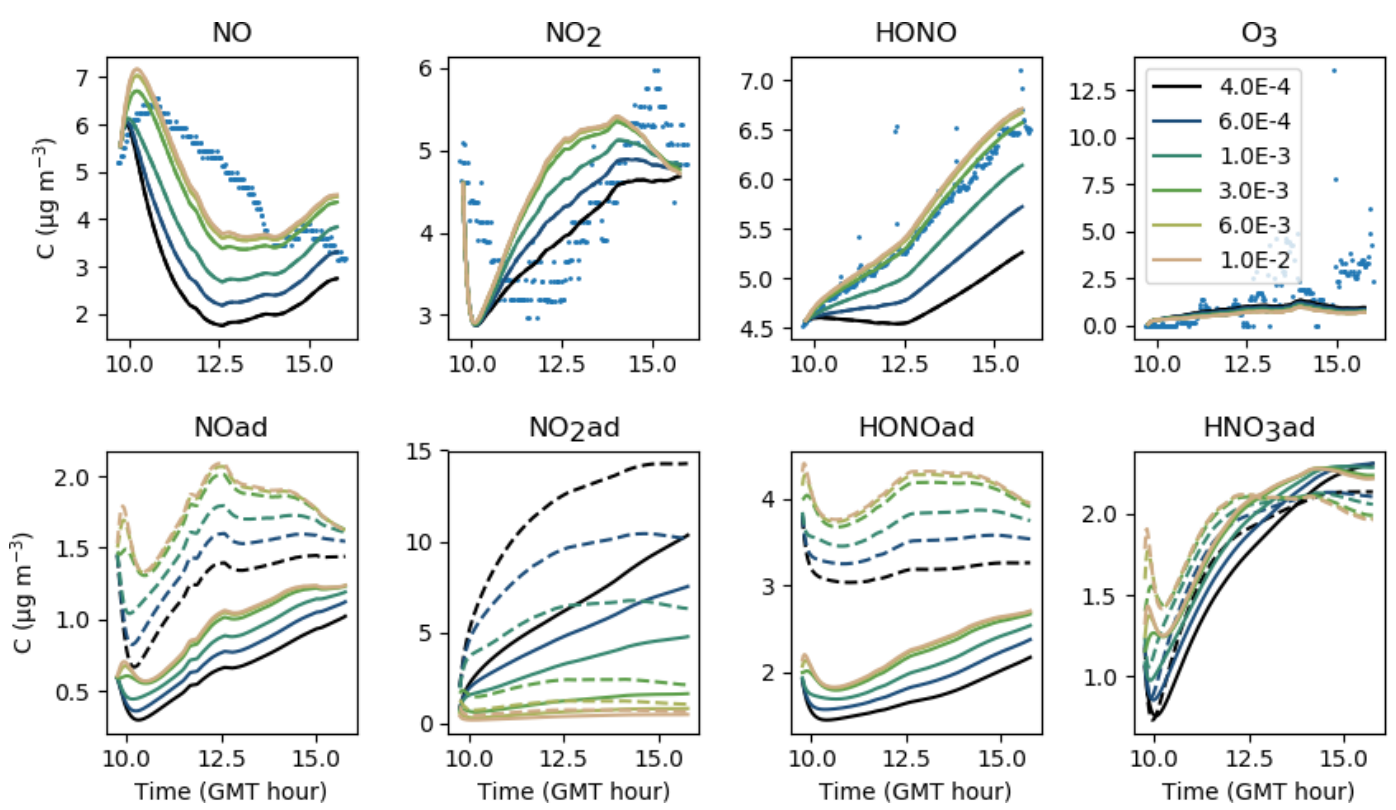

Figure 13. Gas-phase and adsorbed inorganic compounds simulated for different $k_{\mathrm{S} 1}$. The blue dots denote the experimental measurements (Experiment 2). The solid lines represent the concentrations in the sunlit box and the dashed lines the concentrations in the shaded box.

the consumption of $\mathrm{NO}_{(\mathrm{ad})}$, thus curbing the release of $\mathrm{NO}$ to the gas phase. The production of $\mathrm{HONO}_{(\mathrm{ad})}$ is enhanced, which in turn stimulates the HONO release. The production of $\mathrm{NO}_{2(\mathrm{ad})}$ is also enhanced by Reaction $\left(\mathrm{S}_{4}\right)$, which should increase the $\mathrm{NO}_{2(\mathrm{ad})}$ reservoir. However, Reaction $\left(\mathrm{S}_{1}\right)$ competes with desorption in the depletion of $\mathrm{NO}_{2(\mathrm{ad})}$. As Reac- tion $\left(\mathrm{S}_{1}\right)$ reduces the surplus of $\mathrm{NO}_{2(\mathrm{ad})}$ produced by Reaction $\left(\mathrm{S}_{4}\right)$, there is no increase in the $\mathrm{NO}_{2 \text { (ad) }}$ reservoir. The release of $\mathrm{NO}_{2}$ is not enhanced, and the gas-phase $\mathrm{NO}_{2}$ concentration equilibrates with the decreased $\mathrm{NO}$ concentration. In turn, increasing $k_{\mathrm{S} 4}$ lowers the $\mathrm{NO}_{2}$ concentration, whereas it raises the HONO concentration. 

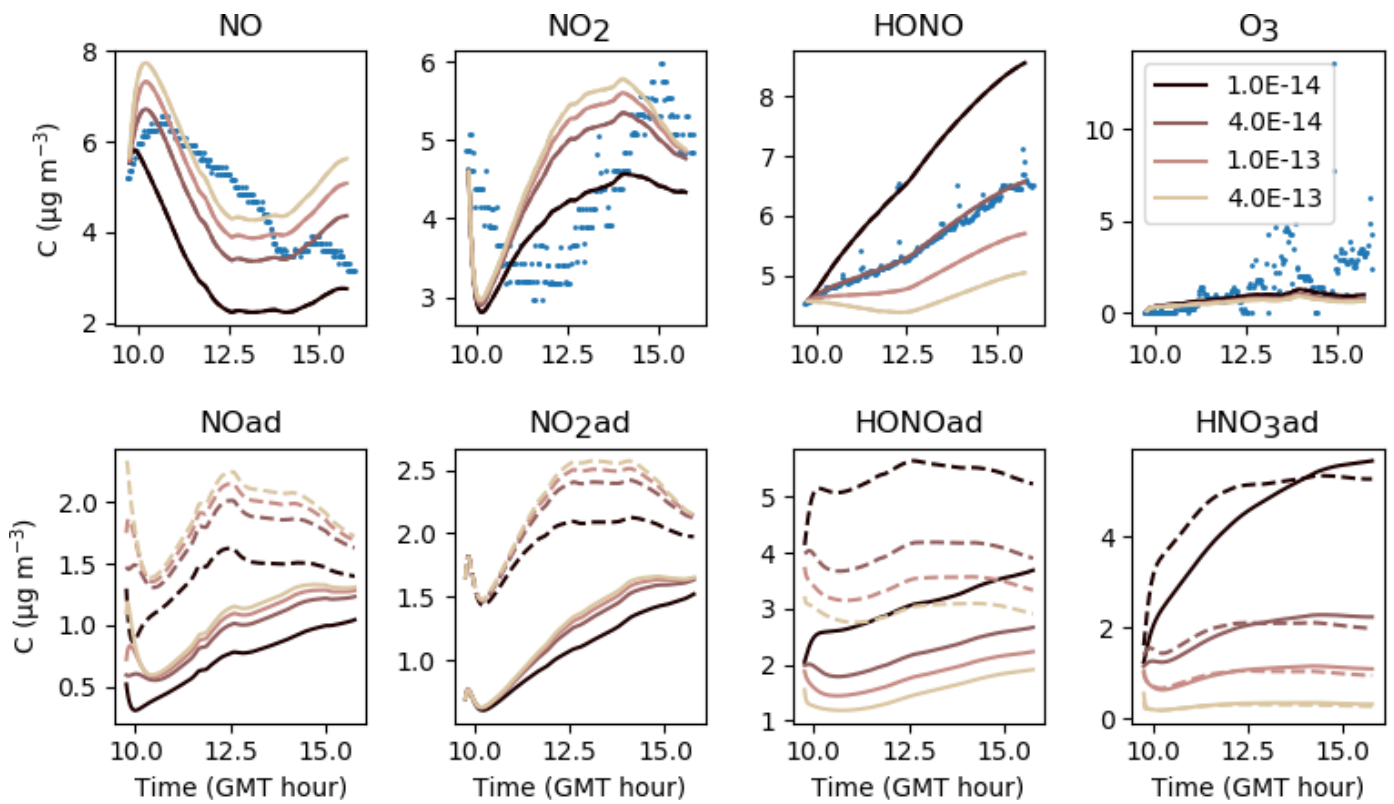

Figure 14. Gas-phase and adsorbed inorganic compounds simulated for different $k_{\mathrm{S} 2}$. The blue dots denote the experimental measurements (Experiment 2). The solid lines represent the concentrations in the sunlit box and the dashed lines the concentrations in the shaded box.
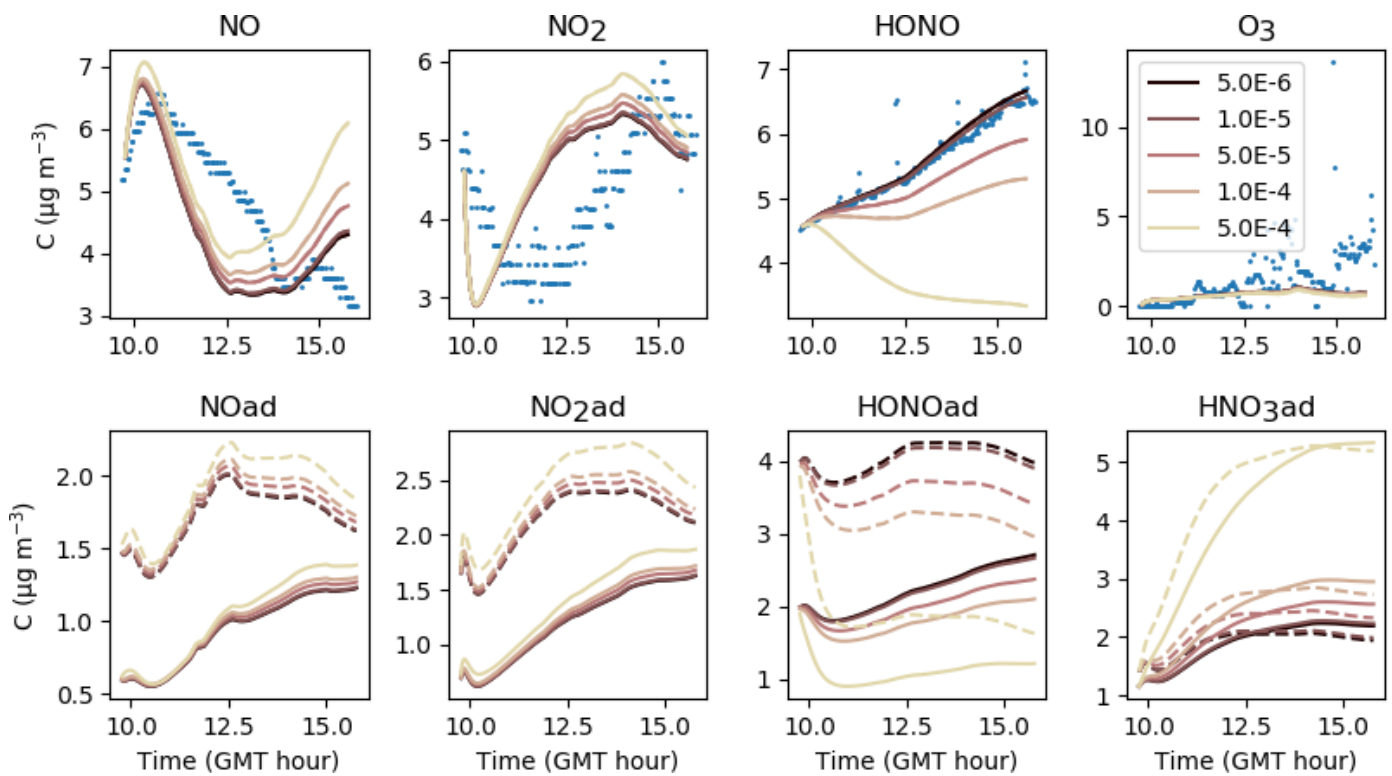

Figure 15. Gas-phase and adsorbed inorganic compounds simulated for different $k_{\mathrm{S} 3}$. The blue dots denote the experimental measurements (Experiment 2). The solid lines represent the concentrations in the sunlit box and the dashed lines the concentrations in the shaded box.

When $k_{\mathrm{S} 4}$ is decreased below $10^{-15}$, the effect of this reaction on the inorganic concentrations vanishes, showing that, similar to Reaction $\left(\mathrm{S}_{3}\right)$, Reaction $\left(\mathrm{S}_{4}\right)$ does not compete with another reaction, contrary to Reactions $\left(\mathrm{S}_{1}\right)$ and $\left(\mathrm{S}_{2}\right)$. Increasing $k_{\mathrm{S} 4}$ increases the HONO concentration but lessens the $\mathrm{NO}_{x}$ level at the same time, which is unfavourable beyond a certain threshold. This suggests that the kinetic constant $k_{\mathrm{S} 4}$ should remain low enough to maintain Reaction $\left(\mathrm{S}_{4}\right)$ upstage as Reaction $\left(\mathrm{S}_{3}\right)$. In these simulations, the value $k_{\mathrm{S} 4}=2 \times 10^{-15}$ allows HONO production to be supported while meeting this requirement.

\subsection{Desorption constants and uptake values}

The desorption constants and uptake coefficients drive the exchanges between the adsorbed and the gas phases. They are now examined. 

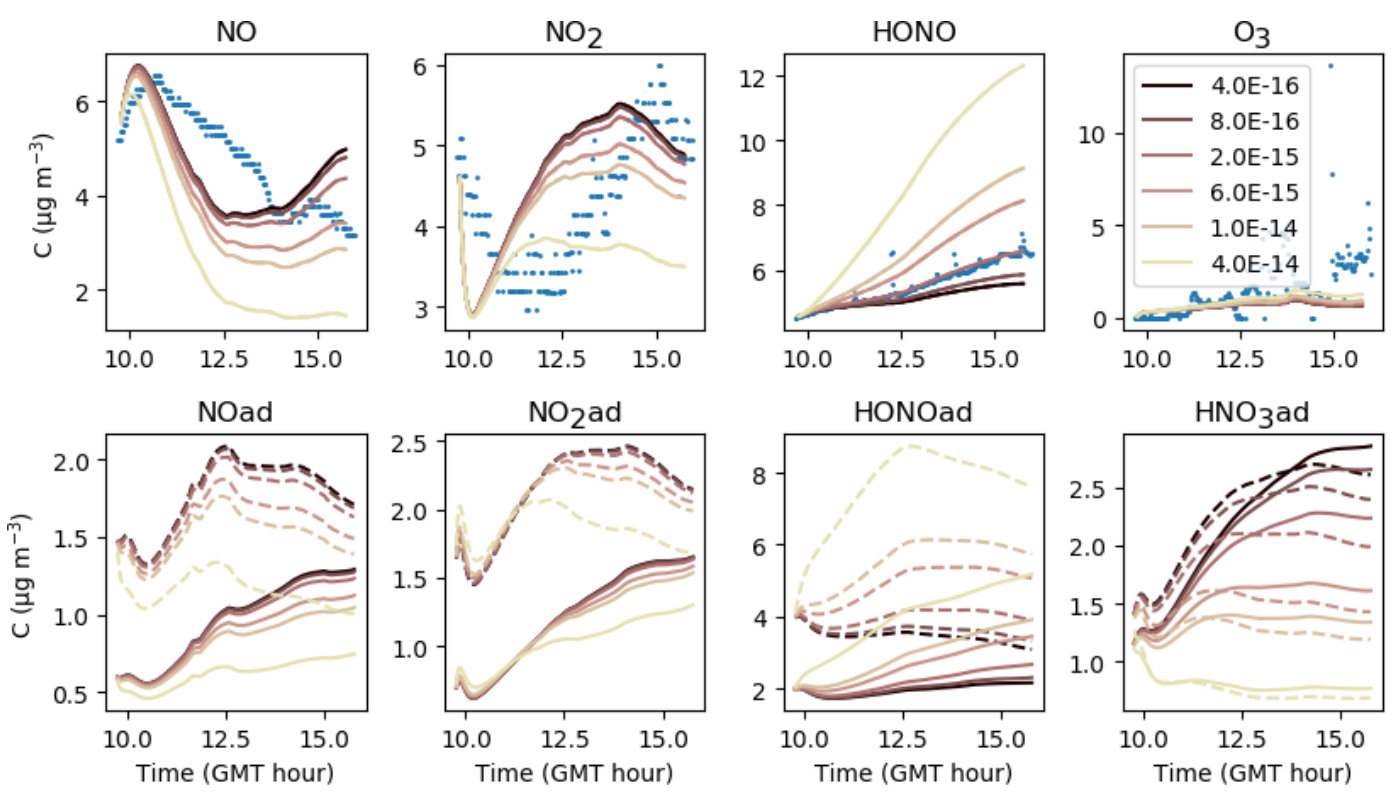

Figure 16. Gas-phase and adsorbed inorganic compounds simulated for different $k_{\mathrm{S} 4}$. The blue dots denote the experimental measurements (Experiment 2). The solid lines represent the concentrations in the sunlit box and the dashed lines the concentrations in the shaded box.

\subsubsection{Nitrogen dioxide}

The uptake coefficient $\gamma \mathrm{NO}_{2}$ is the only parameter characteristic of the heterogeneous chemistry of inorganic compounds that was determined experimentally for the paint boards. This parameter is not modified in Experiments 2 and 3 in which the paint boards were used. Here, the sorption dynamics of $\mathrm{NO}_{2}$ are only modified through the desorption constant $k_{\mathrm{NO}_{2}(\text { ad) }}^{\prime}$. It can be inferred from Fig. 17 that the $\mathrm{NO}_{2}$ concentration is not very sensitive to $k_{\mathrm{NO}_{2}(\mathrm{ad})}^{\prime}$, as the latter must be varied over several orders of magnitude to observe significant changes in $\mathrm{NO}_{2}$ concentrations, likely because the main source of $\mathrm{NO}_{2}$ is transport from outdoors and not secondary chemistry. Increasing $k_{\mathrm{NO}_{2}(\mathrm{ad})}^{\prime}$ decreases the $\mathrm{NO}_{2(\mathrm{ad})}$ reservoir. As less $\mathrm{NO}_{2(\mathrm{ad})}$ is available, less $\mathrm{HONO}_{(\mathrm{ad})}$ is produced by Reaction $\left(\mathrm{S}_{1}\right)$, thus resulting in a decreased release of $\mathrm{HONO}$ to the gas phase. To maintain sufficient $\mathrm{NO}_{2}$ adsorption and a large enough HONO concentration, the parameter $k_{\mathrm{NO}_{2} \text { (ad) }}^{\prime}$ should be kept low. It is set to $k_{\mathrm{NO}_{2}(\mathrm{ad})}^{\prime}=10^{-22} \mathrm{~s}^{-1}$ molec. $^{-1}$ in the reference simulations.

\subsubsection{Nitric oxide}

To date, all box models (Sarwar et al., 2002; Carslaw, 2007; Courtey et al., 2009; Mendez et al., 2015) assume a zero deposition velocity for NO after the values reported by Nazaroff and Cass (1986). A zero deposition velocity corresponds to an uptake coefficient close to zero, thus preventing the molecules from colliding with surfaces and becoming adsorbed.

Figure 18 investigates the sensitivity of inorganic concentrations to $\gamma_{\mathrm{NO}}$, which is varied between $\gamma_{\mathrm{NO}}=10^{-8}$ and the maximum value $\gamma_{\mathrm{NO}}=\infty$. The coefficient $\gamma_{\mathrm{NO}}=\infty$ is obtained by assuming that all collisions are efficient, i.e. $k_{\mathrm{DEP}, i}^{j}=k_{\text {tran }, i}^{j}$. When $\gamma_{\mathrm{NO}}=\infty$, the NO deposition is only limited by transport to the surface. Apart from the beginning of the simulations, no significant variation in the NO concentration is observed between the extreme values investigated, showing that in this experiment, deposition has a negligible contribution to the gas-phase NO concentration. The first part of the simulated profile can be improved by about $10 \%$ using the lowest $\gamma$ NO value.

The concentration variations with desorption constant $k_{\mathrm{NO}(\mathrm{ad})}^{\prime}$ are presented in Fig. 19. When $k_{\mathrm{NO}(\mathrm{ad})}^{\prime}$ is increased, $\mathrm{NO}_{(\mathrm{ad})}$ evaporates towards the gas phase. In contrast, when $k_{\mathrm{NO}(\mathrm{ad})}^{\prime}$ is decreased, the release of NO is less efficient and the NO concentration decreases, leading to a decrease in the $\mathrm{NO}_{2}$ concentration. Then, since less $\mathrm{NO}_{2}$ is available on surfaces for hydrolysis, less HONO is produced. As a result, decreasing $k_{\mathrm{NO}(\mathrm{ad})}^{\prime}$ too much decreases the three $\mathrm{NO}_{y}$ compound concentrations in the gas phase.

In turn, the parameters $\gamma_{\mathrm{NO}}$ and $k_{\mathrm{NO}(\mathrm{ad})}^{\prime}$ should be fixed to maintain NO in the gas-phase form preferentially, which corroborates the use of a very low deposition velocity, as reported in the literature. In this paper, an uptake coefficient $\gamma_{\mathrm{NO}}=8 \times 10^{-9}$ is chosen for all simulations. The desorption constant $k_{\mathrm{NO}(\mathrm{ad})}^{\prime}$ is set to $8 \times 10^{-21} \mathrm{~s}^{-1}$ molec. $^{-1}$ for Experiments 2 and 3 , while a lower value $2 \times 10^{-22} \mathrm{~s}^{-1}$ molec. $^{-1}$ appears to be required to simulate Experiment 1 .

\subsubsection{Nitrous acid}

The adsorption-desorption dynamics of HONO are investigated by varying the uptake coefficient $\gamma_{\mathrm{HONO}}$ (Fig. 20) and 

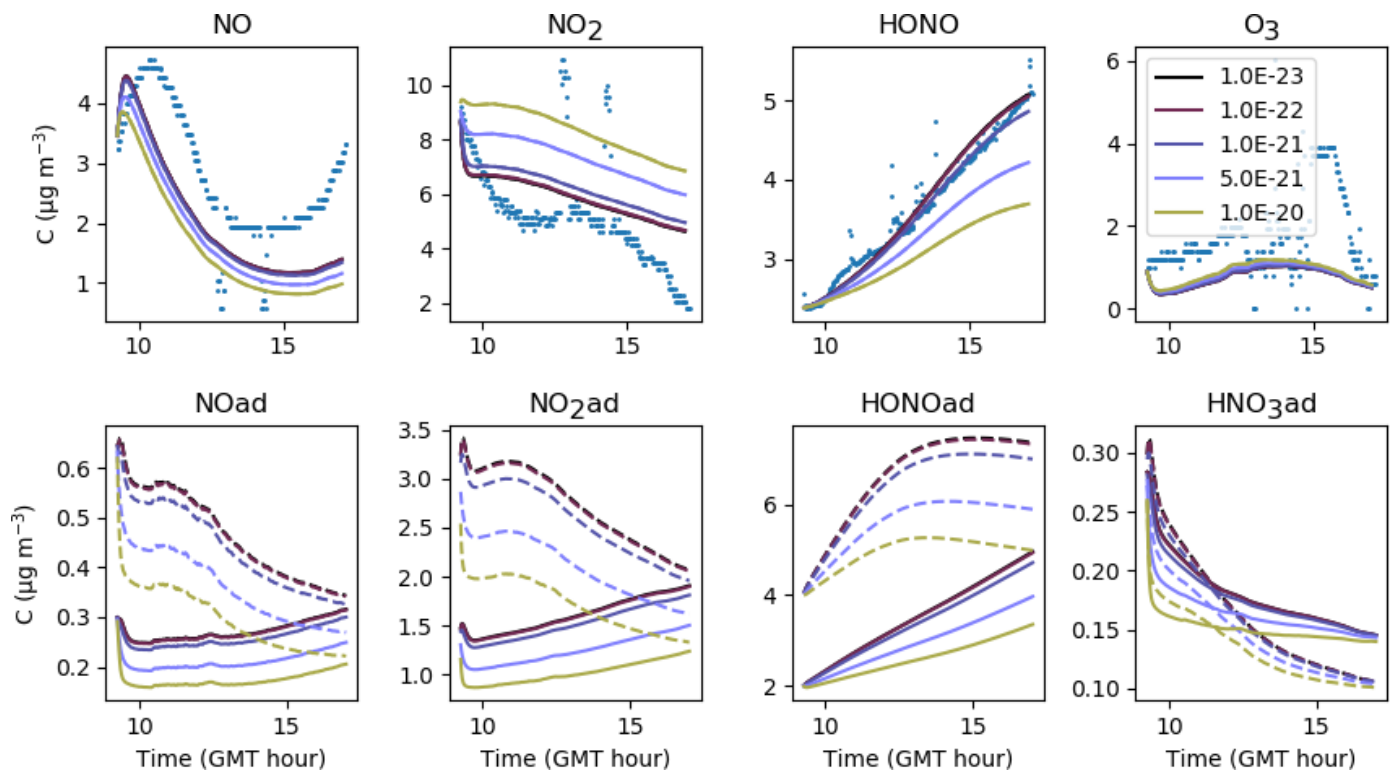

Figure 17. Gas-phase and adsorbed inorganic compounds simulated for different $k_{\mathrm{NO}_{2}(\mathrm{ad})}^{\prime}$. The blue dots denote the experimental measurements (Experiment 3). The solid lines represent the concentrations in the sunlit box and the dashed lines the concentrations in the shaded box.
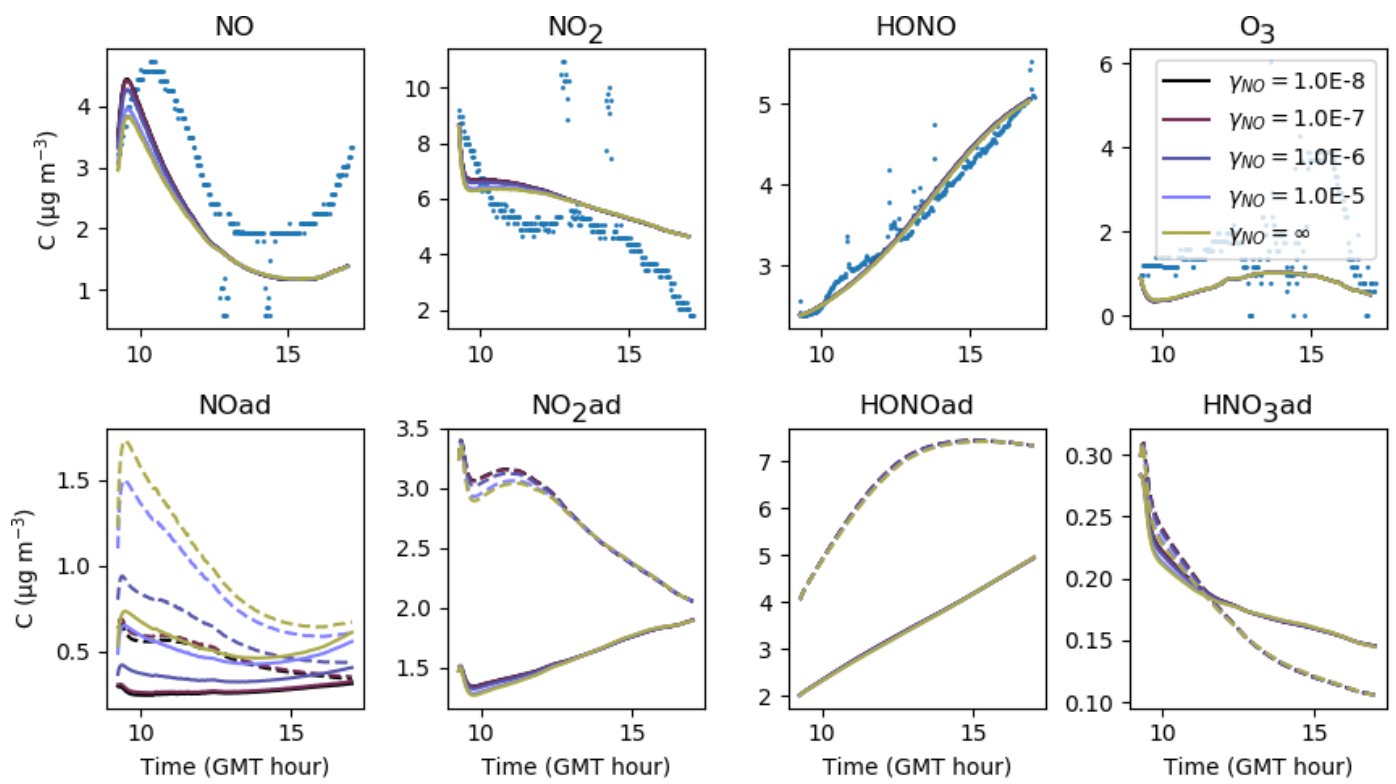

Figure 18. Gas-phase and adsorbed inorganic compounds simulated for different $\gamma$ NO. The blue dots denote the experimental measurements (Experiment 3). The solid lines represent the concentrations in the sunlit box and the dashed lines the concentrations in the shaded box.

the desorption constant $k_{\mathrm{HONO} \text { (ad) }}^{\prime}$ (Fig. 21). Contrary to NO, small variations in the uptake coefficient and desorption constant cause the HONO concentration to vary greatly. HONO is not brought by transport from the outdoors and is only produced by secondary chemistry, which justifies the critical importance of these parameters in controlling the transfers between the homogeneous gas phase and surfaces. Increasing

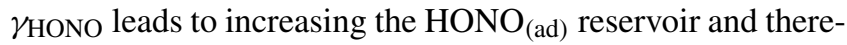

fore to decreasing the gas-phase HONO. When $\gamma_{\mathrm{HONO}}$ tends to zero, the gas-phase HONO concentration is determined by the desorption constant $k_{\mathrm{HONO}}^{\prime}$ (ad) only. As the HONO concentration is sensitive to both $\gamma_{\mathrm{HONO}}$ and $k_{\mathrm{HONO}(\mathrm{ad})}^{\prime}$, a balance between these parameters must be found. An increase in $\gamma_{\mathrm{HONO}}$ can compensate for an increase in $k_{\mathrm{HONO}(\text { ad) }}^{\prime}$, and, reciprocally, a decrease in $\gamma_{\text {HONO }}$ must be associated with a decrease in $k_{\mathrm{HONO}(\mathrm{ad})}^{\prime}$. Several choices (large $\gamma_{\mathrm{HONO}}$ and 

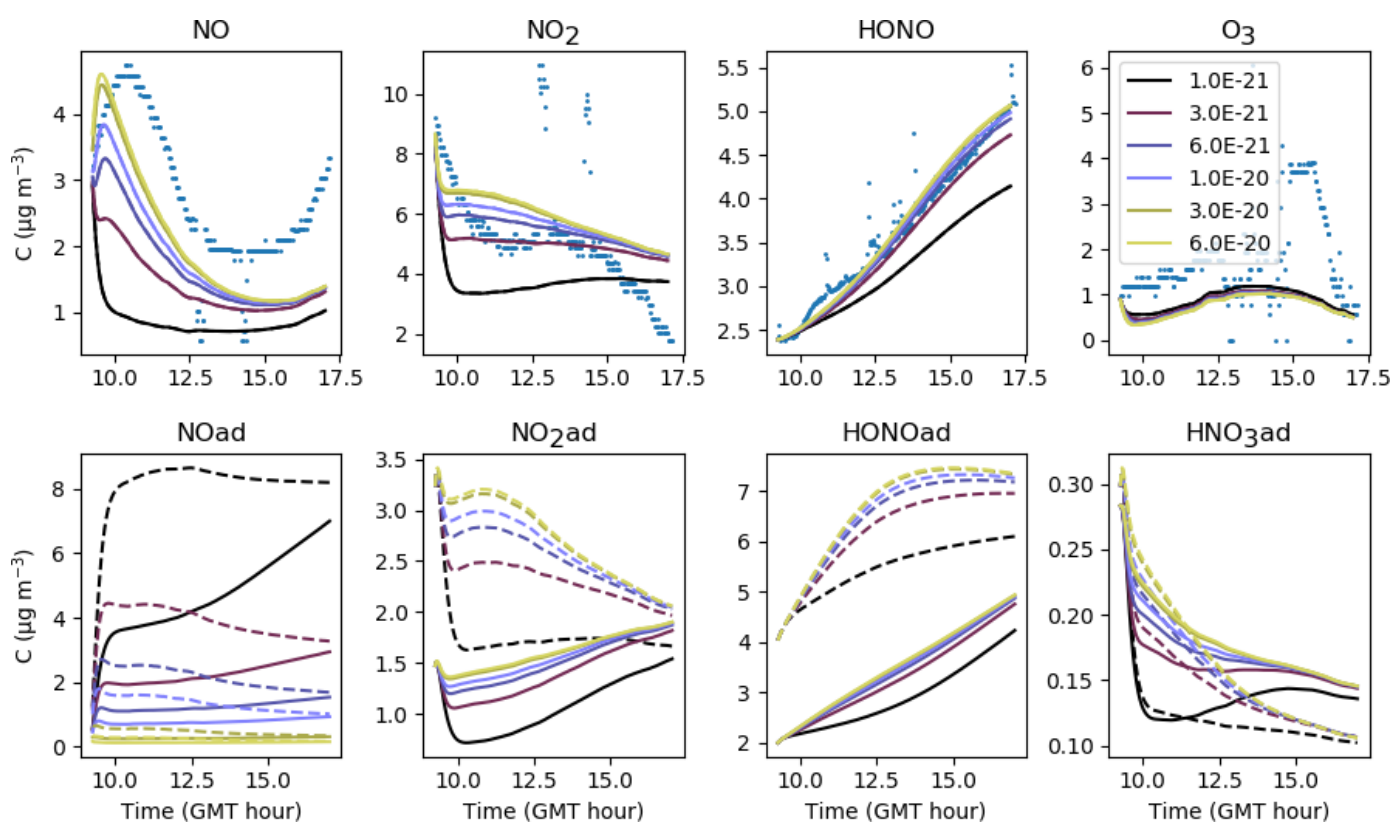

Figure 19. Gas-phase and adsorbed inorganic compounds simulated for different $k_{\mathrm{NO}(\mathrm{ad})}^{\prime}$. The blue dots denote the experimental measurements (Experiment 3). The solid lines represent the concentrations in the sunlit box and the dashed lines the concentrations in the shaded box.
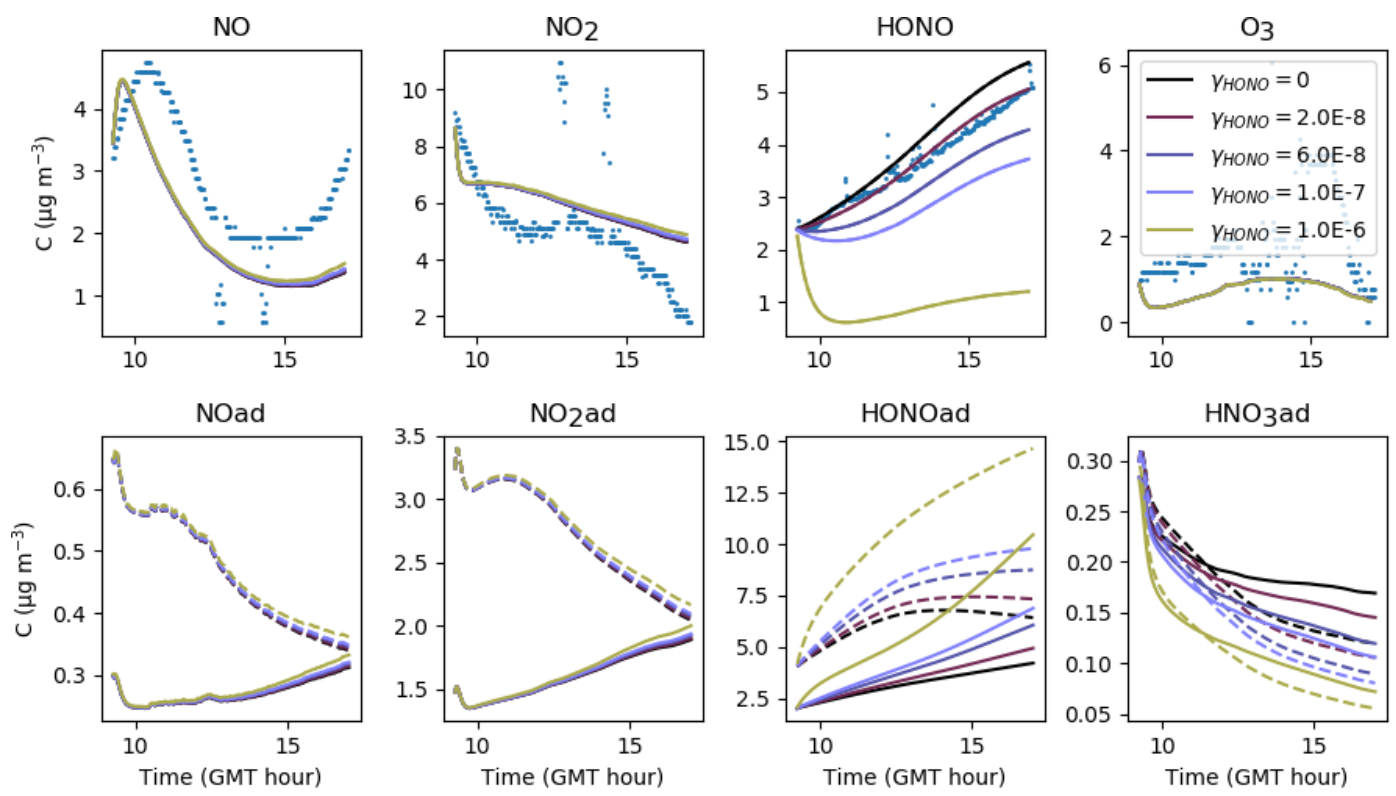

Figure 20. Gas-phase and adsorbed inorganic compounds simulated for different $\gamma_{\text {HONO }}$. The blue dots denote the experimental measurements (Experiment 3). The solid lines represent the concentrations in the sunlit box and the dashed lines the concentrations in the shaded box.

$k_{\mathrm{HONO}(\mathrm{ad})}^{\prime}$ vs. low $\gamma_{\mathrm{HONO}}$ and $\left.k_{\mathrm{HONO}(\mathrm{ad})}^{\prime}\right)$ can simulate the HONO concentration correctly. However, the time variations of the HONO concentration may behave differently depending on the chosen set of parameters. In this example, if both $\gamma_{\mathrm{HONO}}$ and $k_{\mathrm{HONO}(\mathrm{ad})}^{\prime}$ are large, the HONO concentration tends to decrease at the end of the simulation, whereas a monotonous increase is observed in the experiment. This suggests that low values of $\gamma_{\mathrm{HONO}}$ and $k_{\mathrm{HONO}(\mathrm{ad})}^{\prime}$ are better suited. The values $\gamma_{\mathrm{HONO}}=2 \times 10^{-8}$ and $k_{\mathrm{HONO}(\mathrm{ad})}^{\prime}=$ $5 \times 10^{-22} \mathrm{~s}^{-1}$ molec $^{-1}$ are retained for the reference simulations. By comparison, considering an average humidity of $45 \%$, the relationship between humidity and $\gamma_{\text {HONO }}$ mea- 

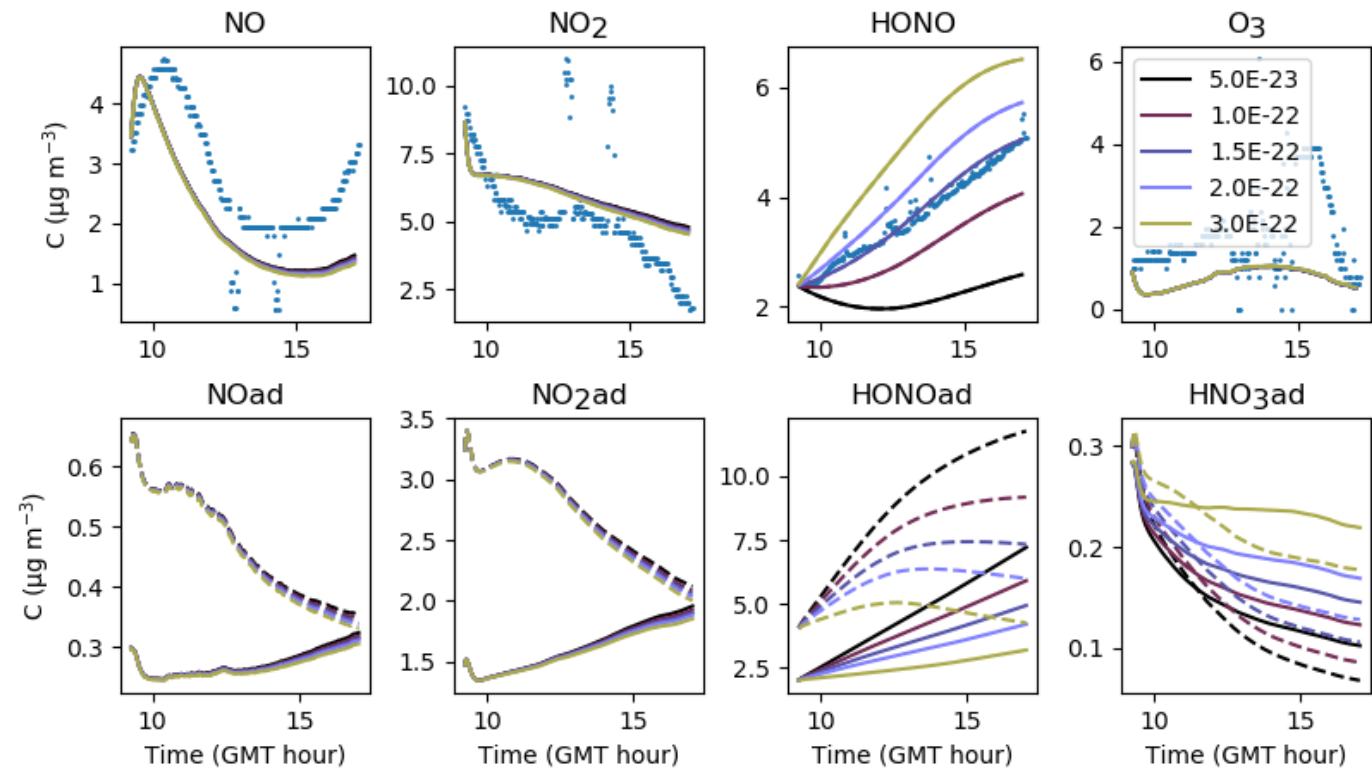

Figure 21. Gas-phase and adsorbed inorganic compounds simulated for different $k_{\mathrm{HONO} \text { (ad) }}^{\prime}$ The blue dots denote the experimental measurements (Experiment 3). The solid lines represent the concentrations in the sunlit box and the dashed lines the concentrations in the shaded box.
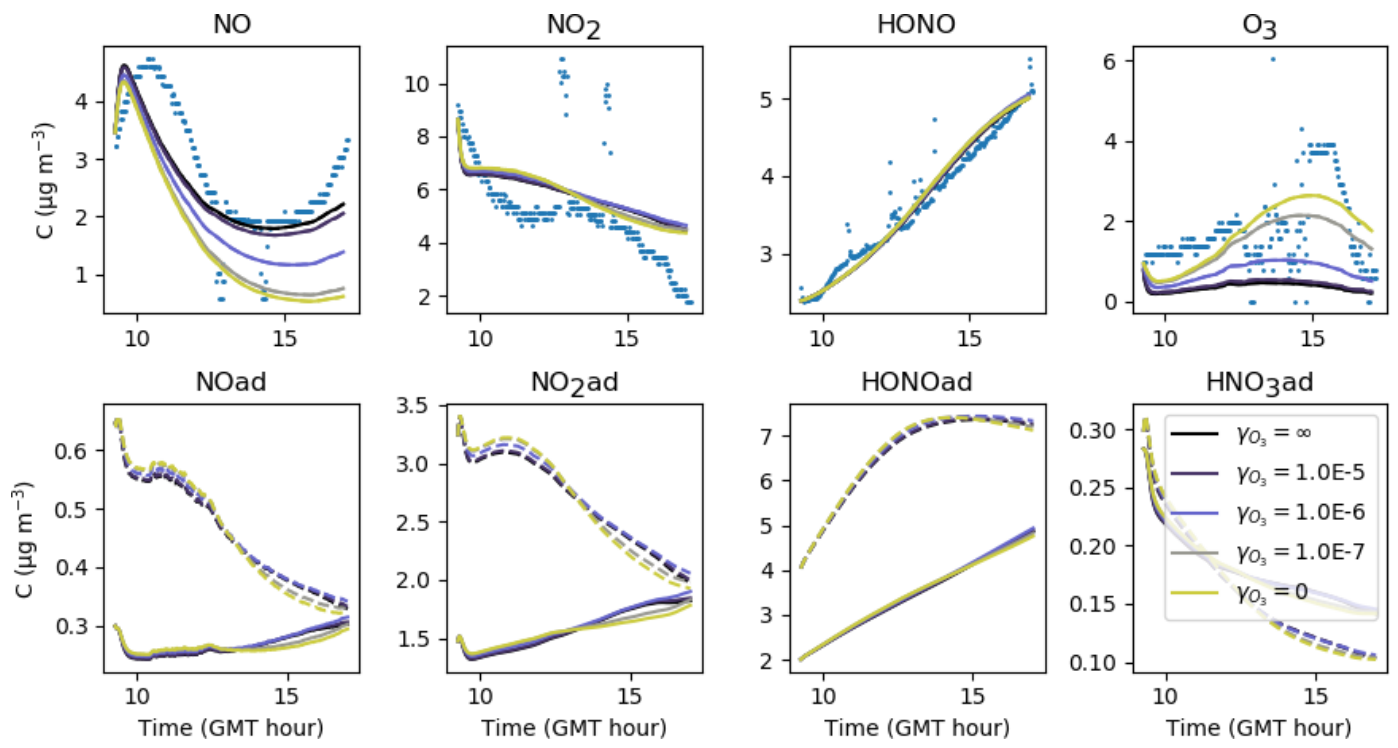

Figure 22. Gas-phase and adsorbed inorganic compounds simulated for different $\gamma_{\mathrm{O}_{3}}$. The blue dots denote the experimental measurements (Experiment 3). The solid lines represent the concentrations in the sunlit box and the dashed lines the concentrations in the shaded box.

sured on $\mathrm{TiO}_{2}$ surfaces, found by El Zein and Bedjanian (2012) under dark conditions, gives $\gamma_{\mathrm{HONO}}=1.6 \times 10^{-6}$, which is a value higher than the one determined here. However, we recall that the same uptake value is used for all materials constituting the room (walls, floor and window), which complicates the analogy.

Finally, while significant variations of HONO concentrations are observed, changes in $\mathrm{NO}$ and $\mathrm{NO}_{2}$ are imperceptible, thus showing the poor correlation between HONO and
$\mathrm{NO}_{x}$ concentrations in these experiments with anti-UV windows.

\subsubsection{Ozone}

In all simulations presented above, the $\mathrm{O}_{3}$ concentrations are not altered by any change in $\mathrm{NO}_{x}$ and HONO concentrations. This is an expected behaviour, considering that the main source of $\mathrm{O}_{3}$ is transport from the outdoors and that 
its main sink is deposition. Figure 22 shows that variations in the uptake coefficient $\gamma_{\mathrm{O}_{3}}$ modify the $\mathrm{O}_{3}$ concentration significantly and also the NO concentration through homogeneous chemistry. When $\gamma_{\mathrm{O}_{3}}$ tends to zero, the $\mathrm{O}_{3}$ concentration increases up to a value very close to the experimental one, whereas the NO concentration decreases to concentrations much lower than those observed. With an uptake coefficient $\gamma_{\mathrm{O}_{3}}=10^{-6}$ and no desorption reaction for $\mathrm{O}_{3}$, both $\mathrm{O} 3$ and $\mathrm{NO}$ are correctly modelled: although lower than the experimental record, $\mathrm{O}_{3}$ remains within $60 \%$ of the measured concentration, while the NO RMSE remains close to 1.

\section{Modelling high $\mathrm{NO}_{2}$ concentrations: focus on Experiment 1}

When analysing the optimized simulations, it can be noticed that the parameters fitting Experiments 2 and 3 are similar but can significantly differ from some of those fitting Experiment 1 , especially the ones controlling the adsorptiondesorption of the $\mathrm{NO}_{y}$ compounds. The difficulty in simulating Experiment 1 (Fig. 7) lies in handling the fast transition from a moderate $\mathrm{NO}_{2}$ concentration to a very high one. To prevent the HONO and NO secondary production from rocketing after the $\mathrm{NO}_{2}$ injection, $k_{\mathrm{NO}(\mathrm{ad})}^{\prime}$ was decreased and $\gamma_{\text {HONO }}$ was increased to limit the NO and HONO releases. To preserve satisfying NO and $\mathrm{HONO}$ levels before the injection, the initial concentrations of $\mathrm{NO}_{(\mathrm{ad})}$ and $\mathrm{HONO}_{(\mathrm{ad})}$ were increased in order to counterbalance the weaker release of these species.

In spite of the above, changing the model parameters could not completely mitigate the NO and $\mathrm{HONO}$ breakouts caused by the massive $\mathrm{NO}_{2}$ supply. Previously, the modelling of the HONO production in high $\mathrm{NO}_{2}$ conditions, i.e. $\mathrm{NO}_{2}$ concentrations exceeding $25 \mathrm{ppb}$, was already pointed out by Mendez et al. (2017) as a challenging issue. As in this study, the experimental HONO step-up caused by the $\mathrm{NO}_{2}$ injection was moderate, which the existing model failed to replicate by overestimating the HONO increase. Mendez et al. (2017) proposed coping with this by introducing a compound, SURF, representing the number of sites available for $\mathrm{NO}_{2}$, thus limiting the amount of $\mathrm{NO}_{2(\mathrm{ad})}$ for surface hydrolysis.

In this paper, a similar solution is implemented by extending the definition of SURF to all surface compounds introduced in this model. Here, SURF represents the number of sites available for $\mathrm{NO}, \mathrm{HONO}, \mathrm{NO}_{2}$ and $\mathrm{HNO}_{3}$. SURF is incorporated in the adsorption-desorption reactions but only modifies the kinetics of these reactions when its "concentration" is less than unity. In other words, as long as many surface sites are available, the sorption dynamics behave as usual, but as soon as the surface approaches saturation, the kinetics of the adsorption reactions are increased by 1 order, in addition to being slowed down by the SURF "concentration" being less than unity.
The resulting profiles are presented in Fig. 23 using the same parameters as the optimized simulation. An important difference with Mendez et al. (2017) is that the $\mathrm{NO}, \mathrm{NO}_{2}$ and $\mathrm{O}_{3}$ concentrations are not fixed to their measured values. In this test, the $\mathrm{NO}_{2}$ injection causes the three $\mathrm{NO}_{y}$ compounds to increase. The magnitude of this increase is determined by the initial value of the SURF concentration. When this value is very large, the concentration profiles converge to the optimized simulation (Fig. 7). Conversely, when the initial SURF concentration is decreased, the sorption of $\mathrm{NO}_{2}$ and related species is reduced, which generates an excess of gas-phase $\mathrm{NO}_{y}$.

From Fig. 23, we may conclude that the parameterization of desorption needs improvement or that the contribution of $\mathrm{NO}_{2}$ to the secondary formation of $\mathrm{HONO}$ and $\mathrm{NO}$ is overestimated. These results agree with the work of Collins et al. (2018), who performed indoor time-resolved measurements of $\mathrm{HONO}$ and $\mathrm{NO}_{2}$ under both positive and negative perturbations. Their measurements indicated a weak correlation between the concentrations of both species. Similar behaviour was observed during the SURFin campaign (Alvarez et al., 2013), during which the HONO concentration increased rapidly after ventilation periods and remained in a near-steady state despite $\mathrm{NO}_{2}$ variations. The SURF compound introduced by Mendez et al. (2017) to model these data made it possible to decrease the coupling between the two species. However, the modelled HONO concentration still retained more sensitivity to $\mathrm{NO}_{2}$ than what the measurements indicated. It appears from Fig. 23 that extending the definition of SURF to all sorbed compounds introduced in this model does not improve the problem.

\section{Discussion}

Considering the number of parameters involved in this model, a given simulation result is likely reachable by different parameter combinations. Additionally, some parameters that could replicate the records presented in this study are typical of the room where the experiments took place and would be hardly transferable to other indoor environments. These are the filtration factor, velocity of the air, desorption constants and uptake coefficients. Although these parameters are basically environmentally dependent and nonunique, several conclusions can be drawn from these tests regarding general principles of IAQ modelling.

The air-mixing velocity introduced as in Mendez et al. (2017) appears to be a critical parameter for the four main species leading the inorganic chemistry. The building filtration factor, generally taken as unity, is also a determining factor. This parameter should not be confused with the ventilation rate $\left(k_{\mathrm{AER}}\right)$ that encompasses leaks to both the outside and to the rest of the building. The building filtration factor controls the fraction of air influx coming from outside the building. In these experiments, its value is far from unity, thus 

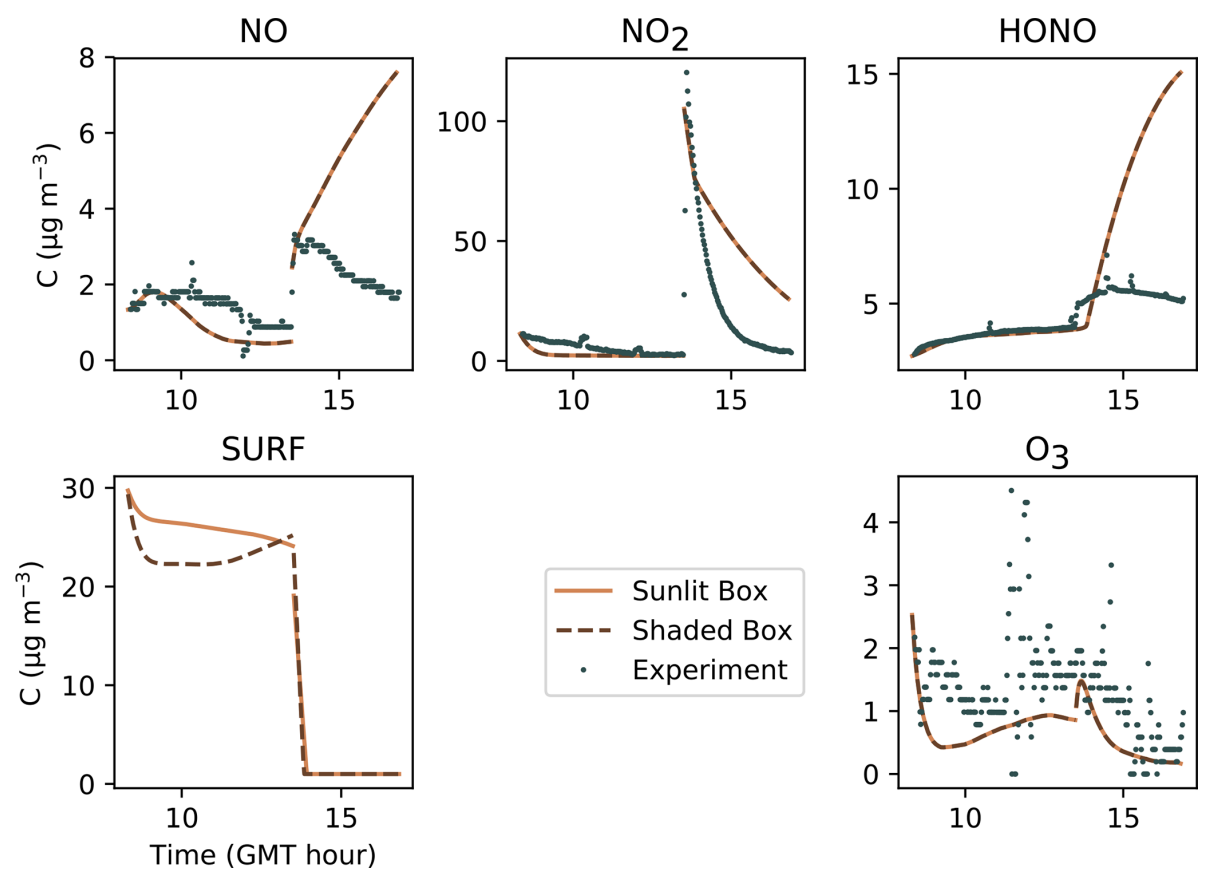

Figure 23. Implementation of a surface saturation effect using the compound SURF. The dots denote the experimental records, the solid lines denote the concentrations simulated in the sunlit box, and the dashed lines denote the concentrations in the shaded box.

featuring low infiltration. Using a value of unity would have led to overestimating the intake of outdoor pollutants, thus mitigating the importance of heterogeneous phenomena.

The surface hydrolysis of $\mathrm{NO}_{2}$ produces sorbed $\mathrm{HONO}$ and $\mathrm{HNO}_{3}$ that further react to produce sorbed NO. The kinetics of this reaction are determined by its kinetic rate $k_{\mathrm{S} 1}$ and also by the $\mathrm{NO}_{2}$ adsorption-desorption reactions that control the variations of the $\mathrm{NO}_{2(\mathrm{ad})}$ reservoir. The $\mathrm{NO}_{2 \text { (ad) }}$ concentration variations largely influence the variations of the other sorbed species concentrations through Reaction $\left(\mathrm{S}_{1}\right)$, which could be considered the cornerstone of indoor heterogeneous chemistry in this model. A very small adjustment in the stoichiometry of Reaction $\left(\mathrm{S}_{1}\right)$ allows a significant increase in the HONO secondary production in all experiments.

The NO secondary production mainly derives from Reaction $\left(\mathrm{S}_{2}\right)$, which competes with the HONO desorption. The kinetic rates of these reactions can be influenced by the nature of the surface materials. The release kinetics of these species flow from their sorbed concentrations, which likely depend on a variety of parameters. This environmental dependence could explain why the yields of HONO and NO reported in the literature can vary a lot from one study to another (Finlayson-Pitts et al., 2003). Reactions $\left(S_{3}\right)$ and $\left(\mathrm{S}_{4}\right)$ can influence the $\mathrm{NO}_{y}$ concentration time variations, but their impacts seem less predominant.

Regarding the sorption dynamics, HONO is extremely sensitive to the values of its uptake coefficient and desorption constant, since it is almost entirely produced by hetero- geneous chemistry. Obviously, these parameters have antagonist effects that can neutralize each other. The proper calibration of these parameters can be oriented by the shape of the sorbed species profile with respect to the gas-phase experimental profile. Contrary to HONO, the NO concentration does not seem to be affected by the uptake coefficient $\gamma \mathrm{NO}$. Similarly to the $\mathrm{OH}$ radical, NO is likely too reactive to be affected by deposition. When deposition has a negligible contribution compared with homogeneous reactivity, the influence of the species uptake coefficient on the gas-phase concentration can be considered to be null, whatever its genuine value may be. In this case, the uptake coefficient can be set to zero as an apparent uptake value.

The simulations presented in Sect. 4 show that the desorption constants are the parameters that are the most difficult to set, especially for NO and HONO. The problem is less striking for $\mathrm{NO}_{2}$ since the main source of $\mathrm{NO}_{2}$ is transport from the outdoors in these experiments. By using a common value of $k_{\mathrm{HONO}(\mathrm{ad})}^{\prime}$ for the three experiments (reference simulations), the simulated HONO concentrations show an overestimation of $95 \%$ and $78 \%$ for Experiments 1 and 3. Using the same $k_{\mathrm{NO}(\mathrm{ad})}^{\prime}$ in Experiments 2 and 3, the simulated NO concentrations remain as similar to the measured concentrations as using the optimized parameters. However, it is impossible to use the same value in Experiment 1 without making the NO concentration increase well above the measured values.

Small variations in uptake coefficients and desorption constants can be supported by differences in wall covering be- 
tween experiments. In the first experiment, walls were naked, whereas in subsequent experiments, walls were covered by boards freshly coated with a paint made of the same organic matrix. According to Finlayson-Pitts et al. (2003), the composition of the surface film of water can play an important role in determining the yields of NO and HONO, but the nature of the underlying material should not influence this chemistry unless it is sufficiently reactive to modify the composition of the surface film. The surface topology can also influence the material adsorption capacity: experiments conducted by Wainman et al. (2001) to study the influence of the surface nature on $\mathrm{NO}_{2}$ hydrolysis showed that HONO concentrations were significantly enhanced when synthetic carpet was used instead of Teflon surfaces. They suggested that this was caused by the greater surface quantity provided by the carpet fibres, allowing more room for the reaction to occur. In this study, it could be argued that differences in roughness between the walls and paint boards, combined with differences in uptake values, may account for variations of surface sorption capacity between the first and following experiments. However, these elements are not sufficient to support a difference in $k_{\mathrm{NO}(\mathrm{ad})}^{\prime}$ of almost 3 orders of magnitude (see Set 1 in Table 5).

In light of this, it can be inferred that a more sophisticated parameterization of the desorption reactions may be required to improve this model. Rather than competitive adsorptiondesorption kinetics, the adsorption-desorption phenomenon may be represented by an equilibrium approach, which depends on the mass ratio of adsorbed to gas phase. Such improvement may also alleviate the problems observed after the $\mathrm{NO}_{2}$ injection during Experiment 1. Similar to Mendez et al. (2017), we observe that the measured increase in HONO after the $\mathrm{NO}_{2}$ injection is moderate, and similar to the models tested by Mendez et al. (2017), the $\mathrm{H}^{2} \mathrm{I}$ model overestimates this increase in HONO concentration. Collins et al. (2018) succeeded in simulating gas-phase $\mathrm{HONO}$ at a high $\mathrm{NO}_{2}$ level using persistent source and sink processes with only a small contribution from $\mathrm{NO}_{2}$ uptake. To explain the poor correlation between the two species concentrations, Collins et al. (2018) suggested that gas-phase HONO could be in equilibrium with a precursor reservoir of nitrite and/or HONO dissolved in surface films or sorbed on surfaces. Thanks to the introduction of the compound $\mathrm{HONO}_{(\mathrm{ad})}$, the current model includes this type of reservoir. Indeed, the HONO produced by Reaction $\left(\mathrm{S}_{1}\right)$ first remains adsorbed before being released to the gas phase. However, even considering an intermediate compound $\mathrm{HONO}_{(\text {ad) }}$, the connection between $\mathrm{NO}_{2}$ and HONO remains too strong. A different type of desorption model based on equilibrium rather than competition for surface sites may decrease this coupling. In addition, introducing another compound interacting with $\mathrm{HONO}_{(\mathrm{ad})}$, such as nitrite, should further decrease the influence of Reaction $\left(\mathrm{S}_{1}\right)$ on the $\mathrm{HONO}_{(\mathrm{ad})}$ concentration and thus further attenuate the dependence of the gas-phase $\mathrm{HONO}$ on $\mathrm{NO}_{2}$.

\section{Conclusions}

In this paper, a new numerical model combining homogeneous and heterogeneous chemistry is implemented and proved able to simulate the concentrations of inorganic compounds. For the first time, $\mathrm{O}_{3}, \mathrm{HONO}$ and $\mathrm{NO}_{x}$ species are simulated all at once and compared with the experimental records acquired in a real room. The specificity of this model is to incorporate secondary reactions that were highlighted by laboratory studies but that are still absent from IAQ models. It is also one of the first models to consider the variations of direct and indirect light throughout the day. This feature is of particular importance in studying the impact of photolytic processes on indoor chemistry. After developing and testing the model in the absence of these processes in the present work, it can now be used to simulate data obtained with UVtransparent windows that allow photochemistry to occur.

The comparison between the simulation results and experimental data allowed the tuning of the model parameters, which led to several conclusions: (i) the building filtration factor and velocity of air mixing are important parameters that should receive more attention; (ii) for the considered simulation duration (a third of one day on average), the proper assessment of the initial concentrations is critical; (iii) whereas deposition and surface reactivity are treated together by current models, the distinction between sorption and surface reactions appears to be essential. This distinction is based on the introduction of sorbed species that also have the possibility to desorb. To better constrain these sorptiondesorption processes, there is a need for surface material characterization, especially for measurements of $\mathrm{O}_{3}, \mathrm{NO}_{2}$ and $\mathrm{HONO}$ uptake coefficients and for $\mathrm{NO}, \mathrm{NO}_{2}$ and $\mathrm{HONO}$ desorption constants in various conditions of temperature, humidity and irradiation. (iv) The success of this model in simulating inorganic species largely arises from better consideration of surface chemistry. Whereas Reactions $\left(\mathrm{S}_{3}\right)$ and $\left(\mathrm{S}_{4}\right)$ could be considered to be of secondary importance, Reaction $\left(\mathrm{S}_{2}\right)$ appears to be as important as Reaction $\left(\mathrm{S}_{1}\right)$, which is currently the only surface reaction taken into account in IAQ models. Reaction $\left(\mathrm{S}_{2}\right)$ may account for unexplained variations in NO vs. HONO production ratios and should clearly be integrated. Finally, the implementation of a surface saturation effect highlights the need for a more complex parameterization of desorption. In the future, further investigations using an equilibrium-type approach that depends on the mass ratio of adsorbed to gas phase may bring key improvements. 


\section{Appendix A: List of symbols}

\section{Symbol}

$\alpha_{i}$

$\beta_{\mathrm{HONO} / \mathrm{HNO}_{3}}$

$C_{i}^{j}$

$C_{i}^{\text {Out }}$

$D_{i}$

$\eta$

$f$

G

$\gamma_{i}$

$H$

I

$J_{i}$

$k_{i,(\mathrm{ad})}$

$k_{\mathrm{H}, i}$

$k_{\text {AER }}$

$k_{\mathrm{BOX}}^{j}$

$k_{\mathrm{DEP}, i}^{j}$

$k_{\text {react, } i}^{j}$

$k_{\text {tran }, i}^{j}$

$k_{\mathrm{S}}$

$\kappa_{i}$

L

$l$

$\lambda$

$M_{i}$

$m_{i}^{j}$

$m_{i}^{\text {Out, } j}$

$\mu, \sigma$

$N$

$n_{\mathrm{H}_{2} \mathrm{O}}$

$v$

$\omega_{i}$

P

$\phi_{i}$

$Q_{p i}$

$R_{i q}^{j}$

$\rho$

$S_{\text {gas }}$

$S_{\text {paint }}^{j}$

$S_{\text {room }}$

$S_{\eta}$

$T$

$T_{\mathrm{c}, i}$

$t$

$t_{\mathrm{h}}$

$\theta$

\section{Description}

Tuneable variable allowing control of the desorption of species $i$

Stoichiometric coefficients of the $\mathrm{NO}_{2}$ heterogeneous hydrolysis

Concentration of species $i$ in the box $j$

Outdoor concentration of species $i$

Diffusion coefficient of species $i$

Air dynamic viscosity

Outdoor-to-indoor filtration factor

Marker referring to the shaded box

Uptake coefficient of species $i$

Relative humidity

Light intensity

Photolysis constant of species $i$

Desorption constant of species $i$

Henry's law constant of species $i$

Air exchange rate between the room and outside the room

Air exchange rate between the boxes

Deposition rate of species $i$ in box $j$

Surface adhesion rate of species $i$ in box $j$

Transport-limited deposition rate of species $i$ in box $j$

Kinetic rate of Reaction (S)

Cross section of species $i$

Marker referring to the sunlit box

Characteristic length of the room

Light wavelength

Molar mass of species $i$

Mass of species $i$ in box $j$

Outdoor mass of species $i$ introduced in box $j$

Gaussian function parameters

$\mathrm{NO}_{2}$ concentration (ppb)

Number of water molecules in the room

Air kinematic viscosity

Thermal velocity of species $i$

Ambient pressure

Quantum yield of species $i$

Emission rate of species $i$ from source $p$

Mass reaction rate of species $i$ with species $q$ in box $j$

Air volumetric mass

Surface allowing gas transfer between the two boxes

Surface of paint in the box $j$

Total surface of the room

Sutherland's constant

Room temperature

Critical temperature of species $i$

Time

Hour of day (GMT)

Zenith angle
Unit

$\mathrm{kg} \mathrm{bar}^{-1} \mathrm{~mol}^{-1}$

-

$\mu \mathrm{g} \mathrm{m}^{-3}$

$\mu \mathrm{g} \mathrm{m}^{-3}$

$\mathrm{m}^{2} \mathrm{~s}^{-1}$

$\mathrm{kg} \mathrm{m}^{-1} \mathrm{~s}^{-1}$

-

$-$

$-$

$-$

$\mathrm{W} \mathrm{m} \mathrm{m}^{-2}$

photons $\mathrm{cm}^{-2} \mathrm{~s}^{-1}$

$\mathrm{s}^{-1}$ molec. $^{-1}$

bar mol kg-1

$\mathrm{s}^{-1}$

$\mathrm{s}^{-1}$

$\mathrm{s}^{-1}$

$\mathrm{s}^{-1}$

$\mathrm{s}^{-1}$

$\mathrm{s}^{-1}$

$-$

$-$

$\mathrm{m}$

$\mathrm{nm}$

$\mathrm{g} \mathrm{mol}^{-1}$

$\mu \mathrm{g}$

$\mu \mathrm{g}$

$\mathrm{h}, \mathrm{h}$

$-$

$\mathrm{m}^{2} \mathrm{~s}^{-1}$

$\mathrm{m} \mathrm{s}^{-1}$

$\mathrm{Pa}$

$\mu \mathrm{g} \mathrm{s}^{-1}$

$\mu \mathrm{g} \mathrm{s}^{-1}$

$\mathrm{kg} \mathrm{m}^{-3}$

$\mathrm{m}^{2}$

$\mathrm{m}^{2}$

$\mathrm{m}^{2}$

K

K

K

$\mathrm{s}$

$\mathrm{h}$

$-$ 
Symbol Description

$U \quad$ Mean air velocity parallel to the surface

$u^{*} \quad$ Friction velocity

$u_{\text {inf }} \quad$ Average velocity of air in the room

$V_{\mathrm{c}, i} \quad$ Critical volume of species $i$

$V_{\text {box }}^{j}$

$V_{\text {room }}$

$v_{\text {trd }, i}$

$y$

$\zeta$
Volume of box $j$

Total volume of the room

Transport-limited deposition velocity of species $i$

Distance from surface

Actinic flux

\section{Unit}

$\mathrm{m} \mathrm{s}^{-1}$

$\mathrm{ms}^{-1}$

$\mathrm{m} \mathrm{s}^{-1}$

$\mathrm{cm}^{3} \mathrm{~mol}^{-1}$

$\mathrm{m}^{3}$

$\mathrm{m}^{3}$

$\mathrm{ms}^{-1}$

$\mathrm{m}$

photons $\mathrm{cm}^{-2} \mathrm{~nm}^{-1}$ 


\section{Appendix B: Concentration initialization}

This Appendix presents the figures corresponding to the initialization procedure described in Sect. 3.3. In these figures, "No init" is the simulation performed without initializing the compounds which were not detected during the campaign. "Reference" is the simulation run corresponding to the optimized simulation (see Sect. 4). The correspondence between these simulation runs and the experimental concentrations is assessed by computing the MNGE over the first $5000 \mathrm{~s}$, denoted by the red dots, for $\mathrm{NO}$ and $\mathrm{NO}_{2}$.
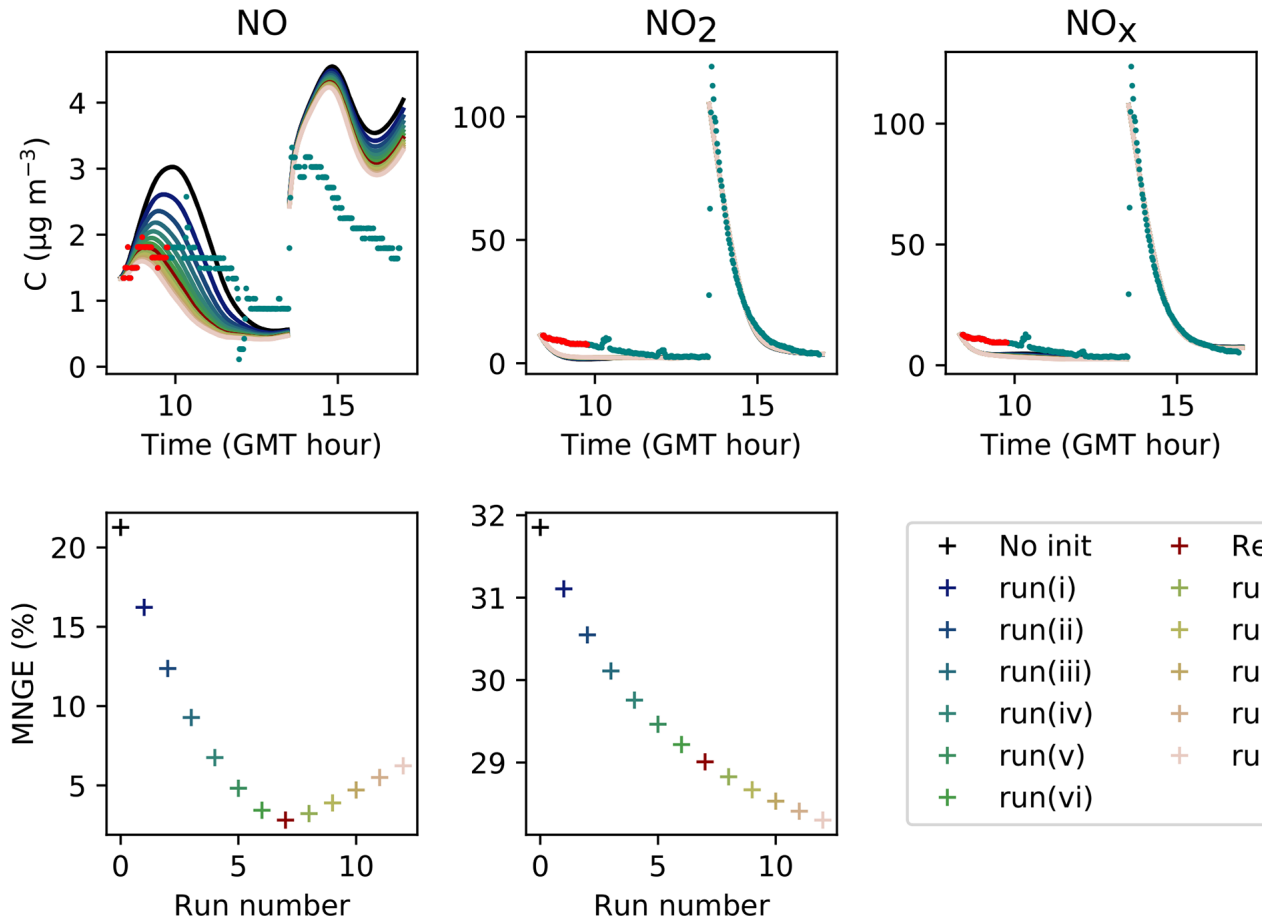

$\begin{array}{llll}+ & \text { No init } & + & \text { Reference } \\ + & \text { run(i) } & + & \text { run(viii) } \\ + & \text { run(ii) } & + & \text { run(viii) } \\ + & \text { run(iii) } & + & \text { run(x) } \\ + & \text { run(iv) } & + & \text { run(xi) } \\ + & \text { run(v) } & + & \text { run(xii) } \\ + & \text { run(vi) } & & \end{array}$

Figure B1. Concentration initialization for Experiment 1: for this experiment, proper initial concentrations are considered to be achieved when the MNGE with respect to $\mathrm{NO}$ reaches a minimum. The $\mathrm{MNGE}$ of $\mathrm{NO}_{2}$ remains high because the parameter optimization regarding $\mathrm{NO}_{2}$ focused on the correct modelling of the second part of the experiment (see Sect. 6, modelling high $\mathrm{NO}_{2}$ concentrations). 

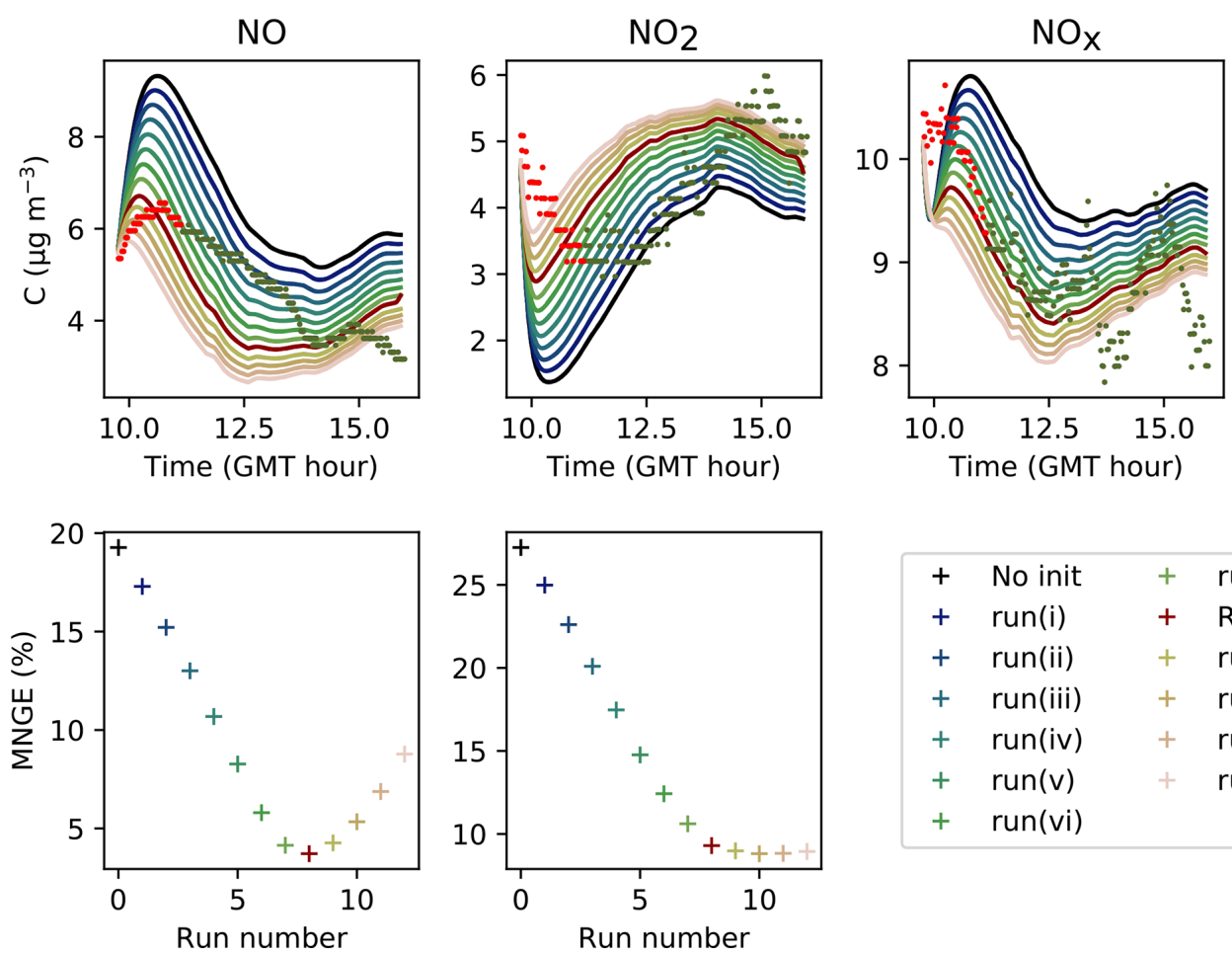

$\begin{array}{rlll}+ & \text { No init } & + & \text { run(vii) } \\ + & \text { run(i) } & + & \text { Reference } \\ + & \text { run(ii) } & + & \text { run(ix) } \\ + & \text { run(iii) } & + & \text { run(x) } \\ + & \text { run(iv) } & + & \text { run(xi) } \\ + & \text { run(v) } & + & \text { run(xii) } \\ + & \text { run(vi) } & & \end{array}$

Figure B2. Concentration initialization for Experiment 2: for this experiment, proper initial concentrations are considered to be achieved when the MNGE with respect to $\mathrm{NO}$ reaches a minimum, while the $\mathrm{MNGE}$ of $\mathrm{NO}_{2}$ reaches stabilization.
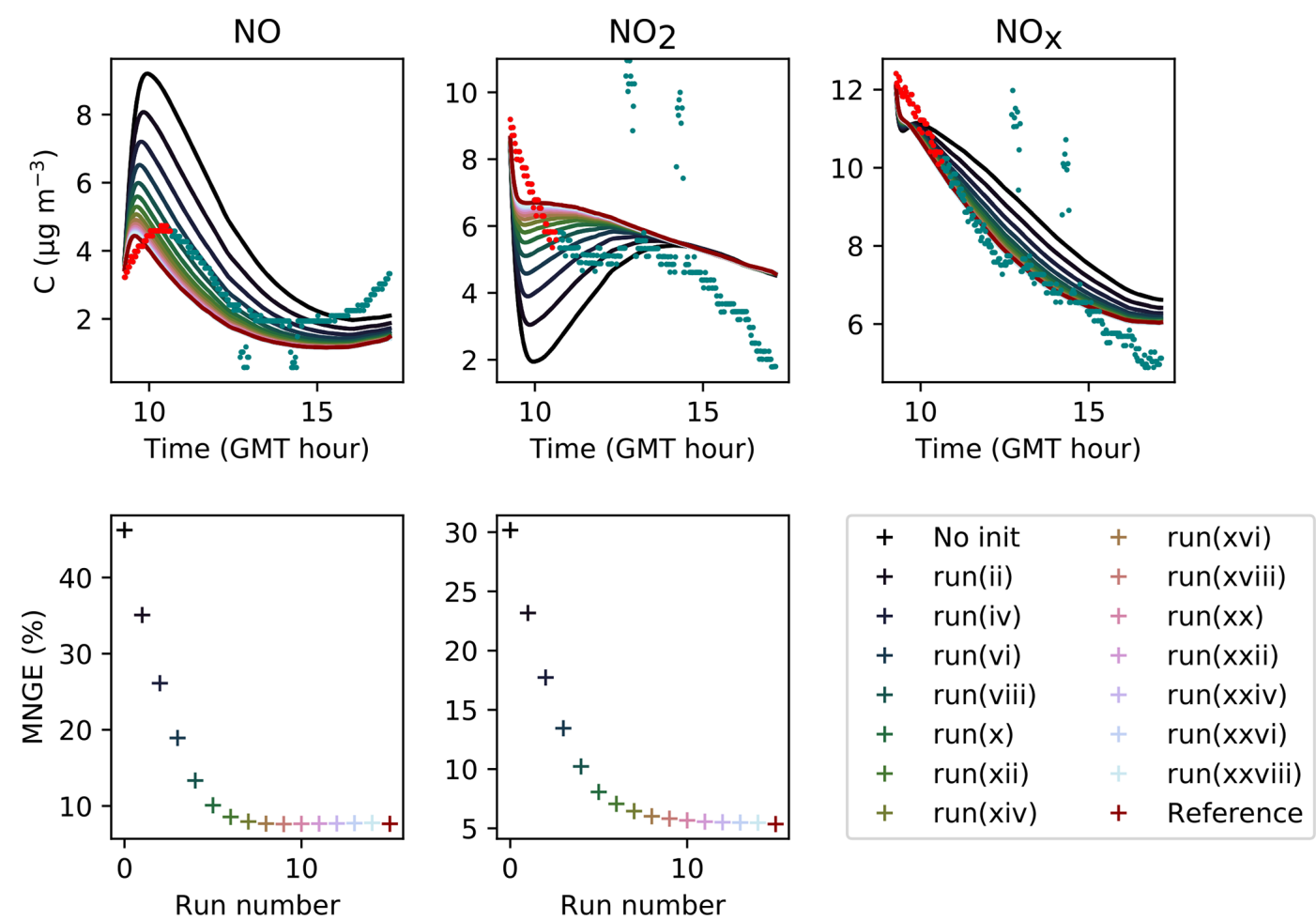

Figure B3. Concentration initialization for Experiment 3: for this experiment, proper initial concentrations are considered to be achieved when the MNGEs with respect to $\mathrm{NO}$ and $\mathrm{NO}_{2}$ have converged to stable values. 
Code availability. The code is available at https://doi.org/10.5281/zenodo.4627671 (Fiorentino and Sartelet, 2021).

Data availability. Data are not made publicly available yet, as research is currently ongoing using these data.

Author contributions. HW and KS conceived the project. EAF and KS developed the code. EAF, KS and HW developed the methodology. EAF performed formal analysis, visualization and investigations. EAF wrote the draft. KS and HW reviewed the draft. HW acquired the funding.

Competing interests. The authors declare that they have no conflict of interest.

Acknowledgements. This work is a contribution to the Labex Serenade (no. ANR-11-LABX-0064) funded by the "Investissements d'Avenir" French Government programme of the French National Research Agency (ANR) through the A MIDEX project (no. ANR11-IDEX-0001-02). The experimental campaign from which the data shown in this paper originated was supported by the same funding. The authors would like to thank the LCE members who contributed to the acquisition of these data, namely Adrien Gandolfo, Amandine Durand and Sasho Gligorovski.

Financial support. This research has been supported by the LABEX SERENADE (grant no. ANR-11-LABX-0064).

Review statement. This paper was edited by Augustin Colette and reviewed by two anonymous referees.

\section{References}

Alvarez, E. G., Amedro, D., Afif, C., Gligorovski, S., Schoemaecker, C., Fittschen, C., Doussin, J.-F., and Wortham, H.: Unexpectedly high indoor hydroxyl radical concentrations associated with nitrous acid, P. Natl. Acad. Sci. USA, 110, 13294 13299, 2013.

Alwarda, R., Zhou, S., and Abbatt, J. P.: Heterogeneous oxidation of indoor surfaces by gas-phase hydroxyl radicals, Indoor Air, 28, 655-664, 2018.

Ascher, U. and Petzold, L.: Computer Methods for Ordinary Differential Equations and Differential-Algebraic Equations, ISBN 978-0-89871-412-8, Society for Industrial and Applied Mathematics, Philadelphia, 1998.

Carslaw, N.: A new detailed chemical model for indoor air pollution, Atmos. Environ., 41, 1164-1179, 2007.

Carter, W.: Development of the SAPRC-07 chemical mechanism, Atmos. Environ., 44, 5324-5335, 2010.
Chen, N. H. and Othmer, D. F.: New generalized equation for gas diffusion coefficient., J. Chem. Eng. Data, 7, 37-41, 1962.

Collins, D. B., Hems, R. F., Zhou, S., Wang, C., Grignon, E., Alavy, M., Siegel, J. A., and Abbatt, J. P.: Evidence for gas-surface equilibrium control of indoor nitrous acid, Environ. Sci. Technol., 52, 12419-12427, 2018.

Courtey, S., Blondeau, P., Jouandon, E., and Allard, F.: Modeling of the production of secondary gaseous products in confined atmospheres, Build. Environ., 44, 1343-1349, 2009.

El Zein, A. and Bedjanian, Y.: Reactive uptake of HONO to TiO2 surface: "dark" reaction, J. Phys. Chem. A, 116, 3665-3672, 2012.

Falls, A. and Seinfeld, J.: Continued development of a kinetic mechanism for photochemical smog, Environ. Sci. Technol., 12, 1398-1406, 1978.

Febo, A. and Perrino, C.: Prediction and experimental evidence for high air concentration of nitrous acid in indoor environments, Atmos. Environ. A., 25, 1055-1061, 1991.

Finlayson-Pitts, B., Wingen, L., Sumner, A., Syomin, D., and Ramazan, K.: The heterogeneous hydrolysis of $\mathrm{NO}_{2}$ in laboratory systems and in outdoor and indoor atmospheres: An integrated mechanism, Phys. Chem. Chem. Phys., 5, 223-242, 2003.

Fiorentino, E.-A. and Sartelet, K.: $\mathrm{H}^{2} \mathrm{I}$ model (Version v1.0), Zenodo, https://doi.org/10.5281/zenodo.4627671, 2021.

Furtaw Jr., E. J., Pandian, M. D., Nelson, D. R., and Behar, J. V.: Modeling indoor air concentrations near emission sources in imperfectly mixed rooms, J. Air Waste Manag. Assoc., 46, 861868,1996

Gandolfo, A.: Incidence de la chimie hétérogène des oxydes d'azote sur la qualité des atmosphères intérieures: impacts des nanoparticules de $\mathrm{TiO}_{2}$ dans les peintures, $\mathrm{PhD}$ thesis, Aix-Marseille University, 2018.

Gandolfo, A., Bartolomei, V., Alvarez, E. G., Tlili, S., Gligorovski, S., Kleffmann, J., and Wortham, H.: The effectiveness of indoor photocatalytic paints on $\mathrm{NO}_{x}$ and HONO levels, Appl. Catal. BEnviron., 166, 84-90, 2015.

Gandolfo, A., Gligorovski, V., Bartolomei, V., Tlili, S., Alvarez, E. G., Wortham, H., Kleffmann, J., and Gligorovski, S.: Spectrally resolved actinic flux and photolysis frequencies of key species within an indoor environment, Build. Environ., 109, 5057, 2016.

Gandolfo, A., Rouyer, L., Wortham, H., and Gligorovski, S.: The influence of wall temperature on $\mathrm{NO} 2$ removal and HONO levels released by indoor photocatalytic paints, Appl. Catal. BEnviron., 209, 429-436, 2017.

Gandolfo, A., Chen, H., Kukui, A., Durand, A., Temime-Roussel, B., Kleffmann, J., Wortham, H., and Gligorovski, S.: Indoor atmosphere field campaign: impact of photocatalytic paints on air quality, in preparation, 2021.

Gery, M., Whitten, G., Killus, J., and Dodge, M.: A photochemical kinetics mechanism for urban and regional scale computer modeling, J. Geophys. Res.-Atmos., 94, 12925-12956, 1989.

Goliff, W. S., Stockwell, W. R., and Lawson, C. V.: The regional atmospheric chemistry mechanism, version 2, Atmos. Environ., 68, 174-185, 2013.

Grøntoft, T. and Raychaudhuri, M. R.: Compilation of tables of surface deposition velocities for $\mathrm{O} 3, \mathrm{NO} 2$ and $\mathrm{SO} 2$ to a range of indoor surfaces, Atmos. Environ., 38, 533-544, 2004. 
Holland, F., Hofzumahaus, A., Schäfer, J., Kraus, A., and Pätz, H.-W.: Measurements of $\mathrm{OH}$ and $\mathrm{HO}_{2}$ radical concentrations and photolysis frequencies during BERLIOZ, J. Geophys. Res.-Atmos., 108, PHO 2-1-PHO 2-23, https://doi.org/10.1029/2001JD001393, 2003.

Jenkins, A. C. and Birdsall, C. M.: The vapor pressures and critical constants of pure ozone, J. Chem. Phys., 20, 1158-1161, 1952.

Joback, K. G. and Reid, R. C.: Estimation of pure-component properties from group-contributions, Chem. Eng. Commun., 57, 233243, 1987.

Kaper, H. and Ferziger, J. H.: Mathematical theory of transport processes in gases, North-Holland Publishing, Amsterdam, 1972.

Kim, Y., Sartelet, K., and Seigneur, C.: Comparison of two gasphase chemical kinetic mechanisms of ozone formation over Europe, J. Atmos. Chem., 62, 89-119, 2009.

Kowal, S. F., Allen, S. R., and Kahan, T. F.: Wavelength-resolved photon fluxes of indoor light sources: Implications for $\mathrm{HO}$ x production, Environ. Sci. Technol., 51, 10423-10430, 2017.

Lai, A. C. and Nazaroff, W. W.: Modeling indoor particle deposition from turbulent flow onto smooth surfaces, J. Aerosol Sci., 31, 463-476, 2000.

Lide, D. R.: CRC handbook of chemistry and physics, Internet Version 2005, available at: http://www.hbcpnetbase.com (last access: 15 May 2019), CRC Press, Boca Raton, FL, 2005.

Linstrom, P. and Mallard, W.: NIST Chemistry WebBook, NIST Standard Reference Database Number 69, National Institute of Standards and Technology, Gaithersburg MD, 20899, https://doi.org/10.18434/T4D303.

McQuiston, F. C., Parker, J. D., and Spitler, J. D.: Heating, ventilating, and air conditioning: analysis and design, John Wiley \& Sons, New York, 2004.

Mendez, M., Blond, N., Blondeau, P., Schoemaecker, C., and Hauglustaine, D. A.: Assessment of the impact of oxidation processes on indoor air pollution using the new time-resolved INCA-Indoor model, Atmos. Environ., 122, 521-530, 2015.

Mendez, M., Blond, N., Amedro, D., Hauglustaine, D. A., Blondeau, P., Afif, C., Fittschen, C., and Schoemaecker, C.: Assessment of indoor HONO formation mechanisms based on in situ measurements and modeling, Indoor air, 27, 443-451, 2017.

Mochida, M. and Finlayson-Pitts, B. J.: FTIR Studies of the Reaction of Gaseous $\mathrm{NO}$ with $\mathrm{HNO}_{3}$ on Porous Glass: Implications for Conversion of $\mathrm{HNO} 3$ to Photochemically Active $\mathrm{NO}_{x}$ in the Atmosphere, J. Phys. Chem. A, 104, 9705-9711, 2000.

Morrison, G., Lakey, P. S., Abbatt, J., and Shiraiwa, M.: Indoor boundary layer chemistry modeling, Indoor Air, 29, 956-967, 2019.

Nazaroff, W. W. and Cass, G. R.: Mathematical modeling of chemically reactive pollutants in indoor air, Environ. Sci. Technol., 20, 924-934, 1986.

Nikitin, E. D., Pavlov, P. A., Popov, A. P., and Nikitina, H. E.: Critical properties of hydrogen peroxide determined from direct measurements, The J. Chem. Thermodyn., 27, 945-952, 1995.

Ramazan, K. A., Syomin, D., and Finlayson-Pitts, B. J.: The photochemical production of HONO during the heterogeneous hydrolysis of $\mathrm{NO}_{2}$, Phys. Chem. Chem. Phys., 6, 3836-3843, 2004.

Ravindran, P., Davis, E., and Ray, A.: Diffusivities of low-volatility species in light gases, AIChE Journal, 25, 966-975, 1979.
Rosenbrock, H.: Some general implicit processes for the numerical solution of differential equations, The Computer Journal, 5, 329330, 1963.

Sandu, A., Verwer, J., Blom, J., Spee, E., Carmichael, G., and Potra, F.: Benchmarking stiff ode solvers for atmospheric chemistry problems II: Rosenbrock solvers, Atmos. Environ., 31, 34593472, 1997.

Sartelet, K., Hayami, H., Albriet, B., and Sportisse, B.: Development and preliminary validation of a modal aerosol model for tropospheric chemistry: MAM, Aerosol Sci. Technol., 40, 118127, 2006.

Sarwar, G., Corsi, R., Kimura, Y., Allen, D., and Weschler, C. J.: Hydroxyl radicals in indoor environments, Atmos. Environ., 36, 3973-3988, 2002.

Sato, H., Watanabe, K., Levelt Sengers, J., Gallagher, J., Hill, P., Straub, J., and Wagner, W.: Sixteen thousand evaluated experimental thermodynamic property data for water and steam, J. Phys. Chem. Ref. Data, 20, 1023-1044, 1991.

Shen, H., Tan, H., and Tzempelikos, A.: The effect of reflective coatings on building surface temperatures, indoor environment and energy consumption - An experimental study, Energ. Buildings, 43, 573-580, 2011.

Stockwell, W., Middleton, P., Chang, J., and Tang, X.: The 2nd generation regional acid deposition model chemical mechanism for regional air quality modeling, J. Geophys. Res.-Atmos., 95, 16343-16367, 1990.

Stockwell, W. R., Kirchner, F., Kuhn, M., and Seefeld, S.: A new mechanism for regional atmospheric chemistry modeling, J. Geophys. Res.-Atmos., 102, 25847-25879, 1997.

Tlili, S., Gandolfo, A., Durand, A., Wortham, H., and Gligorovski, S.: Modeling of the spatio-temporal distribution of solar radiation in rooms: an advance for indoor air chemistry, in preparation, 2021.

Wainman, T., Weschler, C. J., Lioy, P. J., and Zhang, J.: Effects of surface type and relative humidity on the production and concentration of nitrous acid in a model indoor environment, Environ. Sci. Technol., 35, 2200-2206, 2001.

Weschler, C.: Chemistry in indoor environments: 20 years of research, Indoor Air, 21, 205-218, 2011.

Weschler, C. J. and Shields, H. C.: Production of the hydroxyl radical in indoor air, Environ. Sci. Technol., 30, 3250-3258, 1996.

Weschler, C. J., Shields, H. C., and Naik, D. V.: Indoor chemistry involving $\mathrm{O}_{3}$, $\mathrm{NO}$, and $\mathrm{NO}_{2}$ as evidenced by 14 months of measurements at a site in Southern California, Environ. Sci. Technol., 28, 2120-2132, 1994.

Won, Y., Waring, M., and Rim, D.: Understanding the spatial heterogeneity of indoor $\mathrm{OH}$ and $\mathrm{HO}_{2}$ due to photolysis of $\mathrm{HONO}$ using computational fluid dynamics simulation, Environ. Sci. Technol., 53, 14470-14478, 2019.

Yarwood, G., Rao, S., Yocke, M., and Whitten, G.: Updates to the Carbon Bond Chemical Mechanism: CB05 Final Report to the US EPA, RT-0400675, available at: https://www.camx.com/ (last access: 12 May 2021), 2005.

Zhao, H., Gall, E. T., and Stephens, B.: Measuring the building envelope penetration factor for ambient nitrogen oxides, Environ. Sci. Technol., 53, 9695-9704, 2019. 